UCRL-ID--112058

DE93 008757

\title{
Selection of Candidate Container Materials for the Conceptual Waste Package Design for a Potential High Level Nuclear Waste Repository at Yucca Mountain
}

\author{
R.A. Van Konynenburg \\ W.G. Halsey \\ R.D. McCright \\ W.L. Clarke, Jr. \\ Lawrence Livermore National Laboratory \\ G.E. Gdowski \\ KMI, Inc.
}


The materials selections described in this report are the culmination of many years of efiort. W. G. Halsey was principally responsible for development of the selection criteria. R. D. McCright contributed considerable personal insight into the corrosion behavior of materials, led the Metal Barriers effort, and wrote an earlier, brief version of this report. G. E. Gdowski was responsible for much of the degradation mode survey work. W. L. Clarke, Jr., contributed insights from years of experience with materials in the nuclear power industry, and leads the Corrosion \& Electrochemical Processes Section of the Materials Division of the Chemistry and Materials Science Department at Lawrence Livermore National Laboratory as well as serving as Technical Project Offic:er for LLNL participation in the Yucca Mountain Site Characterization Projest. R. A. Van Konynenburg contributed in the areas of radiation effects and carbon-14 release, and edited this report. 


\section{Contents}

\section{Foreward}

Abstract

I. Introduction

II. Background of Conceptual Design and Materials Choices

III. Performance Requirements, Conceptual Design, and Service Conditions

IV. Preliminary Selection Criteria

V. Materials Considered

VI. Material Evaluations

VII. Summary and Conclusions

References

Appendix A: Parameters, Weighting Factors, and Passing Scores for Candidate Metal Alloys

Appendix B: Materials Evaluation Detailed Scoresheets

Microfiche - Peer Review Report 


\begin{abstract}
Preliminary selection criteria have been developed, peer-reviewed, and applied to a field of 41 candidate materials to choose three alloys for further consideration during the advanced conceptual design phase of waste package development for a potential high level nuclear waste repository at Yucca Mountain, Nevada. These three alloys are titanium grade 12 , Alloy $\mathrm{C}-4$, and Alloy 825 . These selections are specific to the particular conceptual design outlined in the Site Characterization Plan. Other design concepts that may be considered in the advanced conceptual design phase may favor other materials choices.
\end{abstract}


The Yucca Mountain Site Characterization Project is engaged in evaluating a site in southern Nevada for its suitability to host the nation's first high level nuclear waste repository. As part of this effort, Lawrence Livermore National Laboratory has been concerned for a number of years with developing and evaluating the performance of waste packages for the potential repository. As is the case in the development of any engineering product, one of the key aspects is the choice of materials to be used. Because of the rather rigorous and exacting requirements that have been established for these packages by federal regulations, as well as the detailed scrutiny that has been and most likely will continue to be applied to all decisions pertaining to them, we have chosen to adopt a somewhat formal, documented process to select 'he materials to be used.

Under the Nuclear Waste Policy Act of 1982,1 which provided for the U.S. geological repository development program, a Site Characterization Plan (SCP) was required, and was published for Yucca Mountain by the U.S. Department of Energy's Office of Civilian Radioactive Waste Management in 1988.2 Within this SCP, a conceptual design for the waste packages was presented. This design incorporated a thin-walled contciner made from a single, corrosion-resistant metal or alloy.

Six materials were initially chosen using a brief set of criteria, and were listed in the SCP as candidates for use in the conceptual design. More detailed selection criteria were subsequently developed to use in choosing among them, in order to narrow the field of materials to be considered as candidates for the next phase, called the advanced conceptual design. Because these criteria were much more detailed and differently weighted than those originally used to arrive at the SCP candidate list, we decided to apply them to a larger field of candidates, which ultimately numbered 41 .

This report describes the background of the conceptual design and the suite of materials initially considered for it, the waste package performance requirements and expected service conditions, the preliminary selection criteria that have been developed, and the full list of 41 materials more recently considered. The detailed application of the criteria to the candidate materials is described, ranking is performed, and conclusions and recommendations are presented. A briefer version of this report was presented at the Focus ' 91 meeting. ${ }^{3}$

As is often the case in any development program of this scope, complexity, and duration, the requirements, assumptions, and management guidance have changed over time. At the time of writing this report (November 1992) the range of options being considered for the advanced conceptual design has expanded beyond the relatively simple thin-walled, single metal container of the conceptual design. Since the preliminary selection criteria have been applied only to the original conceptual design, the resulting choices are really appropriate only to it. Nevertheless, the approach used in selection, as well as many of the detailed criteria that were applied, are relevant to other design options as well. We therefore present this information both to document what was done for the 
conceptual design as well as to set the stage for the selection process that will be used for the advanced conceptual design. It should be understood that the materials choices that will result for the advanced conceptual design may differ from those arrived at in the conceptual design stage, since the basic design concepts may differ.

\section{BACKGROUND OF CONCEPTUAL DESIGN AND MATERIALS CHOICES}

Since 1981, package developers in the Yucca Mountain Site Characterization Project (YMP) and its predecessor, the Nevada Nuclear Waste Storage Investigations (NNWSI) Project, have considered a number of materials for fabrication of waste package containers for disposal of high-level vitrified nuclear waste and spent fuel from commercial nuclear power plants. We have focused mainly on a thin-walled container made from a single, corrosion-resistant metal or alloy since 1983, and this design has served as the basis for the conceptual design. 4 However, we have also given some consideration to other waste package configurations and to various classes of materials that might be appropriate for them. A detailed history of the materials considerations in the YMP/NNWSI project has been given in a previous report. 5 The following discussion is derived from references 4 and 5 .

Initially, horizons in both the saturated zone (below the water table) and in the unsaturated zone (above it) were under consideration for location of the potential repository. The choice between these two zones has a major impact on the design of the waste packages and on the materials to be considered for the waste package containers. Up to 1982 other candidate repositories in the USA, as well as in other countries, had been proposed for location deep in the saturated zone. This location, combined with the possibility of some empty space inside spent fuel packages, required container designs that incorporated walls sufficiently thick to withstand the resulting high hydrostatic pressure without buckling, in order to assure containment. In addition to pressure, the containers would be subject to constant aqueous corrosion conditions, and many of the designs therefore incorporated additional wall thickness to provide for general corrosion allowance. Since thick walls were required for these reasons, advantage was also taken of them in some cases to provide self-shielding of the gamma radiation emitted by the waste. This could reduce the dose rates outside the packages to levels at which an argument could be made that radiolytic changes to the chemical environment would be insignificant and could safely be ignorec' in projecting corrosion behavior. The thick-walled container thus became the de iacto standard design. Within the NNWSI, attention was centered on cast irons and cas! and wrought steels to be used in thick sections (approximately $25-30 \mathrm{~cm}$ ) for re:pository designs in the saturated zone.

In the summer of 1982, a project decisiorı was made to propose location of the potential repository in the unsaturated zone, some 300-400 meters below the surface and some 200 meters above the water table. As a result of this decision, the focus of the NNWSI container work was shifted to thin-walled containers for the waste package, hecause there would be no significant external pressure acting on the container in the unsaturated zone, and thick walls were thus not needed for 
mechanical strength. Their elimination could result in weight, space, and cost savings. Use of a thin-walled container put greater emphasis on the resistance of the container miaterial to all pertinent forms of environmental degradation, including oxidation in the vapor phase and aqueous corrosion in the condensed phase. The initial emplacement conditions were expectea to be dry and to remain so for a long period of time. Thus, while it was thought that aqueous corrosion could occur during transient periods when water entered the repository environment, immersion of large numbers of containers or large areas of containers was not viewed as a likely or continuing occurrence.

The writing of the so-called "Orange draft" of the SCP was begun at a project leadership meeting in Orange, Califorria, in early 1983. In conjunction with the writing of this draft, an evaluation of potential candidate materials for the containers was conducted. 6 In the first screening, a wide range of engineering metals and alloys was considered, ranging from plain carbon steel to zirconium. A list of 31 candidate materials was narrowed to 17 , and these materials were evaluated using four criteria: mechanical properties, weldability, cost, and corrosion behavior. In this evaluation, each of these four criteria was weighted equally. The result was recommendation of three candidate materials for the conceptual design of the container. These three materials were austenitic stainless steels (AISI 304L, AISI $316 \mathrm{~L}$ ) and a related nickel-rich austenitic alloy (Alloy 825 ).

The conceptual design report was completed in 1984.4 Two gentric designs were advanced, one for spent fuel waste packages and the other for borosilicate glass. The latter results from Savannah River Site defense waste or West Valley, New York, commercial waste reprocessing and will be cast into a stainless steel pour canister, which will then be "overpacked" with disposal containers. Liquid and sludge wastes at the Hanford, Washington site are expected to be processed similarly. Conceptual designs have focused on a nominal one-cm thick container wall; subsequently we have suggested some variation in the wall thickness to accommodate different fabrication processes and to compensate for the lower strength materials. In 1983, the idea was explored of directly using the stainless steel pour canister as the disposal container for reprocessed high-level defense waste. However, further analysis revealed that the time-temperature-strain history that would occur during the glass pouring operation could cause a sensitized microstructure to develop on some locations on the stainless steel canister surface. Such a microstructure would be prone to corrosion (intergranular attack or intergranular stress corrosion cracking) in the anticipated oxidizing environment of the potential Yucca Mountain repository. Consequently, the design discussed in the SCP made use of an outer container surrounding the inner pour canister for the glass waste packages. A single-walled container with the same outside diameter was planned for the spent fuel containers, to make possible uniform borehole diameters.

In 1984 the Congress formally requested that the NNWSI undertake a two-year feasibility study on the use of copper and copper materials as possible waste package container materials. This study was conducted during FY -85 and $F Y-86$. Close co-operation with the Copper Development Association (CDA) and the International Copper Research Association (INCRA) resulted in the 
recommendation of three candidate materials that merited further study: oxygenfree copper (CDA 102); 7\% aluminum bronze (CDA 613); and 70/30 copper-nickel (CDA 715). The two-year feasibility study indicated some performance concerns with these candidate materials, but it concluded that these were viable candidates and should be considered along with the austenitic candidate materials. ${ }^{7}$

Considerable experimental work was initiated on the austenitic materials in 1983 and on the copper-based materials in 1984. The intent of the work was to determine the comparative performance limitations of the various candidate materials. In 1987 work was resumed on a new version of the SCP; this version was finally released in early 1988 (as the Consultation Draft) and later in the same year (as the Statutory Draft) ${ }^{2}$. Extensive degradation mude surveys were prepared in 1988-89 on the candidate materials by critically analyzing information in the technical literature on the performance of these materials in a variety of natural and chemical environments. ${ }^{8}$ Information gaps serve to suggest areas where experimental work is needed. Mechanistically-based performance models have also been surveyed, ${ }^{9}$ and these are being adapted to the environments and timeframes associated with the repository. Selection criteria were developed during the period 1988-90 that make possible quantitative rankings in some 34 separate categories. ${ }^{10}$ A "peer review" panel was convened in September 1988 to review an early draft of the criteria. These criteria are considerably more comprehensive than the candidate selection criteria used in 1983.

Because of recommendations from various segments of the technical community that more robust designs and more durable materials should be considered, additional degradation mode surveys have been prepared on highly corrosion resistant materials. Summaries of these surveys are available.11-13 These materials comprise titanium and titanium-based alloys, and nickel-based alloys containing chromium, iron, molybdenum and other elements. These materials are evaluated herein along with the six candidate materials (AISI 304L, AISI 316L, Alloy 825, CDA 102, CDA 613, and CDA 715) that have been considered by the Project for a longer period of time and were discussed in detail in the Yucca Mountain SCP. As a further option, a number of "alternate concepts" are being formulated for consideration as even more robust configurations. Some of these involve multiple metal barriers, thick walls, packages containing filler materials inside the container or packing materials outside the container, and metal/ceramic combinations. The options that appear to be most promising will be studied in the advanced conceptual design phase. 
III. PERFORMANCE REQUIREMENTS, CONCEPTUAL DESIGN, AND SERVICE CONDIT!ONS

It is generally recognized that waste packages must be designed and constructed to perform the functions of containing the waste and enabling it to be handled in a safe manner. Overall performance requirements for the high level waste repository were established by the Environmental Protection Agency as 40CFR Part 191 in 1985.14 This regulation was remanded by court action in 1987, and was recently invalidated by the National Energy Policy Act of 1992. Among other requirements, this regulation set limits to the total release of certain radionuclides to the accessible environment over 10,000 years.

Detailed $p$, formance requirements for repository subsystems, including the engineered barrier systern (EBS), were established by the Nuclear Regulatory Commission regulation 10CFR Part 6015 in 1983 . This regulation is also subject to change under the National Energy Policy Act of 1992, but the work reported here was performed during the period when this regulation was in force. Among other requirements, this regulation specifies that containment of high level waste within the waste packages must be "substantially complete" for a period (yet to be determined by the NRC) which will be in the range of 300 to 1000 years in duration. Despite considerable effort on the part of the Department of Energy, the Nuclear Regulatory Commission, and their contractors, there has so far not been an agreed-upon translation of the term "substantially complete" into quantitative terms that could serve as a clear engineering design goal.

Regulation 10CFR Part 60 also specifies that the release rate of any radionuclide from the EBS following the containment period must not exceed one part in 100,000 per year of the inventory of that radionuclide calculated to be present at 1,000 years following permanent closure of the repository.

At the present time, it appears that the most difficult aspect of these regulations for the waste packages to meet in the expected environment of a potential Yucca Mour cain repository would be containment and controlled release of carbon-14 as ${ }^{14} \mathrm{CO}_{2}$, since it would exist as a gas. ${ }^{16}$ These requirements translate into a very stringent quality control requirement initially, a very small fraction of leaking containers over 10,000 years, and a very small failure rate per year. The carbon14 release problem is currently under study by the Science Advisory Board of the Environmental Protection Agency, and the regulation changes called for by the National Energy Policy Act of 1992 may change these requirements.

In addition to providing containment and holping to control release, the waste package container must be compatible with the waste forms, must not compromise the performance of other repository components, and must provide for transportation, handling, retrievability, and unique identification.

The conceptual design of the waste packages that was presented in the Site Characterization Plan consisted of a closed, metallic, thin-walled cylinder about 66 $\mathrm{cm}$ in diameter and 300 to $500 \mathrm{~cm}$ long. The $300-\mathrm{cm}$ length applizd to the vitrified 
high-level waste, while the longer packages were planned for spent fuel. The metal was to be corrosion resistant and about one centimeter th:sk, as noted above. Somewhat thicker walls were to be used at the top and bottom.

Several fabrication options were considered, such as rolled and welded plate, casting, and extrusion. The bottom could either be integral with the body of the container, or might be forged and welded to it. All fabrication joints except the final closure could readily be annealed to relieve residual stresses. The final closure has been identified as a feature that could potentially limit long-term container performance and should therefore receive special attention. Annealing the final closure joint could not be performed easily, since it wnuld subject the spent fuel or high level waste to temperatures that could be deleterious to their long term controlled release performance. Reports have been prepared on the evaluation of various tabrication and closure processes by engineers at Babcock and Wilcox, working on subcontract with LLNL. 17,18

In the scheme presented in the SCP, the waste package was to be placed in a vertical or horizontal borehole with an air gap surrounding it in a mined repository at least 200 meters above the water table in a stratum of welded, devitrified, tuff rock (the Topopah Spring member of the Paintbrush tuff inside Yucca Mountain, Nye County, Nevada). This location would result in a relatively dry condition without hydrostatic or significant lithostatic loads. Thus, the stresses in service would be limited to residual stresses, such as those that could result from closure welding for a welded container, and the static loads from the weight of the container itself and the waste. Small loads resulting from sloughed rock would also be possible. Additional transient and impact loads would be applied during transportation, handling, and retrieval (if it occurred). The container must be able to survive a small drop or handling impact without loss of integrity. Noticeably damaged containers would not be emplaced in the repository.

After emplacement, the containers would be subject to a temperature vs. time history that would depend on the designed heat loading (also known as the areal power density) and the heat transfer properties of the rock, including the gas and liquid phases. In the SCP design, the peak temperature of the containers was to be about $250^{\circ} \mathrm{C}$, reached in a few years to a few decades, and it would be followed by a slow decrease over centuries. ?his temperature-time profile is important both in determining the external corrosion environment and in establishing the longterm thermal treatment to which the metal would be subjected. The latter can give rise to metallurgical changes, such as phase changes, in some metals, as well as to annealing of residual stresses. The effect of the long-term thermal aging on the weld metal and the heat-affected-zones around welds is of particular interest.

The corrosion environment may also change with time. When the containers are at temperatures above the local boiling point (about $96^{\circ} \mathrm{C}$ at the potential repository elevation) bulk liquid water contact can be ruled out on thermodynamic grounds. The environment during this period would consist of a warm air - dry steam mixture that wouid resuic in iow-temperature oxidation of the container material. When the temperature dropped below the boiling point of water, the containers should still remain free of buik liquid water, for three reasons. First, the large dried-out region 
of rock combined with the very low rate of infiltration of water at Yucca Mountain are expected to prevent return of liquid water to the rock nea.- the packages for a considerable time. Second, even when the nearby rock became rewetted, the capillary properties of the rock combined with the low rate of infiltration and the designed air gap around the packages would prevent access of bulk liquid water to the packages. Finally, each package would always be at a higher temperature than the rock wall near it. This is dictated by the fact that the package would always constitute a stronger heat source than the rock, and the second law of thermodynamics dictates that heat always flows from a hotter to a colder body. If both the package and the rock wall became wet, by some unspecified and unanticipated mechanism, there would be a net evaporation from the package and a net condensation on the rock, as a result of the temperature difference, thus restoring the package to dryness. During the entire effective life of the packages, therefore, it is expected that they would not be contac'ed by buik liquid water. There would be chemisorbed and physisorbed layers of water molecules as determined by temperature, humidity, surface roughness, and presence or absence of hygroscopic species. The character of the resulting degradation modes may be either of a dry oxidation type or an aqueous corrosion type, depending on the thickness of the water layer.

All this having been said, it is still prudent to allow for the possibility that some packages may be contacted by bulk water for some period of time. This might result from draining of the "condensation halo" near the edge of the repository, for example, or from an isolated case of fracture flow, or from the unanticipated case of repository inundation. If contact with bulk water occurred, the resulting aqueous environment at the packages would be conducive to corrosion processes such as general metal dissolution, pitting attack, crevice corrosion, stress corrosion cracking and other environmentally assisted cracking, and other possible corrosion modes.

The groundwater associated with the repository site is near neutral to slightly alkaline in $\mathrm{pH}$, oxygenated, and fairly low in ionic content, with sodium bicarbonate as the main dissolved species. Mechanisms have been suggested by which the solutes in the groundwater could become more concentrated and thereby result in a more aggressive corrosion environment. Although these mechanisms do not seem likely, it is difficult to rule out such a situation, and pruaience demands that it be considered.

Gamma radiation will be emitted by the waste as a result of radioactive decay. In the conceptual design, the thin-walled container offers little shielding.

Consequently, one must consider the radiolytic altsiations that would be produced in the package environment, particularly during the first few decades. ${ }^{19}$ Radiolysis of moist air produces species such as ozone, nitrogen oxides, nitric acid, and ammonia. Hydrogen peroxide is produced in radiolysis of liquid water. These species are known to be reactive with many metals. Radiolytic effects would be smaller in later years, as the packages cool, since the radionuclides producing both the majority of the heat (strontium-90 and cesium-137) and the gamma radiation (cesium-137) have he - -ives near 30 years. 
Further discussion of possible corrosion processes and other degradation effects on an emplaced container surface has been presented elsewhere.20 It should be kept in mind that there may be considerable variation in environmental conditions and meta!.'urgical conditions over the entire ensemble of waste packages in the repository. The conceptual design envisioned some 40,000 waste packages to be emplaced with an area spanning a few square kilometers over a time period of 25 to 30 years. One con expect a considerable variation in environmental parameters in a natural system of this size. The containers would be fabricated from many different heats of metal, having a range of compositions. It should therefore be expected that the response of the containers to the environment will likewise show substantial variation.

\section{PRELIMINARY SELECTION CRITERIA}

Preliminary selection criteria have been developed 10 for use in narrowing the list of possible candidate materials to a manageable few for further detailed study. The development of these criteria took into account the conceptual design, the performance requirements, and the expected and bounding service conditions. The preliminary criaria that were settled upon at this stage encompass a variety of disparate feature but fall into two main categories: (A) those related to the performance of the $x$.ttainer material in the repository, and $(B)$ non-performancerelated topics dealing with cost, engineering experience, and the practical considerations of fabricating containers from the material. We decided to assign weighting factors and numerical scores to the criteria so that an overall score or figure of merit could be determined for each candidate. This would then enable us to rank them and to choose the "best" candidates for further consideration.

An important aspect of the development of such a scoring system involving selection criteria that include a range of different aspects is the assignment of the relative weighting factors. This assignment necessarily requires the application of judgment, since there is no universally agreed-upon way of balancing these features against each other. We therefore applied our own judgment initially. In order to open this process up to input representing a variety of points of view, we submitted our suggested weighting factors, as well as the set of detailed criteria as a whole, to a peer review process. The peer panel was comprised of six experts in various aspects of metallurgy, corrosion of metals, and metal fabrication, who had backgrounds in industry, academia, and consulting. The recommendations of the peer review panel were incorporated into the preliminary selection criteria. The peer review report is enclosed as microfiche.

Within the two main categories mentioned above, the criteria are further divided into seven topical areas. These topical areas, together with the weighting factors that we have assigned after peer review, are shown in Table 1. 
Table 1 TOPICAL AREAS OF PRELIMINARY SELECTION CRITERIA

\section{Weighting Facior}

14

30

16

10

20

5

5

\section{Part A Material Performance}

A) Mechanical performance

B) Chemical performance

C) Predictability of performance

D) Compatibility with other materials

\section{Part B Fabricability, Cost. and Other Considerations}

E) Fabricability

F) Cost

G) Previous experience with the material

As can be seen, the highest weighting factor is applied to the chemical performance, which includes corrosion and oxidation. This reflects the overriding importance of maintaining containment over long periods of time, and the general belief that the most likely mode of breach of containment is corrosion or oxidation.

The next highest weighting is given to fabricability, recognizing the sine qua non that the material chc . $2 n$ must be workable into practical containers that can be reliably sealed.

Predictability ranks next, since a major aspect of the process of licensing will be development of a sufficiently convincing assessment of long-term performance to provide a "reasonable expectation" or "reasonable assurance" that the performance requirements will be met. Like "suh stantially complete" containment, these terms have not been quantitatively defined by the regulatory agencies.

Next is mechanical performance, recognizing the need for adequate mechanical behavior in handling and storage. Compatibility with the other materials present is required to make sure that the containers work together with the other designed multiple barriers to produce true defense in depth.

Cost and previous experience have the lowest weighting factors. There is some overlap between previous experience and all the other factors, since they have influenced past application of materials. Thus, previous experience is in a sense already covered implicitly in the others.

Perhaps the aspect that involves the most application of judgment is the assignment of relative weighting to cost versus the other topical areas. As noted above, in our initial 1983 screening of materials, cost was one of four criteria, each assigned equal weight, the other three being mechanical properties, weldability, and corrosion behavior. During the various presentations, publications, and reviews that followed this screening, we received input from several institutions and individuais in thie teclinical community in general. The consensus appeared to be that cost should have a lower relative ranking. One basis for this belief is that higher standards of longevity and predictability have been set for waste containers 
than for other engineering products, and that we should therefore emphasize higher quality materials, which also have higher costs. In addition, îne waste containers are not expected to be under surveillance throughout their design life, in contrast to other engineered systems, anc' would not be replaced if they fail, as is the case for other systems. Therefore it is necessary to be more conservative and to choose materials with superior projected behavior, which implies higher cost.

Finally, there are those who argue that in order to obtain a license for a nuclear waste repository, we must be able to achieve a broad consensus for approval of the design, including not only technical specialists but the public as well. The public (with some justification) associates iower cost with orer performance. If the public comes to believe that we are "cutting corners" by using "cheap" materials to contain waste which by some accounts is perceived by them (rightly or wrongly) as perhaps the most significant threat to public health and safety on the horizon, this consensus could be difficult to come by.

In any case, in these preliminary selection criteria we s re chosen to rank cost lower in importance thian performance and fabricability. It will be interesting to gauge the response from the community at large, particularly in view of the recently publis: ed cost estimates, 21 which evaluate overall waste container costs in billions of dollars.

Within tach of the seven topical areas, there are several specific sub-topics, each of which receives a share of the topic area weighting. At this level the criteria are material independent and are equally applicable to any candidate container material. It should be noted that each of the performance criveria must be considered for a variety of combinations of material conditions and environments. The conditions and environments considered are the following: (1) base material/closure (weld) material; (2) as-fabricated condition/aged condition; (3) nominal or expected environment/potential or bounding environment. Note that some of the criteria are interrelated and may overlap as noted above in connection with the "previous experience" criterion. The material independent selection criteria topic areas, sub-topics, and weighting factors are shown in Table 2. 
Table 2 COMPLETE CRITERIA FOR PRELIMINARY CONTAINER

MATERIAL SELECTION

Weighting Factors

Part A: MATERIALPERFORMANCE

14

6
6
2

30

8

7

10

5

16

4

4

4

4

10

5
5

A. Mechanical performance

A1 Strength

A2 Toughness

A3 Phase Stability

B. Chemical performance

B1 Resistance to general corrosion (oxidation, aqueous corrosion)

B2 Resistance to pitting, crevice, or other iocaiized attack

B3 Resistance to environmentally accelerated cracking (stress corrosion cracking and $\mathrm{H}$ embrittiement)

B4 Resistance to microbiologically influenced corrosion

C. Predictability of performance

C1 Existence of predictive methods to explain and predict degradation phenomena and to extrapolate existing performance data to repository time scales and conditions, or ability to develop such methods

C2 Existence of long-term performance data

C3 Ability to generate required data

C4 Relative licensability

D. Compatibility with other materials

D1 Interactions with waste form

D2 Interactions with the package environment and borehole liner

PART B: EABRICABILITY COST AND OTHER CONSIDERATIONS

20

E. Fabricability

E1 Fabricability of container body

E2 Ability to close and seal the crsntairer

E3 Inspectability of closure

E4 Post-closure damage tolerance

F. Cost

As-fabricated container costs

2

Associaied exceptionai repository handling costs

1

F3 Strategic availability of material 
E

3

2

G. Previous experience with the material

G1 Previous engineering experience with the material

G2 Existing engineering standards for the material

A brief explanation and justification of the relevance of each of the sub-topics follows:

A1. Strength - This is a measure of the ability of a material to carry a mechanical load without deforming. High strength is not required in this application, but a moderate amount is needed to carry the loads in lifting, handling, and storage.

A2. Toughness - This is a measure of the energy required to fracture a material, and it evaluates the ductility, or conversely, the brittleness, of the material. Toughness is particularly important for resisting impact loads, such as may occur in handling.

A3. Phase Stability - This is a measure of the degree to which an alloy will maintain its detailed chemical and crystallographic structure when subjected to the expected temperature and mechanical stress conditions over time. Phase changes can be detrimental to mechanical and corrosion properties.

B1. Resistance to general corrosion (oxidation, aqueous corrosion) General corrosion is a chemical degradation process that occurs over the entire exposed surface of a metal part. It can occur under dry conditions, in which case it is called oxidation, or under wet conditions, where it is termed aqueous corrosion. At relatively low temperatures, the latter is often a more rapid process, involving local galvanic effects and migration of ions in aqueous solution. General corrosion could destroy containment.

B2. Resistance to pitting, crevice, or other localized attack - In these forms of corrosion the metal is degraded in smaller regions as compared with the attack covered by B2. These modes are also capable of compromising containment.

B3. Resistance to environmentally accelerated cracking (stress corrosion cracking and hydrogen embrittlement) - Under certain conditions these failure modes can produce rapid failure of metal parts. They depend sensitively on particular chemical species in the environment, and again are threats to containment. 
B4. Resistance to microbiologically influenced corrosion - In recent years microbes have been found to be responsible for many corrosion failures. They cannot be ruled out in the potential repository, since some have been found to survive extremes of temperature and radiation dose rate. Metabolic products from some microbes could substantially alter the chemical environment near the metal surface. Other microbes specifically oxidize certain metals.

C1. Existence of predictive methods to explain and predict degradation phenomena and to exirapolate existing performance data to repository time scales and conditions, or ability to develop such methods - - This is important in projecting long term behavior. While such extrapolation will always be accompanied by uncertainty, an effort is made to compare the difficulty of doing so for different materials.

C2. Existence of long-term performance data - Although the timescale of interest for a repository exceeds the history of the use of nearly all potential candidate metals, some have a more extensive performance data base than others. Long-term performance data help to provide confidence in predictions.

C3. Ability to generate required data - This involves a judgment of the difficulty of accumulating data on the metal that is necessary for performance assessment and licensing.

C4. Pelative licensability - This is a judgment of the expected ease or difficulty of demonstrating sufficient performance predictability to allow licensing, given previous licensing experience, data, and models.

D1. Interactions with waste form - Deleterious chemical or corrosion interactions with spent fuel or borosilicate glass must be avoided to insure containment.

D2. Interactions with the package environment and borehole liner - This is similar to D1, but involves the package external environment.

E1. Fabricability of container body - This is an evaluation of the ease with which the main body of the container can be made, and its quality controlled.

E2. Ability to close and seal the container - This mainly refers to welding, and is important in establishing containment. Quality control of the welding process is an important consideration here.

E3. Inspectability of closure - The containers must not only be sealed, they must be known to be sealed. Inspection must be performable with confidence. 
E4. Post-closure damage tolerance - This is a judgment of the fragiity of the container if fabricated frc.n the material in question.

F1. As-fabricated container costs - These must be estimated from available information.

F2. Associated exceptional repository handling costs - This accounts for individual characteristics of materials such as weight, brittleness, and toxicity.

F3. Strategic availability of material - This is a measure of the likelihood of supply of a sufficient quantity of the material over the long term.

G1. Previous engineering experience with the material - This is a measure of the variety of applications and years of experience with the material.

A high score gives confidence against something unexpected occurring.

G2. Existing engineering standards for the material - This is another measure of experience with the material and familiarity within the technical community.

In applying the criteria, we have tried to be as quantitative as possible and to compare candidat? materials on as common a basis as possible. Even so, some of the criteria are eitl,er inherently subjective or there is insufficient information available to treat them in an objective, quantitative fashion. In addition the individual peculiarities of the candidates must be taken into account. For example, in considering localized corrosion, an important parameter is the likelihood that the repository environment will have present an ionic species that promotes pitting, at a high enough concentration to affect performance. It is known that pitting of different metals is affected by different ionic species. Therefore, this criterion must consider different species for the various candidates, but the intent is the same for all, that is to evaluate the degree to which pitting attack might be a performance limiting problem.

Minimum or maximum acceptable limits can be established for some of the criteria, such as the one applying to mechanical strength. For others, no minimum or maximum passing values can be assigned, either because the property is not precisely quantifiable, a clear limit cannot be selected, or sufficient data are not available for a particular candidate. Nevertheless, the first step in applying the criteria was a "pass or fail" test, in which a candidate either was retained or rejected based either on whether or not a particular property value fell within established limits, or, lacking such limits, whether it was subjectively judged adequate or inadequate with respect to the property.

After the "pass or fail" test, the surviving candidates were subjected to quantitative scoring for each criterion. Where possible and relevant, the range of values of the parameter in question was made to correspond to a scale of points so that a point value could be tabulated for each candidate. In some cases this was not justified 
or not possible. For example, once the minimum strength requirement was satisfied, there was little benefit to having greater strength, since the thickness of material to be used was established independently of strength, for corrosion protection.

A detailed discussion of each criterion is given in Appendix A.

\section{MATEPIALS CONSIDERED}

A total of forty-one materials were considered. The so-called "SCP-6" candidate materials (the six listed in the Site Characterization Plan) were considered in detail. These materials are conveniently grouped into two families: (1) iron-based and nickel-based alloys having an austenitic (face-centered cubic) structure, specifically AISI 304L stainless steel, AISI 316L stainless steel, and nickel-rich Alloy 825 ; (2) copper and copper-based alloys, specifically oxygen-free pure copper (CDA 102), 7\% aluminum bronze (CDA 613), and 70/30 copper-nickel (CDA 715).

Thirty-two other engineering materials were also evaluated against the selection criteria, but with less rigor than the SCP-6, because these materials have not been as extensively considered by the YMP/NNWSI in the past. For instance, these materials were not considered in the container fabrication and closure process evaluations. Several of them are fairly new materials and have been developed for rather specific applications; it is not known how they will perform in other circumstances. These materials included several other stainless steels (both austenitic and ferritic grades), several nickel-based alloys ( $\mathrm{Ni}-\mathrm{Cr}-\mathrm{Mo}$ and $\mathrm{Ni}-\mathrm{Cu}$ alloys), other copper-based alloys, titanium and Ti-based alloys, zirconium, alloy steels, carbon steels, and cast irons. All of the material that had been evaluated in the 1983 study were included, 6 as well as some other materials that had been suggested in the intervening years at various workshops and other project reviews and functions.

Of the common engineering alloy systems, the ones not represented in the candidate list are those based on aluminum, lead, magnesium, tin, and zinc. These metals do not have adequate mechanical properties at the temperatures of interest for the conceptual design container. However, they could be considered as external coating or cladding materials or as internal filler materials in other designs employing multiple barrier concepts.

A listing of the materials considered is given in Table 3. The Unified Numbering System (UNS) designation is given for each metal or alloy. The detailed composition of each material can be found by locating the corresponding American Society for Testing and Materials (ASTM) designation in the UNS handbook, 22 and consulting the appropriate ASTM standard. 
Table 3 MATERIALS CONSIDERED IN THE SELECTION EVALUATION OF CANDIDATES FOR NUCLEAR WASTE CONTAINERS

Common Designation

\section{Stainless Steels}

$304 \mathrm{~L}$

304ELC

$316 \mathrm{~L}$

$316 \mathrm{LN}$

$317 \mathrm{~L}$

321

347

409

430

$26 \mathrm{Cr}-1 \mathrm{Mo}$

$29 \mathrm{Cr}-4 \mathrm{Mo}$

Ferralium 255

Nitronic 33

Nitronic 50
UNS Designation

530403

S30403

S31603

S31653

S31703

S32100

S34700

$\mathrm{S} 40900$

$\$ 43000$

S44626

$\mathrm{S} 44700$

S32550

$\mathrm{S} 21900$

S20910
Remarks

One of the SCP-6 Materials

One of the SCP-6 Materials
2. Nickel-Base and High Nickel Stainless Alloys

20Cb3 (Carpenter 20Cb3) N08020

AL6X(Allegheny-Ludlum) N08366

JS700(Jessop 700)

625 (Inconel 625)

825 (Incoloy 825)

N08700

N06625

N08825

N06985

G-3 (Hastelloy G-3)

G-30 (Hastelloy G-30)

N06030

C-276 (Hastelloy C-276)

\$10276

N06022

N06455

C-4 (Hastelloy C-4)

400 (Monel 400)

N04400

One of the SCP-6 Materials

Given full evaluation

3. Allor Steels

$9 \mathrm{Cr}-1 \mathrm{Mo}$

J82090 (ASTM A 217)

4. Carbon Steels

AISI 1020

A537

G10200

K02400

5. Cast Irons

Nodular Gray $\quad$ F43000

Si Cast Iron

F47001 


\section{Copper and Copper-Based Alloys}

$\begin{array}{lll}\text { CDA } 102 & \text { C10200 } & \text { One o; the SCP-6 Materials } \\ \text { CDA } 110 & \text { C11000 } & \\ \text { CDA } 122 & \text { C12200 } & \\ \text { CDA 613 } & \text { C61300 } & \text { One of the SCP-6 Materials } \\ \text { CDA 71' } & \text { C71500 } & \text { One of the SCP-6 Materials }\end{array}$

7. Titanium and Titanium-Based Alloys

Ti Grade 2 R50400

Ti Grade $7 \quad$ R52400

Ti Grade $12 \quad$ R53400 Given full evaluation

\section{Zirconium and $\mathrm{Zr}$-Based Alloys}

$\begin{array}{ll}\text { Zr 702 } & \text { R60702 } \\ \text { Zircaloy 2 } & \text { R60802 } \\ \text { Zircaloy 4 } & \text { R60804 }\end{array}$

\section{MATERIAL EVALUATIONS}

The quantitative application of 34 separate criteria to 41 candidate metals would require a large amount of experimental data. In some cases, such as for the SCP-6 candidates, which we have had under consideration for several years, many of the needed data are available. In other cases, particularly for some of the alloys developed in recent years, data are more sparse.

In view of this situation we decided to apply quantitative scoring only to the SPC-6 candidates and to one selected alloy from each of the two higher performance alloy groups, i.e., the titanium-based and the nickel-based alloys. These two additional alloys are titanium grade 12 and Alloy C-4. The bases for selecting these two alloys are given in the respective degradation mode surveys.11,12 We judged that they were the best in their alloy groups for the present application. For the other 32 candidates, we applied comparative qualitative judgment.

Accordingly, four of us (WLC, RDM, WGH, and GEG) met on July 30 and 31, 1991, and collectively scored the eight named candidates, and two of us (RDM and GEG) applied our judgment during the next week to the others.

As described above, the first step was to apply the pass-or-fail tests. The results were that Alloy $825,7 \%$ aluminum bronze (CDA 613), 70/30 copper-nickel (CDA 715), Alloy C-4, and titanium grade 12 all passed readily. AISI 304L and 316L stainless steels barely passed some of the locaiized and stress corrosion resistance criteria. High purity copper (CDA 102) failed the tests for mechanical strength, weldability of the tinal closure, and external handling during emplacement. It is important to state again that these criteria were applied to a single-metal, thin-walled container design. The materials that barely passed or 
failed these criteria may be quite suitable for other designs that incorporate thicker walls or multiple barriers. As previously noted, much of the information used in the evaluations came from the degradation mode surveys and the process evalutions for fabrication and closure.

The next step was quantitative evaluation of the remaining seven leading alloys. The score sheets that we developed for them are given in Appendix B. A comparison of the total scores for these alloys is given in Table 4.

\section{Table 4 QUANTITATIVE SCORES OF MATERIALS THAT RECEIVED DETAILED EVALUATIONS}

\begin{tabular}{ll} 
Material & Score \\
\hline Ti-Grade 12 & 691 \\
Alloy C-4 & 685 \\
Alloy 825 & 651 \\
316L stainless steel & 600 \\
304L stainless steel & 588 \\
70/30 Cu-Ni (CDA 715) & 501 \\
Al-Bronze (CDA 613) & 484 \\
Pure Cu (CDA 102) & 0 (failed at least one criterion)
\end{tabular}

Note: A perfect score would be 994 points.

A few remarks are pertinent to these scores:

1. The reason why AISI $316 \mathrm{~L}$ and $304 \mathrm{~L}$ stainless steels rank higher than the copper-based alloys is primarily because they have a larger experience base. However, as noted, these materials barely passed the localized corrosion and stress corrosion pass-fail criteria.

2. Both the aluminum bronze and the $70 / 30$ copper-nickel were rated low in performance and predictability. The aluminum bronze suffered from lack of experience in fabrication, welding, industrial usage, and performance modeling.

3. The high purity copper, as noted earlier, failed on the basis of strength (criterion A1), weldability (criterion E2), and external handling (criterion E4). It also suffers from the same performance limitations as the aluminum bronze and the copper-nickel.

The qualitative comments on the remaining 32 candidates are as follows:

1. Stainless Steels

304ELC Extra low carbon version of Type 304 ss. Expected to have similar properties to $304 \mathrm{~L}$, except for greater resistance to sensitization.

316LN Nitrided version of Type 316L. Expected to have similar properties. 
317L Higher Mo (3-4 wt.\%) version of 316L (2-3 wt.\% Mo). Expected to have somewhat better localized corrosion resistance than $316 \mathrm{~L}$, but will be susceptible to chloride-induced stress corrosion crackinu (SCC) because of Ni content (11-15 wt.\%). Therefore, it is expected to score lower than other alloys which contain both high $\mathrm{Ni} \mathrm{(>40} \mathrm{wt. \% )} \mathrm{and}$ similar Mo content (e.g. Alloy 825).

321 Ti-stabilized Ni-Cr stainless steel with no Mo addition, therefore localized corrosion is a concern. Expected to have similar corrosion properties to Type $304 \mathrm{~L}$ stainless steel.

347 Columbium (Niobium) stabilized Ni-Cr stainless steel with no Mo addition, therefore localized corrosion is a concern. Expected to have similar corrosion properties to Type 304L stainless steel.

Nitronic 33 and Nitronic 50

$\mathrm{Mn}$ and $\mathrm{N}$ additions impart greater yield strength. However, $\mathrm{Mn}$ addition in place of Ni decreases resistance to SCC. Nitronic grades subject to localized corrosion.

$409,430,26 \mathrm{Cr}-1 \mathrm{Mo}, 29 \mathrm{Cr}-4 \mathrm{Mo}$

These are ferritic stainless steels, which as a class of materials generally have problems with welds primarily due to grain growth in weld and HAZ regions. Post-weld treatment does not alleviate all embrittlement problems and may even enhance some. In addition, fracture toughness of these materials is poor. Ferritic stainless steels are generally immune to chloride induced SCC; the $26 \mathrm{Cr}-1 \mathrm{Mo}$ and $29-\mathrm{Cr}-4 \mathrm{Mo}$ grades are very resistant to localized corrosion. The 409 stainless steel was failed on criterion A2 (toughness), A3 (phase stability), and E2 (weldability).

2. High Nickel Alloys

20Cb3, AL6X, JS700

A group of alloys with intermediate nickel concentration (23 to $38 \%$ ) and Mo concentration of 2-7\%. The Ni addition should enhance SCC resistance, and the Mo addition, localized corrosion resistance. These alloys are expected to have better SCC resistance than the 300 series stainless steels, but not as good as Alloy 825 . The higher Mo alloys would be expected to have better localized corrosion resistance than the standard Alloy 825 . However, a higher Mo version of Alloy 825 is available, and would have decided advantages over these alloys. On the other hand, these alloys will cost less than Alloy 825, and performance in the expected environment may be adequate. Those alloys with $\mathrm{Ni}>24 \%$ do not SCC in any natural environment (sea water, fresh water, etc.), and therefore $\mathrm{J}-13$ types of groundwaters would not be expected to inciuce SCC. Nevertineiess, these are new alloys and do not have as extensive a database as Alloy 825 . 
G-3 This ailoy is similar to Alloy 825 , but it has a higher Mo content $(6-8 \%)$ and a $5 \%$ Co addition. It is expected to have better localized corrosion resistance than Alloy 825, but a higher cost due to the cobalt addition. Again, there is a higher Mo version of Alloy $\mathbf{8 2 5}$.

G-30 Higher $\mathrm{Cr}(28-31 \%)$ version of Alloy G-3. There will likely be problems with welds of such a high $\mathrm{Cr}$ material due to formation of intermetallic precipitates and possibly sigma phase formation.

$625 \mathrm{Nb}$ addition makes this alloy susceptible to ordering and precipitate formation. Alloy does not weld as readily as $\mathrm{Ni}-\mathrm{Cr}$-Mo alloys without $\mathrm{Nb}$. Good base-metal corrosion properties similar to other Ni-C,-Mo alloys.

C-4, C-22, C-276

All have similar corrosion properties, but C-4 has better weldability. There probably will be some precipitate formation in weld. May need to consider mechanical closures. All have very good base-metal corrosion properties.

400 This is a $70 \mathrm{Ni}-30 \mathrm{Cu}$ alloy which has somewhat better aqueous corrosion resistance than $70 \mathrm{Cu}-30 \mathrm{Ni}$, but is more expensive due to the higher $\mathrm{Ni}$ content. Extensive experience in marine applications. Unknown performance in radiation environments, but lack of very stable oxide formation suggests that it would not be sufficiently oxidation resistant when irradiated.

3. Alloy Steels, 4. Carbon Steels, and 5. Cast Irons

With the possible exception of the silicon cast iron, all these materials are not expected to have the necessary general corrosion resistance for the SCP Conceptual Design. In addition, cast irons suffer a localized corrosion form known as graphitization. Alloy steels are difficult to weld because of enhanced brittle martensite formation in the weld. Cast irons and silicon irons are difficult to form in the dimensions of the conceptual design container. All of these materials faiied at least one of the criteria.

6. Copper and Copper-Based Alloys

CDA 706

The 90/10 copper-nickel is expected to have inferior corrosion properties to the 70/30 material (CDA 715) in mildly oxidizing environments. 
CDA 110

Electrolytic tough pitch copper suffers in this application from the same properties that failed high purity $\mathrm{Cu}$ : low strength and difficult weldability for the final closure weld.

CDA 122

This alloy has residual phosphorus which makes the alloy more weldable and marginally stronger. However, it is expected to be less corrosion resistant than CDA 715 and CDA 613. The material failed the same criteria as high purity $\mathrm{Cu}$ (CDA 102).

7. Titanium and Titanium-Based Alloys

$\operatorname{TiGr} 2, \operatorname{Ti} \mathrm{Gr} 7, \operatorname{Ti} \mathrm{Gr} 12$

Ti Gr 7 (palladium addition) and Ti Gr 12 (nickel and molybdenum addition) have better crevice corrosion resistance than unalloyed $\mathrm{Ti}$ Gr 2. Ti Gr 7 is the most expensive. Titanium is highly corrosion resistant to many acids and to high chloride media.

\section{Zirconium}

Commercial $\mathrm{Zr}$ and the Zircaloys are notch sensitive and have low fracture toughness. Welding requires protective atmospheres to prevent oxygen and nitrogen pick-up. Long-term hydriding may be a problem. These are expensive materials. Excellent corrosion resistance in aggressive environments (acids and high $\mathrm{Cl}-$ ).

\section{SUMMARY AND CONCLUSIONS}

The preliminary set of selection criteria, developed by the Yucca Mountain Project (YMP) in 1988-90, were applied to a large number of engineering materials that have been considered for fabrication of nuclear waste containers to be disposed of at a potential repository at Yucca Mountain. These materials ranged from cast iron to zirconium. Other families of materials evaluated were austenitic stainless steels, ferritic stainless steels, carbon and alloy steels, nickel-based alloys, copper and copper-based alloys, and titanium and its dilute alloys. The materials were evaluated on the basis of the YMP conceptual design for the waste package container. In this design, a thin-walled container fabricated from a single metal or alloy would serve as the containment barrier. The environment in which the container will be emplaced is believed to be "dry" and is expected to remain so for a long period of time. However, since aqueous conditions cannot be absolutely ruled out, the performance of the material in these circumstances must be satisfactory and predictable.

The criteria fall into two broad categories: (1) aspects dealing with the performance of the container materia! in the respository environment, and (2) aspects dealing with the economic and practical considerations of fabriciting 
and sealing the containers. The criteria are weighted so that a quantitative comparison amc...y the candidates is obtained. The "performance" criteria account for $70 \%$ of the points awarded, and the other criteria account for $30 \%$. These broader categories are sub-divided into individual criteria (34 in all) with which the materials are scored individually, the appropriate weighting factor applied, and the points totaled. For many of the criteria, there is a minirnum or maximum requirement, in other words, a "pass/fail" threshold, and a successful candidate material must pass all of these.

As a result of performing the evaluation, the following materials are recommended for additional investigations during the advanced conceptual design phase of the YMP:

1. Titanium Grade 12, a dilute alloy containing small additions of nickel and molybdenum (UNS R53400).

2. Alloy C-4, a nickel-based alloy containing appreciable amounts oi chromium and molybdenum (UNS N06455) [this alloy is also known as Hastelloy C-4].

3. Alloy 825 , a high-nickel intermediate austenitic alloy (UNS N08825) [this alloy is also known as Incoloy 825].

It must be emphasized that these selections are specifically made for our conceptual design waste package container. Other design concepts may favor other material selections.

\section{REFERENCES}

1. Nuclear Waste Policy Act of 1982, Public Law 97-425 (January 7, 1983) (NNA. 870327.0801.

2. Depariment of Energy, "Site Characterization Plan, Yucca Mountain Site, Nevada Research and Development Area," Report No. DOE/RW-0199, U.S. D.O.E., Office of Civilian Radioactive Waste Management, Washington, D.C. (1988) (HQO. 881201.0002).

3. R. D. McCright, W. G. Halsey, G. E. Gdowski, and W. L. Clarke, Jr., "Candidate Container Miaterials for Yucca Mountain Wasie Package Designs," p. 125 in Proc. of the Topical Meeting on Nuclear Waste Packaging, Focus '91, American Nuclear Society, La Grange Park, IL (1992) (readily available).

4. W. C. O'Neal, D. W. Gregg, J. N. Hockman, E. W. Russell, and W. Stein, "Preclosure Analysis of Conceptual Waste Package Designs for a Nuclear Waste Repository in Tuff," Report No. UCRL-53595, Lawrence Livermore Nationa! Laboratory, Livermore, CA (1984) (NNA. 891026.0013).

5. R. D. McCright, "An Annotated History of Container Candidate Material Selection," Report No. UCID-21472, Lawrence Livermore National Labcratory, Livermore, CA (1988) (NNA. 890615.0142). 
6. E. W. Rusiell, R. D. McCright, and W. C. O'Neal, "Containment Barriers for High Level Waste Packages in a Tuff Repository," Report No. UCRL-53449, Lawrence Livermore National Laboratory, Livermore, CA (1983) (NNA. 891215.0013).

7. C. F. Acton and R. D. McCright, "Feasibility Assessment of Copper-Base Waste Package Container Materials in a Tuff Repository," Report No. UCID-20847, Lawrence Livermore National Laboratory, Livermore, CA (1986) (NNA. 891026.0011).

8. D. B. Bullen, J. C. Farmer, G. E. Gdowski, R. D. McCright, R. A. Van Konynenburg, and $\mathrm{H}$. Weiss, "Survey of Degradation Modes of Candidate Materials for High-Level Radioactive Waste Disposal," 8 volumes, Report No. UCID-21362, Lawrence Livermore National Laboratory, Livermore, CA (1988) (NNA. 891222.0305 through .0313).

9. J. C. Farmer and R. D. McCright, "Review of Models Relevant to the Prediction of Performance of High-Level Radioactive Waste Disposal Containers," Report No. UCRL-100172, Lawrence Livermore National Laboratory, Livermore, CA (1982) (NNA. 900723.0218).

10. W. G. Halsey, "Preliminary Selection Criteria for the Yucca Mountain Project Waste Package Container Material," Report No. UCRL-ID-104552, Lawrence Livermore National Laboratory, Livermore, CA (1991) (NNA. 910207.0082).

11. G. E. Gdowski, "Survey of Degradation Modes of Four Nickel-ChromiumMolybdenum Alloys," Report No. UCRL-ID-108330, Lawrence Livermore National Laboratory, Livermore, CA (1991) (NNA. 910521.0010).

12. G. E. Gdowski and R. D. McCright, "Corrosion Considerations of High-Nickel Alloys and Titanium Alloys for High-Level Radioactive Waste Disposal Containers," Paper No. 48, Corrosion '91, National Association of Corrosion Engineers, Houston, TX (1991) (NNA. 910925.0010).

13. G. E. Gdowski and R. D. McCright, "Degradation Mode Surveys of High Performance Candidate Container Materials," p. 932 in Proc. of the Second Annual Int'l Conf. on High Level Radioactive Waste Management, Vol. 2, American Nuclear Society, La Grange, Park, IL (1991) (NNA. 911212.0212).

14. Environmental Protection Agency, "40CFR Part 191- Environmental Radiation Proection Standards for Management and Disposal of Spent Nuclear Fuel, High-Level and Transuranic Wastes," Federal Register, Vol. 50, p. 38084 (Sept. $19,1985)$ (HQ 2.870301.5394).

15. Nuclear Regulatory Commission, "10CFR Part 60 - Disposal of High-Level Radioactive Wastes in Geologic Repositories-Technical Criteria," Federal Register, Vol. 48, p. 28194 (June 21,1983) (HQ 2.870302.3019 cr NNA. 891018.0190). 
16. R. A. Van Konynenburg, "Gaseous Release of Carbcr. 14: Why the High Level Waste Regulations Should be Changed," p. 313 in Proc. of the Second Annual Int'l Conf. on High Level Radioactive Waste Management, American Nuclear Society, La Grange Park, IL (1991) (NNA. 920413.0140).

17. H. A. Domian, R. L. Holbrook, and D. F. LaCount, "Fabrication Development for High-Level Nuclear Waste Containers for the Tuff Repository," Report No. UCRL-15965, Lawrence Livermore National Laboratory, Livermore, CA (1990) (NNA. 900925.0062).

18. E. S. Robitz, Jr., M. D. McAninch, and D. P. Edmonds, "Closure Development for High-Level Nuclear Waste Container for the Tuff Repository," Report No. UCRL15964, Lawrence Livermore National Laboratory, Livermore, CA (1990) (NNA. 910211.0118).

19. D. T. Reed and R. A. Van Konynenburg, "Effect of lonizing Radiation on the Waste Package Environment," p. 1396 in "ros. of the Second Annual International Conference on High Level $\mathrm{F}_{\mathrm{S}}$ cactive Waste Management, Vol. 2, American Nuclear Society, La Grange Furk, IL (1991) (NNA. 911212.0247).

20. R. D. McCright, "Container Materials for High-Level Nuclear Waste at the Proposed Yucca Mountain Site," Report No. UCRL-JC-103726, Lawrence Livermore National Laboratory, Livermore, CA (1991) (NNA. 911212.0245).

21. E. W. Russell, W. Clarke, H. A. Domian, and A. A. Madson, "Cost Estimate of High-Level Radioactive Waste Containers for the Yucca Mountain Site Characterization Project," Report No. UCID-21863, Lawrence Livermore National Laboratory, Livermore, CA (1991) (NNA. 900425.0002).

22. Metals and Alloys in the Unified Numbering System. 4th Edition, Society of Automotive Engineers, Inc., Warrandale, PA (1986) (pp 185-195, 210, 220, 223224) (NNA. 910419.0005). 
Appendix A:

\title{
PARAMETERS. WEIGHTING FACTORS. AND PASSING SCORES EOR CANDIDATE METAL ALLOYS
}

\author{
A) Mechanical Performance \\ Weighting Factor: 14
}
A1) Strength
Weighting Factor: 6
Parameter: Yield strength
Passing Score: Adequate/lnadequate (approximately $10 \mathrm{ksi}$ (69 MPa)
Score: Pass (5) / Fail (0) minimum)
Scale: NA

This assures adequate strength for static and handling loads. Absolute minimum values are not currently available; however, typical conceptual design loads are about 1-3 ksi (7-21 MPa) (without safety factor). This criterion applies at the possible $250 \mathrm{C}$ service temperature and must still be met after the long term aging of the material.

A2) Toughness

Weighting Factor: 6

Parameter: Plane-strain fracture toughness $\left(\mathrm{K}_{\mathrm{IC}}\right)$

Passing Score: Adequate/Inadequate (approximately $50 \mathrm{ksi}$ (in) $1 / 2$

Score: Pass (5) /Fail (0) $\left.\left(55 \mathrm{MPa}(\mathrm{m})^{1 / 2}\right)\right)$

Scale: NA

This assures sufficient fracture toughness to withstand impact loads during handling. Absolute minimum values are not currently available; however, typical engineering applications require approximately $50 \mathrm{ksi}$ (in)1/2 (55 MPa(m)1/2). Fracture toughness can be inferred from measured stress intensity factor for fracture Klc (or appropriate empirical correlations or elastic-plastic J-integral method). Note that this criterion must be met by the final closure weld (if welded) and heat affected zone after a long term aging cycle. 
A3) Phase stability

Weighting Factor: 2

Parameter: Relative metallurgical phase stability

Passing Score: Adequate/Inadequate

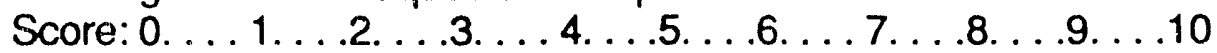

Scale: Bad Poor Moderate Fair Good Excell.

Units: relative phase stability

This measures relative metallurgical stability of base metal and final closure weld (if welded) and heat affected zone during long term (1000 years) aging at moderate temperatures (up to $250 \mathrm{C}$ ).

B) Chernical Performance

Weighting Factor: 30

B1) Resistance to general corrosion (oxidation, aqueous corrosion).

Weighting Factor: 8

Parameter: Time average oxidation rate (micrometers/year)

Passing score: 1.0 micrometer/year maximum

Score: $0 \ldots .1 \ldots . \ldots . \ldots . \ldots 4 \ldots .5 \ldots 6 \ldots . \ldots . \ldots 8 \ldots . \ldots 10$

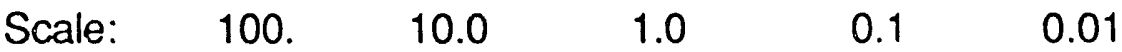

Units: micrometers/year

This is the average general corrosion rate (from oxidation and aqueous corrosion phenomena) for the expected time, temperature and environment for the containment period. The criterion is wall thinning, or the sum of corrosion on the interior and exterior of the container. The passing score then allows for up to 1 millimeter of wastage from oxidation in 1000 years.

32) Resistance to pitting, crevice, or other localized attack.

Weighting factor: 7

Parameter: Penetration rate

Passing score: 1.0 micrometer/year maximum

Score: $0 \ldots .1 \ldots 2 \ldots .3 \ldots 4 \ldots .5 \ldots 6 \ldots 7 \ldots . \ldots 9 \ldots 10$

Scale: $\quad \begin{array}{llllll}100 & 10.0 & 1.0 & 0.1 & 0.01 & 0\end{array}$

Units: micrometers/year

This is the projected average rate of penetration of localized corrosion phenomena during the first 1000 years under the expected metallurgical (including the aged material) and environmental conditions. This criterion applies to both the interior and exterior of the container. A material which does not allow initiation of localized corrosion in the expected environmental and service conditions can be given a ' 0 ' penetration rate. The likelitood of Iccalized corrosion includes consideration of topics such as the difference between the critical potential for pit initiation and the free corrosion potential, 
ionic concentrations expected, possible concentrating effects, thermal conditiors, and quantity of water present, all as functions of time.

B3) Resistance to environmentally accelerated cracking EAC (stress corrosion cracking and hydrogen embrittlement).

Weighting factor: 10

B3a) Threshold stress intensity for corrosion cracking

Weighting Factor: 2

Parameter: $\mathrm{K} / \mathrm{K} / \mathrm{scc}$

Passing score: 0.7 critical stress intensity for SCC

Score: 0. . 1. . 2. . . . . 4. .5. .6. . . 7. .8. .9. . .10

$\begin{array}{llllll}\text { Scale: } 1.0 & 0.8 & 0.6 & 0.4 & 0.2 & 0\end{array}$

Units: stress intensity/critical stress intensity

This is the ratio of expected stress intensity $\mathrm{KI}$ (due to residual stresses, applied stresses, and internal flaws), to the critical stress intensity K/scc for SCC under expected metallurgical (including the aged material), physical, and environmental conditions, both internal and external. The 0.7 ratio passing score is similar to ASME Section XI limits. $K /$ and $K / s c c$ have to be estimated for the selection process, as the design and fabrication processes are not finalized.

B3b) Degree of sensitization (austenitic alloys/SCC)

Weighting factor: 1

Parameter: EPR ratio

Passing score: $5 \%$ maximum

Score: 0. . . 1. . 2. . . . . 4. . .5. .6. . . 7. . .8. . .9. . 10

Scale: $100 . \quad 10 \quad 1.1$

Units: EPR ratio \%

This use the electrochemical potentiokinetic reactivation (EPR) test. The worst case is likely to be the final closure weld and heat affected zone after long term aging. Passing score is a common screening value for testing austenitic stainless steels.

B3c) Threshold potential (austenitic alloys/TGSCC)

Weighting factor: 1

Parameter: $E$ (critical)-E (corrosion)

Passing score: 100 millivolts minimum difference

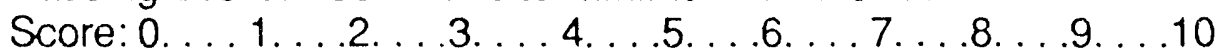

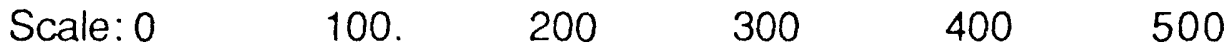

Units: millivolts 
This evaluates the difference between the critical potential for TGSCC and the íce corrosion potential under the expected metallurgical and environmental conditions. This is a common test for comparative corrosion susceptibility. The passing score is a common safety margin for potential difference.

B3d) Smooth specimen stress corrosion cracking

Weighting factor: 2

Parameter: $\mathrm{K} / \mathrm{K} / \mathrm{ssscc}$

Passing score: 0.7 critical stress intensity for SSSCC

Score: 0. . 1. . 2. . .3. . 4. . .5. .6. . . . .8. .9. . .10

$\begin{array}{llllll}\text { Scale: } 1.0 & 0.8 & 0.6 & 0.4 & 0.2 & 0\end{array}$

Units: stress intensity/critical stress intensity

This is the ratio of expected stress intensity $\mathrm{K}_{1}$ (due to residual stresses, applied stresses, and internal flaws), to the critical stress intensity KIssscc for smooth surface SCC under expected metallurgical (including the aged material), physical, and environmental conditions, both internal and external. The 0.7 ratio passing score is similar to ASME Section XI limits. $K_{I}$ and $K_{I}$ ssscc have to be estimated for the selection, as final design and fabrication decisions have not been made.

B3e) Likelihood of sufficient concentration of chemical species for corrosion cracking (for example: chloride for austenitic alloys, ammonia or nitrite for copper alloys)

Weighting factor: 2

Parameter: Likelihood of EAC ion concentrations occurring.

Passing score: Adequate/Inadequate confidence cracking will not occur Score: 0. . . 1. . 2. . . . . 4. . .5. .6. . . . . .8. . . . .10 Scale: High Moderate Low None

Units: Subjective likelihood

This evaluates the expected probability that chemical species in the environment which are known to cause or enhance EAC will occur in concentrations sufficient to propagate a crack through the container wall. This includes consideration of topics such as ionic concentrations expected, possible concentrating effects, thermal conditions, and quantity of water present, all as functions of time and for interior and exterior surfaces.

B3f) Likelihood of sufficient hydrogen concentration to cause degradation

Weighting factor: 1

Parameter: Likelinood of degrading concentrations of $\mathrm{H}$.

Passing score: Adequate/Inadequate confidence embrittlement will not occur

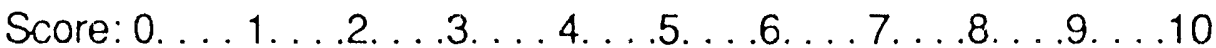

Scale: High Mucierate

Units: Subjective likelihood

Low

None 
This evaluates the expected probability that the r.ydrogen concentration in the environment will cause sufficient $\mathrm{H}$ uptake to cause degradation. This includes consideration of topics such as sources and sinks for hydrogen, radiation fields, surface activators, and the material condition.

B3g) Hydrogen sensitive phases (for example: martensite or sensitized material for austenitic alloys, oxide inclusions for copper alloys)

Weighting factor: 1

Parameter: Phase fraction

Passing score: 0.01 maximum

Score: $0 \ldots .1 \ldots 2 \ldots . \ldots 4 \ldots 5 \ldots 6 \ldots 7 \ldots 8 \ldots . \ldots 9.10$

$\begin{array}{llllll}\text { Scale: } 1.0 & 0.1 & 0.01 & 0.001 & 0.0001 & 0\end{array}$

Units: fraction

This measures the fraction of material composed of phases susceptible to hydrogen cracking, particularly after aging in the final closure weld and heat affected zone.

B4) Resistance to microbiologically influenced corrosion

Weighting Factor: 5

Parameter: Likelihood of microbiologically influenced corrosion (MIC)

Passing score: Adequate/Inadequate confidence MIC will not occur

Score: 0. . . 1. . .2. . .3. . . 4. . .5 . .6. . . 7. . .8. . .9. . . 10

Scale: High Moderate Low None

Units: Subjective likelihood

This evaluates the expected probability that microbiologically influenced corrosion of the material will occur in the repository environment at a rate sufficient to cause container failure. Topics to consider include the likelihood of microorganisms living in the repository environment, their possible effects, and the possibility of effective countermeasures.

C) Predictability of performance

Weighting Factor: 16

(C1) Existence of predictive methods to extrapolate degradation phenomena, and methods to extrapolate existing performance data to repository time scales and conditions, or ability to develop such methods 
Weighting Factor: 4

Parameter: Subjective opir:ion of "predictability"

Passing score: Adequate/Inadequate confidence that adequate predictive methods will be available

Score: $0 \ldots .1 \ldots 2 \ldots .3 \ldots 4 \ldots .5 \ldots 6 \ldots 7 \ldots . \ldots . .9 \ldots 10$

Scale: None Low Moderate High

Units: Predictability

This estimates the likelihood that the degradation phenomena can be predicted sufficiently to allow performance assessment

C2) Existence of long-term performance data

Weighting Factor: 4

Parameter: Literature review finding

Passing score: Adequate/Inadequate data available

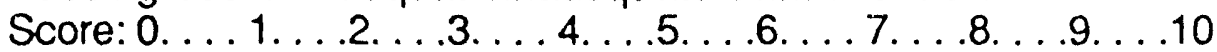

Scale: None Low

Units: relative data availability

Moderate High

Long term data include results from years or decades of exposure to known environments from which extrapolation to longer times is possible if models of the degradation modes exist. Data on materials other than the candidates may be useful if the degradation mode phenomenology is similar enough to be described by the same model.

C3) Ability to generate required data

Weighting Factor: 4

Parameter: Expected ability to generate data

Passing score: Adequate/lnadequate ability to generate data

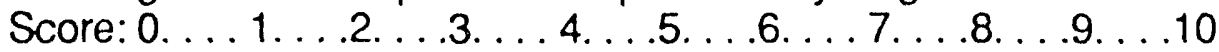

Scale: None Low Moderate High

Units: estimated ability

This estimates the expected ease or difficulty in producing material performance data required for performance assessment and to support the license application. This is a subjective combination of topics such as: volume and types of data needed, the ease in generating the data, and the uncertainties in the data due to variables in the material (such as heat-to-heat variations of critical properties). 
C4) Relative licensability of the material

Weighting Factor: 4

Parameter: Relative licensability

Passing score: Adequate/Inadequate licensability

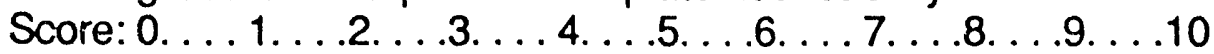

Scale: None Low Moderate High

Units: relative licensability

This estimates the expected ease or difficulty in demonstrating sufficient performance predictability to allow licensing. This is a subjective combination of topics such as development and validation of predictive methods, data availability and validation, prior licensing experience and practice, etc.

D) Compatibility with other materials

Weighting Factor: 10

D1) Interactions with waste form

Weighting Factor: 5

Parameter: Subjective opinion of "Compatibility"

Passing score: Adequate/Inadequate compatibility

Score: 0. . . 1. . .2. . .3. . . 4 . .5. . .6. . . 7. .8. . .9. . .10

Scale: None Low Moderate High

Units: estimate of compatibility

This estimates whether the container material is likely to interact with the waste forms (spent fuel, cladding, glass waste fo $\mathrm{m}$, glass pour canister, etc.) in a.'y way which will compromise performance or the waste package. Examples might include: galvanic coupling, formation of aggressive chemical species, interdiffusion effects, etc. This includes products from the container which affect the waste form as well as products from the waste form which affect the container. This criterion may overlap with other issues.

D2) Interactions with the package environment and borehole liner

Weighting Factor: 5

Parameter: Subjective opinion of "Compatibility"

Passing score: Adequate/Inadequate compatibility

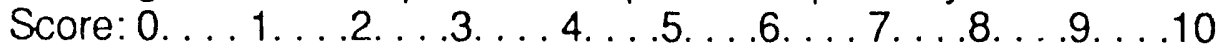

Scale: None Low Moderate High

Units: estimate of compatibility

This estimates whether the material is likely to interact with any features in the nearby emplacement environment (borehole liner, seals, grout, rock, rockbolts, skids, lubricants, etc.) in any way that will compromise performance of the waste 
package or other repository component. Examples might include galvanic coupling, formation of agressive chemical species, interdiffusion effects, etc.

E) Fabricability

Weighting Factor: 20

E1) Fabricability of container body

Weighting Factor: 5

E1 a) General formability

Weighting Factor: 2

Parameter: Subjective opinion of formability

Passing score: Adequate/Inadequate formability

Score: $0 \ldots .1 \ldots .2 \ldots . .3 \ldots 4 \ldots .5 \ldots 6 \ldots 7 \ldots . \ldots . \ldots 9 \ldots 10$

Scale: None Low

Moderate

High

Units: expected formability

This evaluates the availability of processes to form container components from the material considering properties such as ductility, microstructure, weldability, etc.

E1 b) Product quality

Weighting Factor: 2

Parameter: Subjective opinion of quality

Passing score: Adequate/Inadequate product quality

Score: 0. . . 1. . .2. . .3. . 4 . .5. . .6. . . 7. . .8. . .9. . .10

Scale: None Low Hoderate High

Units: expected quality

This evaluates the ability to produce reproducible properties such as composition, microstructure, residual stress, surface finish, etc.

E1 c) Inspectability

Weighting Factor: 1

Parameter: Subjective opinion of inspectability

Passing score: Adequate/Inadequate inspectability

Score: $0 \ldots$. . . .2. . .3. . 4 . .5 . .6. . . . . .8. . .9. . 10

Scale: None Low Moderate High

Units: expected inspectability

I his evaluates the ability to inspect the fabricated material and document properties such as those discussed in E1 b. 
E2) Closeability of container.

Weighting Factor: 5

E2.a) General process considerations

Weighting Factor: 3

Parameter: Subjective opinion of closure processes

Passing score: Adequate/lnadequate closure processes

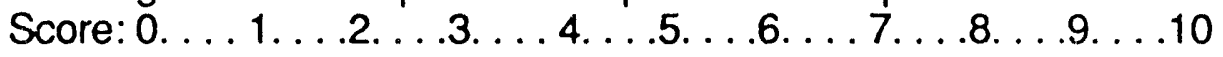

Scale: None Low Moderate High

Units: expected process quality

Is the material conducive to a high quality final closure in a remote operation? Closure studies currently concentrate on welds, but mechanical closure, diffusion bonds and other nonwelded closures are considered. Topics such as process reliability, repairability, safety, filler requirements, and process specifications (such as weld preheat and number of passes etc.) should be considered. It may be possible to quantify this criterion by standard tests once the closure process is selected.

E2b) External process influences

Weighting Factor: 2

Parameter: Subjective opinion of external influences

Passing score: Adequate/Inadequate tolerance

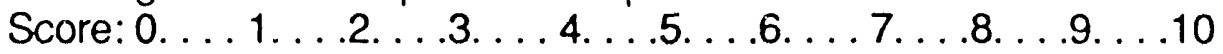

Scale: None Low Moderate
Units: expected tolerance of external influences

Is the material tolerant of external influences on closure quality, considering topics such as joint cleanliness, alignment, temperature variation, material condition, etc.?

E3) Inspectability of closure

Weighting Factor: 5

E3a) General process considerations

Weighting Factor: 3

Parameter: Subjective opinion of inspectability

Passing score: Adequate/Inadequate inspectability

Score: $0 \ldots .1 \ldots .2 . \ldots 3 \ldots .4 \ldots 5 \ldots 6 \ldots . \ldots 7 \ldots . \ldots 9 \ldots 10$

Scale: None Low Moderate High

Units: expected inspectability

Does the material lena itself to inspection of the final closure, considering topics such as possible NDE techniques, grain structure, typical flaw NDE signals, etc.? 
E3b) Detectability

Weighting Factor: 2

Parameter: Ratio of (detection limit flaw size)/(design basis flaw size)

Passing score: 0.5

Passing score: 0.5

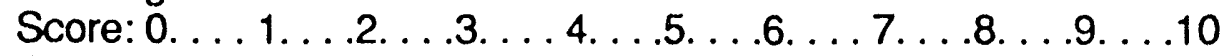

$\begin{array}{lllllll}\text { Scale: } & 2 & 1 & 0.5 & 0.25 & 0.12 & 0.1\end{array}$

Units: size ratio

Are design basis flaws in the container closure large enough to be reliably detected by rapid, remote, NDE techniques?

E4) Damage tolerance of the fabricated and closed container

Weighting Factor: 5

Parameter: Subjective opinion of damage tolerance

Passing score: Adequate/Inadequate damage tolerance

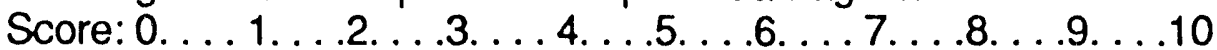

Scale: None Low Moderate High

Units: expected tolerance

This evaluates the ability of the fabricated and closed container material to tolerate routine handling, emplacement, and possible retrieval activities.

F) Cost

F1) As-fabricated container costs

Weighting Factor: 2

Parameter: $\$$ per container

Passing score: NA

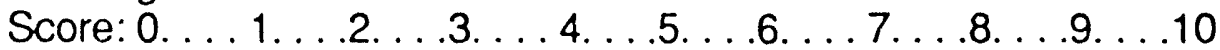

Scale: $125+\begin{array}{lllll}100 & 75 & 50 & 25 & 5-\end{array}$

Units: $\mathrm{K} \$$

This measures the expected cost of a fabricated, closed, and inspected container ready for emplacement. Constant year (1990) dollars.

F2) Associated exceptional repository handling costs

Weighting Factor: 2

Parameter: Relative added cost

Passing score: Adequate/Inadequate cost

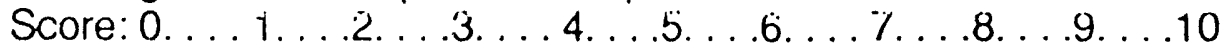

Scale: High Moderate Low None

Units: Relative cost 
This estimates exceptional repository handling costs specific to the material under consideration relative to other materials. This includes costs resulting specifically from physical or chemical properties of the container material. Examples include costs due to careful handling of brittle materials, special handling of toxic materials, etc.

F3 Strategic availability of raw material

Weighting Factor: 1

Parameter: Availability

Passing score: NA

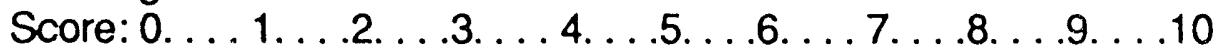

Scale: Low

Moderate

Units: Availability

This evaluates assurance of a long term supply of the raw material needed to fabricate the container.

G) Previous experience with the material

Weighting Factor: 5

G1) Previous relevant engineering experience with the material and closure

Weighting Factor: 3

G1a) Variety of applications

Weighting Factor: 2

Parameter: Variety of applications

Passing score: Adequate/Inadequate applications

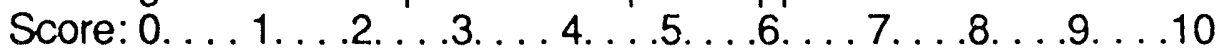

Scale: None Low

Moderate

Units: Variety of applications

High

G1b) Years of experience

Weighting Factor: 1

Parameter: Years in service

Passing score: Adequate/Inadequate experience

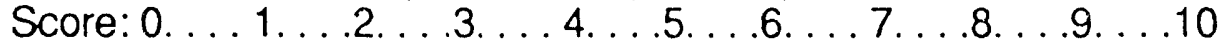

Scale: 0

10

100

1000

$10 \mathrm{~K}$

Units: Years 
G2) Existing engineering standards for the material and closure

Weighting Factor: 2

G2a) ASTM Standards

Weighting Factor: 1

Parameter: ASTM coverage

Passing score: Adequate/lnadequate coverage

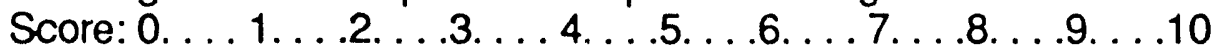

Scale: None Low Moderate High

Units: Extent of ASTM standards

This evaluates the extent of consideration given the material (or equivalent materials) by ASTM standards.

G2b) Other Standards

Weighting Factor: 1

Parameter: Availability of standards

Passing score: Adequate/Inadequate availability

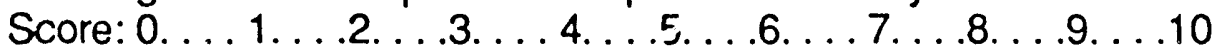

Scale: None Low Moderate High

Units: Extent of other standards

This evaluates the availability of standards for application of the material, such as ASME Boiler and Pressure Vessel Code consideration of the material, or other engineering, construction, or testing standards. 
Appendix B: Materials Evaluation Detailed Scoresheets Material: CDA 613

Cate- Weight Score Point

Comments gory

Total

$\begin{array}{llll}\text { A } & & & 74 \\ \text { A1 } & 6 & 5 & 30 \\ \text { A2 } & 6 & 5 & 30 \\ \text { A3 } & 2 & 7 & 14\end{array}$

B

B1 8

B2 7

B3a 2

B.3b 1

B3C 1

B3d 2

B3e 2

B3f 1

B3g 1

B4 5

172

540

$5 \quad 35$

Radiolysis effects

$35 \mathrm{NH}_{3}$ acceleration

10 Insufficient data

C

C1 4

C2 4

$5 \quad 10$

$9 \quad 9$

$7 \quad 7$

816

2

$\begin{array}{ll}1 & 2 \\ 9 & 9\end{array}$

Based on ANL data

Extreme sensitivity to $\mathrm{NH}_{3}$ and nitrites

$9 \quad 9$

C3 4

C4 4

$7 \quad 35$

D

D1 5

D2 5

3

44

E

E1a 2

E1b 2

8

12

12

12

E1c 1

E2a 3

30

15

15

F. oblems with $\mathrm{Zr}$ conitact

114

6

10

6

E2b 2

12

E3a 3

E3b 2

E4 5

Relatively new alloy

No database to build on

$\mathrm{F}$

F1 2

34

F2 2

10

F3 1

16
8

$G$

16

G1a 2

6

G1b 1

G2a 1

G2b 1

$\begin{array}{ll}3 & 6 \\ 5 & 5 \\ 3 & 3 \\ 2 & 2\end{array}$

Total Score -484

Welding difficult

$\mathrm{Al}_{2} \mathrm{O}_{3}$ formation plus temperature control

Harder than CDA715 \& Alloy 820 


\section{Material: CDA 715}

$\begin{array}{lll}\text { Cate- Weight Score } & \begin{array}{l}\text { Point } \\ \text { Total }\end{array} & \text { Comments }\end{array}$
A
A1 6
76
A2 6
30
A3 2

530
B
B1 8
B2 7
16
Presence of insoluble iron
B3a 2
B3b 1
B3c
B3d
B3e 2
B3f 1

816
B3g 1
132
B4 5
24
Aggravated by radiolysis
21
10
Insufficient data
9
7
14 Comparable to Alloy 825 in ANL tests
4 Radiolysis
9
9
C
C1 4
C2 4
25
C3 4
C4 4
56
12
20
12
12
No database to build on
D
30
D1 5
15
Problems with $\mathrm{Zr}$ contact
D2 5

3
15
Probably will have a number of steel components
E
Eia 2
138
E1b 2
16
E1c 1
18
$\begin{array}{llll}\text { E2a } & 3 & 6 & 18\end{array}$
$\begin{array}{llll}E 2 b & 2 & 7 & 14\end{array}$
$\begin{array}{llll}E 3 a & 3 & 6 & 18\end{array}$
$\begin{array}{llll}E 3 b & 2 & 6 & 12\end{array}$
E4 $53 \quad 7 \quad 35$
$\begin{array}{ll}F & \\ F 1 & 2 \\ F 2 & 2\end{array}$
31
F2 23
8
16
B\&W cost report
$7 \quad$ High nickel content
G
38
G1a 2
16
G1b 1
$\begin{array}{ll}8 & 16 \\ 6 & 6\end{array}$
G2a 1
$8 \quad 8$
G2b 1
8
8
Total Score -501 
Material: 304L

Cate- Weight Score Point Comments gory Total

$\begin{array}{lllll}\text { A } & & & 74 & \\ \text { A1 } & 6 & 5 & 30 & \\ \text { A2 } & 6 & 5 & 30 & \\ \text { A3 } & 2 & 7 & 14 & \text { Metastable }\end{array}$

B 109

$\begin{array}{llll}\text { B1 } & 8 & 7 & 56\end{array}$

$\begin{array}{llll}\text { B2 } & 7 & 1 & 7 \\ \text { B3a } & 2 & 7 & 14\end{array}$

$\begin{array}{llll}\text { B3b } & 1 & 6 & 6\end{array}$

$\begin{array}{llll}\text { B3C } & 1 & 2 & 2\end{array}$

$\begin{array}{llll}\text { B3d } 2 & 3 & 6\end{array}$

$\begin{array}{lll}\text { B3e } 2 & 1 & 2\end{array}$

$\begin{array}{llll}\text { B3f } & 1 & 8 & 8\end{array}$

$\begin{array}{llll}\text { B3g } & 1 & 3 & 3\end{array}$

B4 $5 \quad 1 \quad 5$

C 96

$\begin{array}{llll}\text { C1 } & 4 & 8 & 32\end{array}$

$\begin{array}{llll}\mathrm{C} 2 & 4 & 7 & 28\end{array}$

$\begin{array}{llll}\text { C } 3 & 4 & 8 & 32\end{array}$

$\begin{array}{llll}\mathrm{C} 4 & 4 & 1 & 4\end{array}$

D 70

D1 $55 \quad 7 \quad 35$

$\begin{array}{llll}\text { D2 } & 5 & 7 & 35\end{array}$

E 159

$\begin{array}{llll}\text { E1a } & 2 & 9 & 18\end{array}$

$\begin{array}{llll}\text { E1b } & 2 & 8 & 16\end{array}$

$\begin{array}{llll}\text { E1C } & 1 & 9 & 9\end{array}$

$\begin{array}{llll}\mathrm{E} 2 \mathrm{a} & 3 & 9 & 27\end{array}$

$\begin{array}{llll}E 2 b & 2 & 7 & 14\end{array}$

$\begin{array}{llll}\mathrm{E} 3 \mathrm{a} & 3 & 8 & 24\end{array}$

$\begin{array}{llll}E 3 b & 2 & 8 & 16\end{array}$

$\begin{array}{llll}\text { E4 } & 5 & 7 & 35\end{array}$

$\mathrm{F} \quad 38$

$\begin{array}{llll}\mathrm{F} 1 & 2 & 7 & 14\end{array}$

$\begin{array}{llll}\text { F2 } & 2 & 8 & 16\end{array}$

$\begin{array}{llll}\text { F3 } & 1 & 8 & 8\end{array}$

G 42

$\begin{array}{llll}\text { G1a } & 2 & 9 & 18\end{array}$

$\begin{array}{llll}\text { G1b } & 1 & 6 & 6\end{array}$

$\begin{array}{llll}\text { G2a } & 1 & 9 & 9\end{array}$

$\begin{array}{llll}\text { G2b } & 1 & 9 & 9\end{array}$

Total Score -588 
Material: 316L

$\begin{array}{lll}\text { Cate- Weight Score } & \begin{array}{l}\text { Point } \\ \text { gotal }\end{array} & \text { Comments }\end{array}$

A 72

$\begin{array}{llll}\text { A } 1 & 6 & 5 & 30\end{array}$

A2 $6 \quad 5 \quad 30$

$\begin{array}{llll}\text { A } 3 & 2 & 6 & 12\end{array}$

B 132

$\begin{array}{llll}\text { B1 } & 8 & 7 & 56\end{array}$

$\begin{array}{llll}\text { B2 } & 7 & 3 & 21\end{array}$

B3a 2

B3b 1

B3c 1

B3d 2

$\mathrm{B3e} 2$

B3f 1

B3g 1

B4 5

C

C1 $4 \quad 7$

C2 $4 \quad 6$

C3 $4 \quad 8$

C4 42

D

D1 $55 \quad 7$

D2 $5 \quad 7$

E

E1a 2

E1b 2

E1c 1

E2a 3

E2b 2

E3a 3

E3b 2

E4 5

$\mathrm{F}$

F1 2

F2 2

F3 1

G

G1a 2

G1b 1

G2a 1

G2b 1

816

88

2

3

1

8

3

210

92

28

24

32

8

70

35

35

156

18

14

9

24

16

24

16

35

36

12

16

8

8

42

18

6

9

9
$B \& W$ cost report

Friendly terms with sources

Some fuel: high failure rate of $s / s$, but low probability of occurr Good compatibility with most engineering mat'ls; contaminatec will be recommended for liners \& shield plugs

Substantial database

Substantial database

Substantial database

Substantial database

Substantial database

Substantial database

Substantial database

Substantial database

Total Score -600 (close to failure on a few criteria) 


\section{Material: Alloy 825}

Cate- Weight Score Point gory

A

A1 6

A2 6

A3 2

B

B1 8

B2 7

B3a 2

B3b 1

B3c 1

B3d 2

B3e 2

B3f 1

B3g 1

B4 5

C

C1

C2 4

C3 4

C4 4

D

D1 5

D2 5

E

E1a 2

E1b 2

E1: 1

E2a 3

E2b 2

E3a 3

E3b 2

E4 5

$F$

F1 2

F2 2

F3 1

G

G1a 2

G1b 1

G2a 1

G2b 1

76

530

530

816

196

$8 \quad 64$

$5 \quad 35$

816

$9 \begin{array}{ll}9 & 9\end{array}$

$\begin{array}{ll}7 & 14\end{array}$

$6 \quad 12$

$8 \quad 8$

$6 \quad 6$

$5 \quad 25$

100

20

32

75

40

35

140

16

10

7

14

24

16

35

28

6

16

36

16

5

7

8
Total

Comments
Weld filler metal (Alloy 625) may be a problem

Resistant to acid pitting

24 Similar methods to 316 , but less studied

24 Generally good acceptance in peer discussions

18 dissinilar filler, no $\sigma$

$6 \mathrm{Ni}, \mathrm{Cr}$
Good compatibility

$\mu$ phases, good forming

Alloy 800 widely used

Total Score -651 
Material: C-4

Cate- Weight Score Point gory
A $\quad 74$
A1 $6 \quad 5 \quad 30$
A2 $6 \quad 5 \quad 30$
$\begin{array}{llll}\text { A3 } & 2 & 7 & 14\end{array}$
Metastable, but somewhat better than $316 \mathrm{~L}$
B 252
$\begin{array}{llll}\text { B1 } & 8 & 9 & 72\end{array}$
B2 $7 \quad 9 \quad 63$
$\begin{array}{llll}\mathrm{B} 3 \mathrm{a} & 2 & 9 & 18\end{array}$
B3b 1199
$\begin{array}{llll}\mathrm{B} 3 \mathrm{C} & 1 & 9 & 9\end{array}$
$\begin{array}{llll}\text { B3d } & 2 & 7 & 14\end{array}$ Lack of sufficient data
$\begin{array}{llll}\text { B3e } & 2 & 8 & 16\end{array}$
$\begin{array}{llll}\text { B3f } & 1 & 8 & 8\end{array}$
$\begin{array}{llll}\text { B3g } & 1 & 8 & 8\end{array}$
$\begin{array}{llll}\text { B4 } & 5 & 7 & 35\end{array}$
C 92
$\begin{array}{llll}\text { C1 } & 4 & 6 & 24\end{array}$
C2 $4 \quad 3 \quad 3 \quad 12$
$\begin{array}{llll}\text { C3 } & 4 & 7 & 28\end{array}$
$\begin{array}{llll}\text { C4 } & 4 & 7 & 28\end{array}$
No database on which to build
$\begin{array}{llll}\text { D } & & & 80 \\ \text { D1 } & 5 & 8 & 40 \\ \text { D2 } & 5 & 8 & 40\end{array}$
E 138
$\begin{array}{llll}\text { E1a } & 2 & 7 & 14\end{array}$
E1b $2 \quad 5 \quad 10$ Lack of sufficient data
E1r 1147
$\begin{array}{llll}\mathrm{E} 2 \mathrm{a} & 3 & 6 & 18\end{array}$
$\begin{array}{llll}E 2 b & 2 & 7 & 14\end{array}$
$\begin{array}{llll}\text { E3a } & 3 & 8 & 24\end{array}$
$\begin{array}{llll}\text { E3b } & 2 & 8 & 16\end{array}$
$\begin{array}{llll}\text { E4 } & 5 & 7 & 35\end{array}$
F 24
$\begin{array}{llll}\mathrm{F} 1 & 2 & 2 & 4\end{array}$
$\begin{array}{llll}F 2 & 2 & 8 & 16\end{array}$
$\begin{array}{lllll}\text { F3 } & 1 & 4 & 4 & \text { Alloy content of cobalt \& Iungsten }\end{array}$
G 25
G1a $2 \quad 5 \quad 10$
Gib $i \quad 5 \quad 5$
G2a $1 \quad 5 \quad 5$
G2b $1 \quad 5 \quad 5$
Kure Beach Alloy $\mathrm{C}$ long term exposures
8

6

35

4

6
5
10 Will draw on C-276 applications
Total Score - 685

Comments 
Material: Titanium - Grade 12

$\begin{array}{lll}\text { Cate- Weight Score } & \begin{array}{l}\text { Point } \\ \text { gotal }\end{array} & \text { Comments }\end{array}$

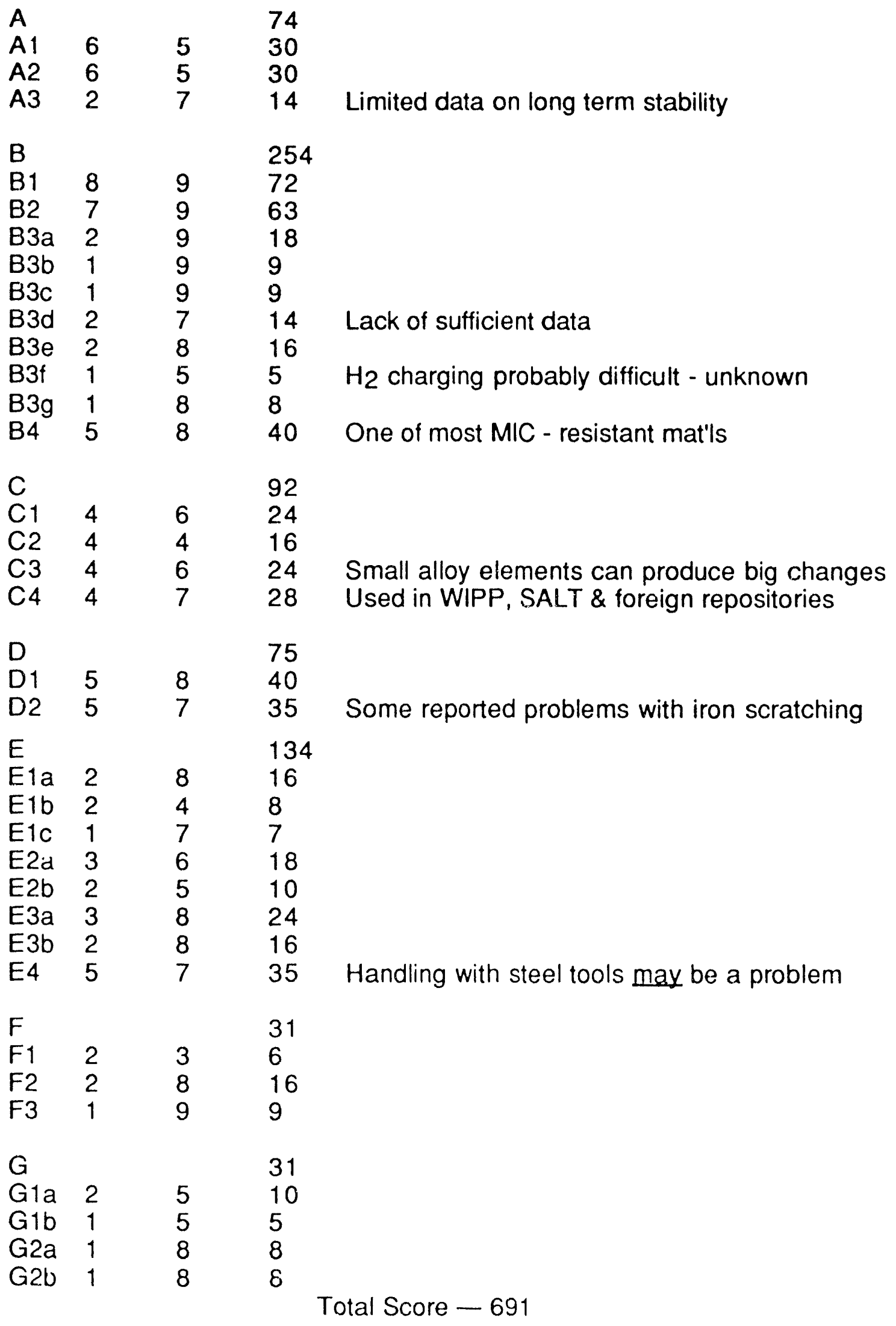


The LLNL Nuclear Waste Management Program (NWMP) had responsibility for the testing, model development, and performance assessment of conceptual designs of the waste package for the Yucca Mountain Project. One portion of this work was the selection, modeling and testing of the container material. As the first step in this material selection, a formal set of selection criteria was established to allow evaluation of candidate materials against a wide variety of performance, engineering, and licensing requirements.

A selection criteria draft was prepared and subjected to an independent peer review. The report of the peer review panel is included in this microfiche. At the time the peer review report was completed, a voluntary suspension wias in effect on quality assurance level I activities to allow response to changes in QA requirements and QA program audit findings. During the work suspension a new waste package program plan was prepared, which altered the schedule and initial application of the selection criteria. The criteria thus became "Preliminary Selection Criteria" and were altered in response to the peer review recommendations. During this delay, the peer review group was disbanded. Thus there was no final comment by the peer review group on the responses made to their recommendations. The preliminary selection criteria are scheduled to be reviewed and updated during the Advanced Conceptual Design phase of the program. 


\title{
PEER REVIEW REPORT
}

\author{
on \\ "Selection Criteria for the Yucca Mountain Project Waste \\ Package Container Material"
}

Prepared By:

Metal Barrier Selection Criteria Peer Review Panel

December 14,1988

$-49-$ 


\section{Metal Barrier Selection Criteria \\ Peer Review Panel Members}

\section{Chairman}

Dr. Robin L. Jones

Electric Power Research Institute

(415) $855-2790$

3412 Hillview Ave.

Palo Alto, California 94303

\section{Panel Members}

Dr. Geoffrey R. Egan

(408) 745-7000

Aptech Engineering

1257 Elko Dr.

Sunnyvale CA 94089

Dr. Richard P. Gangloff

Department of Materials Science

(804) 924-3302

Thornton Hall

University of Virginia

Charlottesville, Virginia 22901

Dr. Robert L. Long

V.P. Planning and Nuclear Safety

(201) 316-7484

G.P.U. Nuclear

One Upper Pond Road

Parsippany, New Jersey 07054

Dr. Martin Prager

Executive Director

Materials Properties Council

3.45 East 47 th Street

New York, New York 10)17

Dr. Roger W. Stachle

Consultant / Adjunct Professor

(612) $482-9493$

Department of Chemical Engine ring \& Materials Science

University of Minnesota

22 Red lox Rd.

North Oaks, Minnesota 5.5127 


\section{SIGNATURE PAGE}

I Robin L. Jones, participated as a member of the Peer Review Panel on the "Selection ( : teria for the Yucca Mountain Project Waste Package Container Material." I provided input to this Peer Review Report and have reviewed this final version.

I concur with the findings and recommendations of this Report.
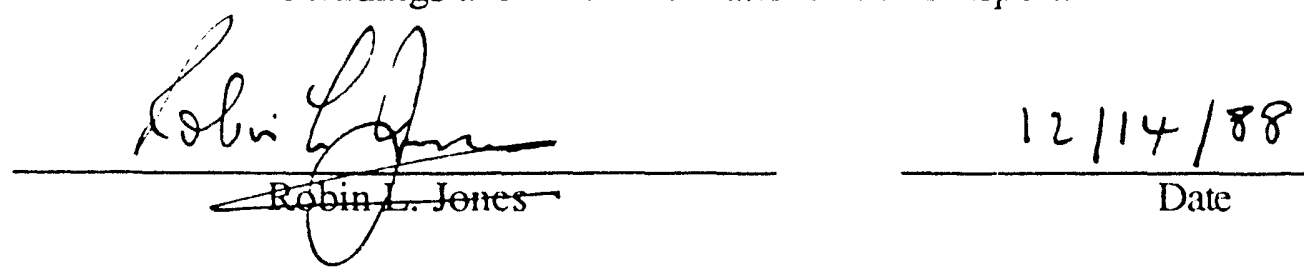

I DO NOT concur with the findings and recommendations of this Report.

Robin L. Jones

Date 


\section{SIGNATURE PAGE}

I, Geoffrey R. Egan, participated as a member of the Peer Review Panel on the "Selection Criteria for the Yucca Mountain Project Waste Package Container Material." I provided input to this Peer Review Report and have reviewed this final version.

I concur with the findings and recommendations of this Report.
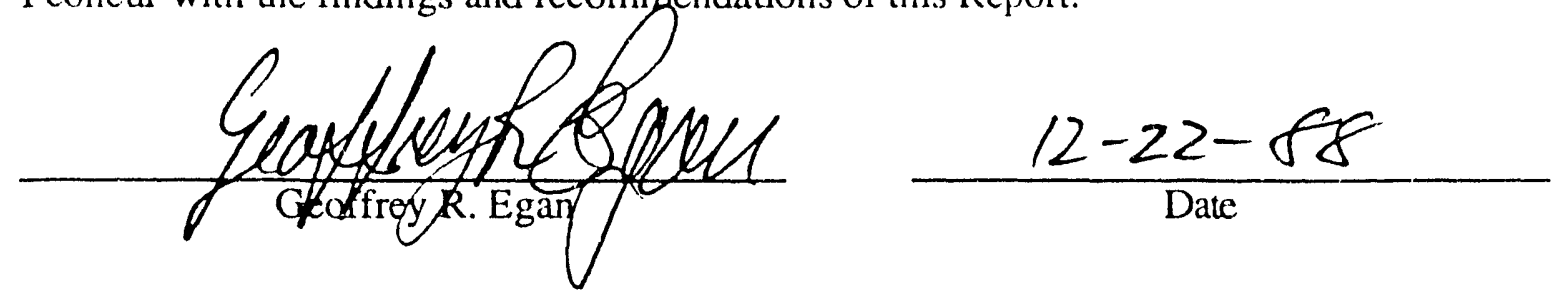

I DO NOT concur with the findings and recommendations of this Report. 


\section{SIGNATURE PAGE}

I, Richard P. Gangloff, participated as a member of the Peer Review Panel on the "Selection Criteria for the Yucca Mountain Project Waste Package Container Material." I provided input to this Peer Review Report and have reviewed this final version.

I concur with the findings and recommendations of this Report.
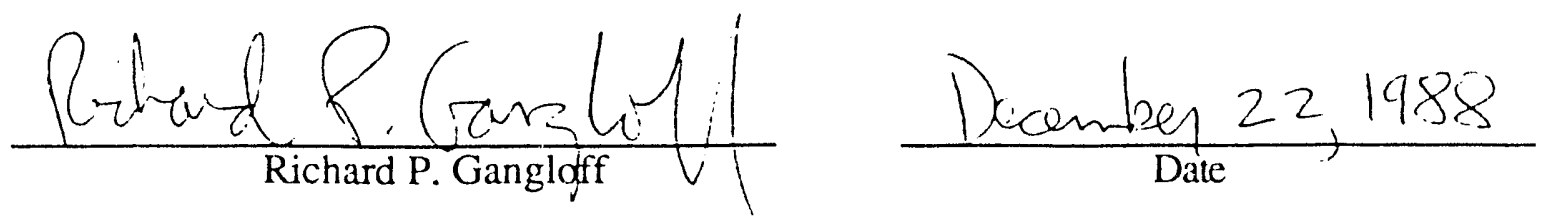

I DO NOT concur with the findings and recommendations of this Report.

Richard P. Gangloff

Date 


\section{SIGNATURE PAGE}

I, Robert L. Long, participated as a member of the Peer Review Panel on the "Selection Criteria for the Yucca Mountain Project Waste Package Container Material." I provided input to this Peer Review Report and have reviewed this final version.

I concur with the findings and recommendations of this Report.
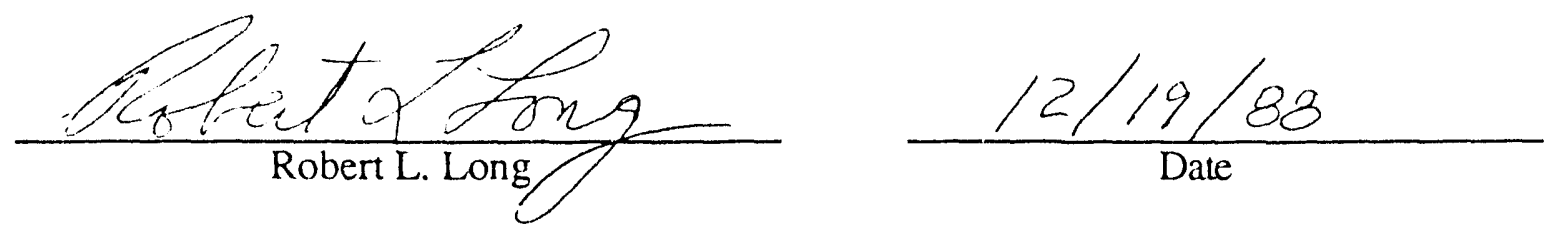

I DO NOT concur with the findings and recommendations of this Report.

Robert L. Long

Date 


\section{SIGNATURE PAGE}

I, Martin Prager, participated as a member of the Peer Review Panel on the "Selection Criteria for the Yucca Mountain Project Waste Package Container Material." I provided input to this Peer Review Report and have reviewed this final version.

I concur with the findings and recommendations of this Report.
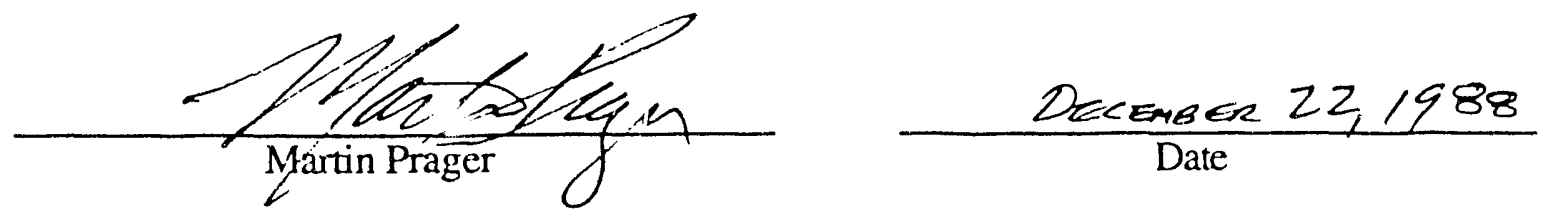

I DO NOT concur with the findings and recommendations of this Report. 


\section{SIGNATURE PAGE}

I, Roger W. Staehle, participated as a member of the Peer Review Panel on the "Selection Criteria for the Yucca Mountain Project Waste Package Container Material." I provided input to this Peer Review Report and have reviewed this final version.

KConcyr with the findings and recommendations of this Report.

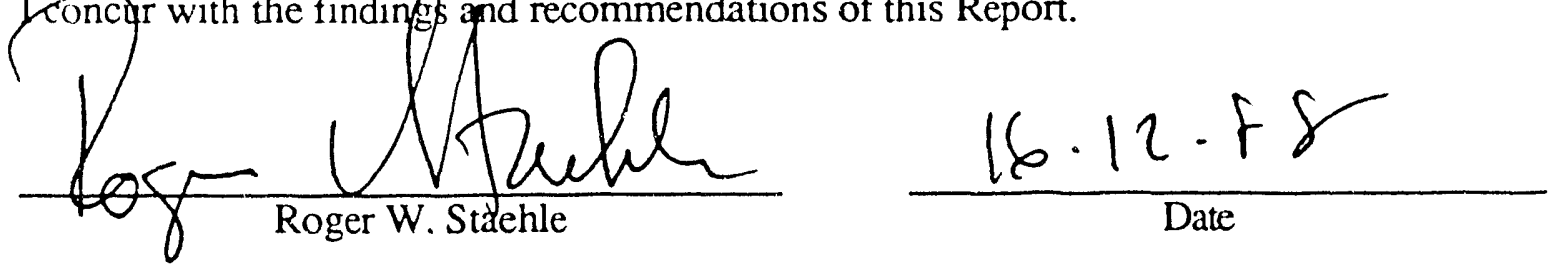

I DO NOT concur with the findings and recommendations of this Report. 


\section{INTRODUCTION}

As directed by the Nuclear Waste Policy Act of 1982, the Department of Energy's Yucca Mountain Project is evaluating a site at Yucca Mountain in Nevada for construction of a geologic repository for the storage of high-level nuclear waste. The Nuclear Waste Management Project (NWMP) at Lawrence Livermore National Laboratory (LLNL) has been assigned responsibility for designing, testing, and analyzing the performance of the waste packages to be stored in the repository at Yucca Mountain. Several waste package concepts will be explored in the Metal Barrier Selection and Testing (MBST) and Alternate Barrier Selection and Testing (ABST) Tasks. The metal barrier concept includes a sealed metal container that separates the nuclear waste from the gcologic environment. An important decision in the MBST is the selection of a metal for the Advanced Conceptual Design (ACI) phase of the Program. This decision begins the iterative process of assessing the feasibility of the metal barrier concent.

A two-step container material selection process is planned. First, selection criteria will be established. Second, these criteria will be used to rank candidate container materials and choose one material for ACD. Because the service performance of the metal barrier is an important repository licensing consideration, both steps in the container material selection process will be peer reviewed in accordance with the requirements of the NWMP Quality Assurance Program Plan (QAPP) as described in LLNL document 033-NWMP-P 2.2, and P 2.5, dated November 19, 1987. As defined in the QAPP, these pecr reviews are intended to provide a basis for the development of a broad base of acceptance for, and confidence in, the initial container material selection decision formulated by the NWMP by completing a serious technical critique of both steps in the metal barrier material selection process. The Peer Review Panel is responsible for evaluating and reponing on the validity of assumptions and extrapolations, the appropriateness and limitations of the methodeling and acceptance criteria employed, the adequacy of work performed or planned, and the supportability of the conclusions drawn.

This decument is the report of the Metal Barrier Selection Criteria Peer Review Panel and presents the Panel's consensus comments on the September 15, 1988 draft of the "Selection Criteria for the Yucca Mountain Project Waste Package Container Material" prepared by William (3. Halsey of LLNL. A copy of the draft decument that was revie wed by the Pancl can be found in Appendix $A$. 


\section{METHODOLOGY}

\subsection{MEMBERSHIP OF THE PEER REVIEW PANEL}

The members of the Metal Barrier Selection Criteria Peer Review Panel are listed below:

Name Affiliation

Dr. Robin Jones (Chaiman)

Electric Power Research Institute (EPRI)

Dr. Geoffrey Egan

Aptech Engineering

Dr. Martin Prager

Materials Properties Council

Dr. Roben Long

GPU Nuclear

Dr. Richard Gangloff

University of Virginia

Dir. Roger Staehle

Consultant / University of Minnesota

These panel members collectively possess the full range of technical expertise necessary to fulfill the peer review function, and their backgrounds provide a number of different, and pertinent, viewpoints:

Areas of Expertise

Material degradation processes

Predictive modelling

Fabrication and joining technology

Component performance assessment

Failure analysis

Nuclear engineering practices
Viewpoints

Academic R\&D community

Industrial R\&D community

Nuclear utility management

Independent consultants

Regulatory

Licensing

A more detailed description of the qualifications of the Peer Review Panel can be found in Appendix B. Lists of publications for each member of the Panel are available in the QA packige for this report. 


\subsection{PEER REVIEW PROCEDURE}

Following completion of the panel selection process, a draft of the Selection Criteria document and copies of the following background material were sent to each Panel Member for their independent

review:

Progress Report on the Results of Testing..., UCID-21044

Annotated History of Candidate Materials Selection - Draft Copy

Scientific Investigation Plan for Metal Barriers - Draft Copy

Reference Waste Package Environment Repor, UCRL-53726

Overview of the Degradation Mode Surveys - Draft Copy

Quality Assurance Procedures 2.2, 2.5

NRC Position Paper on Peer Review.

These seven documents were selected for distribution by the Panel Chairman based on his review of a much more extensive collection of background material that was compiled for him by LLNL technical staff.

Two meetings of members of the Peer Review Panel were held -- at LLNL on September 15 and 16 (Drs. Jones, Egan, Gangloff, Prager, and Stachle participated) and at EPRI on September 23 (Drs. Jones and Long participated). At both meetings, members of the LLNL technical staff provided briefings on significant aspects of the background material and answered questions raised by the Panel Members based on their independent review. $A$ detailed, page-by-page review of the draft of the Selection Criteria document was then performed by the panel members. The consensus results of this page-by-page review are summarized in Appendix (.. To facilitate completion of the peer review proess, Appendix $C$ is fomatted to allow both a respense by the LI,NL, technical staff to each comment and a closute comment by the pancl. 
In addition to providing detailed comments on the draft criteria document, as described in the Peer Review Procedure of the Quality Assurance Program Plan for the Nevada Nuclear Waste Storage Investigations (NNWSI), the author of the criteria informally asked the Panel to consider the following four questions:

- Is this type of comparison a reasonable thing to attempt?

- Are the criteria topics and parameters reasonable?

- Has anything important been forgotten?

- Are the weighting factors and quantitative scales reasonable?

Our responses to these questions are presented in Section 3 of this report. Section 4 contains our conclusions and recommendations. The general issues raised in Sections 3 and 4 should be addressed by the LLNL staff as they revise the Selection Criteria document. 


\section{GENERAL COMMENTS}

This section provides the Panel's responses to the four general questions listed in the previous section.

\subsection{VALIDITY OF APPROACH}

A quantitative comparison of the type proposed is possible and has been used successfully in the past to objectively select the best material from a list of candidates. However, in assessment process described in the draft criteria, the evaluations of different attributes could be performed completely independently. Itence, important interactions between attributes could easily be overlooked. For example, pitting and general corrosion could each be found to be acceptable when evaluated separately but the combination of pitting jlus general corrosion, which would not normally be evaluated at all in this approach, could be unacceptable.

The criteria as written reflect a number of significant preconceptions concerning the container design and site characteristics that are not supported by available information. For example, it is assumed that the container will be closed by welding, that temperatures above $95^{\circ} \mathrm{C}$ will result in a more benign service environment than temperatures below the boiling point, and that the external environment will be more aggressive towards the container than the internal environment. The validity of these and several other similar assunptions is far from certain (mainly because of the lack of firm site data) and reflecting them in the selection process could improperly bias the outcome. For example, an excessive focus on the external environment could mean that some potentially life-limiting phenomena (such as fission product induced cracking from the inside) would not be considered. Changes that are anned at making the documem less dependent upon unsupponed preconceptions are suggested in Appendix C.. However, it should be recognized that the selection criteria cannot te mate completely indegknkent of design and service environment considerations and still remain useful. In fact, the quality of the criteria could be greatly improved if detailed information about the container design and service enviromment were available. In the absence of such data, it will te necessary w) 
make some simplified design and enviromment assumptions. These assumptions should be explicitly stated in the selection criteria document and revised as application-specific information becomes available. The establishment of an event tree or a sequence analysis for all potential degradation mechanisms would aid in this revision process.

\subsection{ATTRIBUTES AND PARAMETERS}

The selection of the material properties (attributes) to be considered and the definition of measures to characterize those attributes (parameters) are the keys to a meaningful caluation. The draft document represents a goef first cut in this regard. However, the absence of detailed design and environmental data is a significant handicap, as already discussed. Moreover, a number of well-chosen attributes currently are characterized by parameters that, while certainly quantifiable, are not related in any direct way to container service performance. To the extent possible, these should be replaced by more servicerelevant parameters: suggestions are detailed in Appendix C.

Cuirently, several attributes are defined in subjective, qualitative terms (e.g."relative metallurgical phase stability"). Although the inclusion of some qualitative parameters probably is unavoidable, it must be recognized that one person's "good" is another person's "fair" or even "poor". Consequently, it is not possible to define a meaningful and defensible passing score for qualitative parameters. Passing scores should be restricted to those parameters that can be quantified.

\subsection{OMISSIONS}

The Pancl identified a few attributes not now included in the criteria that they felt should le: arhed - wese are noted in Aprendix (.. In addition, the draft document completely ignores the fact that most aspects of material performance are probabilistic rather than deterministic in nature and therefore can be characterized properly only in statistical terms. For example, the yelet strength of a material is a statistical property and at least wo numbers (e.g., a specified value and the confidence level associated with that value) are needed to characterize it. These statistical distributions vary greatly for different material properties and, for any given propenty, can differ widely between materials and also between heats of 
a single material. The passing scores specified for all the quantifiable parameters in the document should include a required confidence level, and both the passing scores and the confidence levels should be defensible in terms of engineered barrier performance requirements. This will enhance any probabilistic risk analysis that is to be performed for the project as a whole.

\subsection{WEIGHTING FACTORS AND QUANTTTATIVE SCAIES}

The Pancl disagreed with some of the weighting factors used in the draft document. Suggestions for changes, which generally increase the relative importance of performancerelated atributes, are made in Appendix C. An important deficiency of the draft document is the absence of any explanation of the bases for the various passing scores and quantitative scales. An appendix should be added that justifies all quanitative scores and scales, if possible, in terms of container performance requirements. These justifications undoubtedly will be scrutinized closely during the repository licensing process and therefore, should be consistent with the requirements of the codes and standards that currently define the consensus view of what constitutes good, conservative engineering practice (e.g., safety margins should be the same as those specified for nuclear construction in the ASME Boiler and Pressure Vessel Code). This appendix will indicate the extent to which design and materials selection tasks are integrated. 


\section{CONCLUSIONS AND RECOMMENDATIONS}

1. The Panel's consensus is that the draft selection criteria document, which we reviewed, represents a good first cut at a difficult, but not impossible, task. We believe that the draft document can be improved by incorporating the revisions suggested in Section 3 and Appendix C.

2. Further improvement of the selection criteria would be possible if site characterization data, additional conceptual design data, and well-defined performance requirements were available. Such information would permit identification of a more appropriate set of attributes and parameters than is possible today.

3. Selection of a single material for Advanced Conceptual Design (ACD) may not be practical next year due to lack of the material property data required to apply the criteria. Therefore, to assure that a viable fall-back position is always available, at least two materials from different alloy classes should be carried forward into $A C D$.

4. The selection criteria should be up-dated as the additional information identified in Item 2 above becomes available during ACD. Periodically, these modified criteria should be applied to assess the suitability of the remaining candidate material(s) for the metal barrier application.

5. The Panel urges that every effort possible should be made to facilitate completion of the exploratory shaft to permit documentation of the actual environment and the initiation of in-situ tests. In addition, the Panel feels that an aggressive laboratory experimental program is required to obtain the data necessary for a successful license application. It is imperative that woth laboratory and in-situ testing legen as sem as possible in order to permit long-term tests and to identify any unexpected degradation processes.

6. The Pancl believes that more atcention shoukd be directed towards the definition of container internal environments that may ercur due to release of volatiles from failed fuel reds. The se environments should le: included in the $\Lambda$ ('D) test matrix. 
Appendix A

Selection Criteria Evaluated by the Peer Review Panel 
Selection Criteria for the Yucca Mountain Project waste Package Container Material

\author{
William G. Halsey \\ Lawrence Livermore National Laboratory
}

september, 1988

Draft CRIT-Q $9 / 15 / 88$ 


\section{CONTAINER MATERIAI, SEIECTION CRITERTA}

The Department of Energy's Yucca Mountain Project is evaluating a site at Yucca Mountain in Nevada for construction of a geologic repository for the storage of high-level nuclear waste. Iawrence Livermore National Laboratory's (LLNL) Nuclear Waste Management Project (NWMP) has the responsibility for design, testing, and performance analysis of the waste packages. An important decision in this design is the selection of the material for the waste containers. The container material is referred to as the 'metal barrier' portion of the waste package, and is the

responsibility of the Metal Barrier Selection and Testing Task at LillL. The selection will be done in two steps. First, material-independent selection criteria and quantitative weighting factors will be established. Second, specific candidate materials will be ranked against these criteria to determine a) whether they meet the mandated performance requirements, and b) to provide a comparative score to choose the miterial for advanced design activities. This document sets forth the container material selection criteria.

Relevant background information to set the stage for the selection criteria includes: the performance requirements of the container, possible container designs, and potential service conditions for the container.

Performance requirements for waste packages in the repository are provided in NRC regulation 10CFR60 [1] as "substantially complete containment" for a period of time yet to be determined, but between 300 and 1000 years, and a "controlled release period" of up to 10,000 years. The performance goal for the metal barrier is specified by the DoE in the NNWSI site characterization plan [2] as a maximum fractional container failure rate for different time periods after repository closure. While it is expected that most of the containers will not be exposed to liquid water, provision is made for both "wet" and "dry" containers. These performance goals have changed in detail as the interpretation of substantially complete containment has been refined. The allowed container failure rates range from a low of $0.0001 / y e a r$ for dry containers in the first 100 years, to $0.01 /$ year after 10,000 years. If the repository accepts a total of 35,000 containers, this results in from 3.5 to 350 container failures per year. In addition, the container must be compatible with the waste forms, not compromise performance of other repository components, and must provide for transportation, handing, retrievability, and unique identification.

While the container design is not yet 1 inal, a typical conceptual design is a closed metal cylinuer about $69 \mathrm{~cm}$ in diameter and $300-500$ c.m long with walls about one centimeter thick. The container body might be made from rolled and wolded plate, or it might be cast or extruded. llhe top and bottom might be forged and wolded. All joints except the lind closure can be readily annealed to relieve stress. 'lhe tinal closure has: been identified as a feature that could potentially limit long-term container performance and should receive special attention.

Draft - has not been programmatically approved. 
The waste package will be placed in a mined geologic environment which is below the Nevada desert and well above the water table in a stratum of welded, devitrified, tuff rock. This location results in a relatively dry condition without hydrostatic or significant lithostatic loads. Thus, the stresses in service are limited to the residual stresses in the closure weld and the static load from the weight of the container and waste. Additional transient and impact loads will occur during transportation, handling, and possible retrieval. The container must be able to survive a small drop or handling impact without loss of integrity.

The container will undergo a very long-term but low temperature thermal cycle which may allow metallurgical changes in the material. Decay heat from the spent fuel will raise the temperature of the container surface to as much as $250 \mathrm{C}$ after the repository is closed. Over a period of hundreds of years, the temperature will slowly drop as the waste decays. Some containers may still be over $100 \mathrm{C}$ after 1,000 years, while others may cool more rapidly. The effect of this long-term thermal aging on the weld metal and heat affected zone of the closure weld is of particular interest.

The corrosion environment will also change with time. When the containers are hot, there can be no liquid water contact. The environment then will be a warm air-steam environment conducive to oxidation. When the temperature drops below the boiling point, the low water infiltration rate at Yucca Mountain is expected to limit exposure to water. Condensation is unlikely because the container surface will be the hottest surface in the repository airspace. However, it is considered possible that dripping, or even flow of water onto some of the containers may occur. This would bring about an aqueous phase environment conducive to dissolution, pitting and crevice corrosion, and envirormentally assisted cracking. The groundwater associated with the repository site is near neutral in pH, oxygenated, and fairly low in ionic content. Mechanisms have been proposed by which the solutes in the groundwater could become concentrated and result in a somewhat more aggressive environment.

The gamma radiation from the waste decay will produce radiolytic alterations in the local environment in the early time period. This will include generation of nitrogen oxides or nitric acid and possibly ozone from irradiation of moist air and hydrogen peroxide from irradiation of liquid water. Radiolytic effects will be smaller in the latex years when the temperatures have dropped below boiling because of the assuciated decrease in the radiation dose rate.

It can be seen that a varjety of service conditions, some expected or nominal, and some potential or off-nominal, may be encountered by the container material. The selection criteria for the container material will be discussed taking account of the performance requirements, conceptual design, and service conditions discussed above.

Draft - has not been programmatically approved. 
The criteria fall into two general categories: those related to the performance of the container material in the repository, and those non-performance-related topics dealing with cost and practicability of fabricating a container from the material. Within these categories the criteria are divided into seven topical areas and given relative weighting factors:

Weighting Factor 10

30

15

10

15

10

10

\section{MATERIAL PERFORMANCE}

A) Mechanical performance

B) Chemical performance

C) Predictability of performance

D) Compatibility with other materials FABRICABILITY, COST, AND OTHER CONSIDERATIONS

E) Fabricability

F) Cost

G) Previous experience with the material

Within each of the seven topical areas there are several specific sub-topics, each of which receives a share of the topic area weighting. At this level the criteria are material-independent and are equally applicable to any candidate container material. It should be noted that each of the performance criteria must be considered for a variety of combinations of material conditions and environments (including irradiation). The "worst-case" combination for each material and criterion is the one used for evaluation. The combinations of conditions and environments are the following:

Base material/Closure material

As fabricated/Aged

Nominal environment/Potential environment

Note also that many of the criteria are interrelated and may overlap in some areas. The material-independent selection criteria topic areas, sub-topics, and weighting factors are shown on the next page: 


\section{Material Independent Selection criteria}

Weighting

Factor

10

3

4

3

30

8

10

10

2

15

\section{PART A: MATERIAL PERFORMANCE}

Will the material meet the performance allocated to the container in achieving the containment objectives (substantially complete containment under anticipated processes and events occurring in the repository)? Can the performance of the material under repository conditions be adequately predicted? Will the container material interact favorably with other components?

A) Mechanical performance
1) Strength
2) Toughness
3) Phase stability

B) Chemical performance

1) Resistance to general corrosion (oxidation, aqueous corrosion).

2) Resistance to pitting, crevice, or other localized attack)

3) Resistance to environmentally accelerated cracking (stress corrosion cracking and $\mathrm{H}$ embrittlement).

4) Resistance to microbiologically influenced corrosion

C) Predictability of performance

1) Existence of models to explain and predict

degradation phenomena and models to extrapolate existing performance data to repository time scales and conditions, or ability to develop such models.

2) Existence of long-term performance data.

3) Other predictability issues

D) Compatibility with other materials

1) Interactions with waste form.

2) Interactions with the package environment and borehole liner.

Part B: FABRICABILITY, COST, AND OTHER CONSIDERATIONS

Can a container be made of this material? Is it practicable?

E) Fabricability

1) Fabricaility of container body.

2) Weldability of container

3) Inspectability of closure.

F) $\cos t$

1) As-fabricated container costs.

2) Associated exceptional repository handling costs.

G) Previous experience with the material

1) Previous engiricering experience with the material

2) Available data base on the material

3) Existing engineering standards for the material.

Draft - has not been programmatically approved. 
At the next level of detail, the criteria are described by scalable parameters that can be quantified. This quantification may be either objective (such as relating a physical parameter to a score) or subjective (by professional judgement). In some cases a topic is described by only one parameter, for example A1) strength is described by the parameter "yield strength":

A) Mechanical Performance

A1) Strength

Weighting Factor: 3

Parameter: Yield strength

In other cases several parameters may be used to describe a topic, for example BI) General corrosion is divided into oxidation and aqueous corrosion:

B) Chemical performance

B1) Resistance to general corrosion (oxidation, aqueous corrosion).

Weighting Factor: 8

Bla) Oxidation

Weighting Factor: 4

Parameter: Time average oxidation rate

(micrometers/year)

BIb) Aqueous corrosion.

Weighting Factor: 4

Parameter: Time average dissolution rate

(micrometers/year)

While the criterion topic is material-independent, the scalable parameters, which describe the criteria, will vary with the material being evaluated, particularly in the performance topics. This is true because different materials have different properties and different susceptibilities to degradation. An example of this is found under the topic of localized corrosion, where one parameter is the likelihood that the repusitory environment contains an ionic species that is known to promote pitting attack in a concentration sufficient to cause a performance problem. Different types of metal are pitted by dif ionic species. Therefore, the parameter would vary for different materials, but the intent of the criterion is the same, that is, to evaluate the degree to which pitting attack is a performance-limiting problem.

It should be noted that these selection criteria endeavor to condense a complicated set of interrelated phenomena and conditions into a sufficiently simple set of parameters to allow objective comparison of different materials. It is not intended to discuss in this document al] of the details which must be considered during the selection. It is intended to provide the topic areas and quantitative framework for the selection. Detailed discussions of the degradation and performance topics can be found in the Degradation Mode surveys [3], the site Characterization Plan [2], and other program documents [4].

Draft - has not been programmatically approved. 
It is intended to have a two-part selection process. The first part is a "Pass/Fail" ( $\mathrm{P} / \mathrm{F})$ to determine whether each candidate meets the minimum performance goals for the waste package, and whether it is a practicable material to use in this application. The second part is a "Quantitative Score" (QS) to determine a numerical value for each candidate, allowing the relative merit of each to be compared in order to select the "best" candidate. To support these goals, each parameter should be related to a numerical scale and a passing score determined. with all of this included, the parameter example used before for oxidation looks like this:

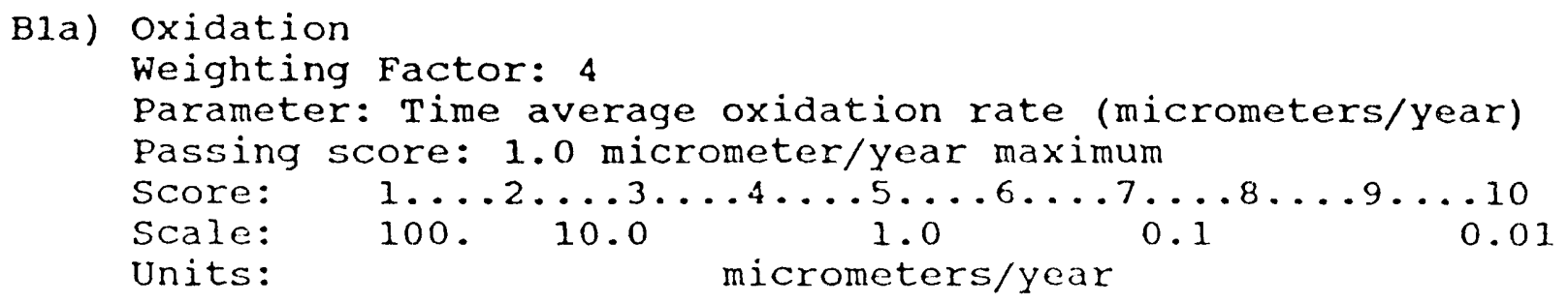

In presenting the criteria, additional commentary is often needed to explain the parameter or scale. In the example above, comments add that the averaged oxidation rate is for the expected temperature and gas phase environment as a function of time during the containment period. Thus, the oxidation rate in the early years, when the container is hottest and the radiation field is highest, might exceed one micrometer/year, but the maximum oxidation expected over a 1000-year containment period would be 1000 micrometers. This one parameter then involves the effects of time, temperature, radiation, chemical environment, and material condition. As stated earlier, the performance criteria should be judged for the worst-case combination of:

Base material/Closure material

As fabricated/Aged

Nominal environment/Potential environment

While it would seem consistent to have both a passing score and a quantitative scale for each criterion, in some cases it is appropriate to eliminate one or the other. Some topics do not really have a "passing score" below which the material is not usable. In these cases, only the quantitative score is established and the passing score is marked "NA" for "not applicable". An example of this is previous experience. There is really no minimum experience required, but a material with many established applications and standards should be easier to license than one without. In other cases, there is a minimum requirement, but having more than that requirement does not really add to the usefulness of the material. An example of this is strength. The container must be strong enough to handle all anticipated loads with a reasonable safety factor, but beyond that, great strength does little good. In these cases, the quantitative scale is omitted with an entry of $\mathrm{NA}$.

Draft - has not been programmatically approved. 
It should be noted that the topic areas were selected to answer the questions of required performance and practicability and are material-independent. The candidate materials have received considerable thought and examination prior to being included in the candidate list. Therefore, it should be expected that most of the candidates will pass all of the minimum score tests, and will compete favorably on the quantitative scoie. Indeed, some criteria or entire topic areas may yield no difierentiation between the candidates. These criteria are still included in we process to document that the candidates meet performance or practicability requirements.

In the following pages are presented the selection criteria with weighting factors, parameters, minimum scores, quantitative scales, and explanatory comments.

\section{References:}

1. "Disposal of High-Level Radioactive Wastes in Geologic Repositories, Technical Criteria," 10 CFR Part 60, Nuclear Regulatory Agency, Federal Register, Rules and Regulations, Vol. 48, No. 120 (Tuesday, June 21, 1983), pp. 28194-28229.

2. "Site Characterization Plan, Consultation Draft, Yucca Mountain Site, Nevada Research and Development Area", U.S. Department of Energy, Office of Civilian Radioactive Waste Management, DOE/RW-0160 (January 1988). (Refer to sections 7.4 and 8.3.5.9).

3. D. B. Bullen, J. C. Farmer, G. E. Gdowski, R. D. Mccright, R. A. Vankonynenburg, and $\mathrm{H}$. Weiss, Survey of Degradation Modes of Candidate Materials for High-Level Radioactive-Waste Disposal Containers, 8 Volumes, Lawrence Livermore National Laboratory, Livermore, California, UCID-21362 (1988).

4. R. D. McCright, W. G. Halsey, R. A. Vankonynenburg, Progress Report on the Results of Testing Advanced Conceptual Design Metal Barrier Materials Under Relevant Environmental Conditions for a Tuff Repository, Lawrence Livermore National Laboratory, Livermore, Caliiornia, UCID-21044 (December 1987). 


\section{PARAMETERS, WEIGHTING FACTORS, AND PASSING SCORES \\ FOR CANDIDATE METAL ALLOYS}

\section{A) Mechanical Performance}

Weighting Factor: 10

\section{A1) Strength}

Weighting Factor: 3

Parameter: Yield strength

Passing Score: $10 \mathrm{ksi}$ minimum

Score: Pass (5) / Fail (0)

Scale: NA

This assures adequate strength for static and handing loads. Note that this criterion must still be met after the long term aging of the material.

A2) Toughness

Weighting Factor: 4

Parameter: Plane-strain fracture toughness (KlC)

passing scorei, 59 ksifinf

Scale: NA

Fracture toughness inferred from stress intensity factor for fracture Klc. Note that this criterion must be met by the final closure weld and heat affected zone after a long term aging cycle.

A3) Phase stability

Weighting Factor: 3

Parameter: Relative metallurgical phase stability

Passing Score: "Fair"

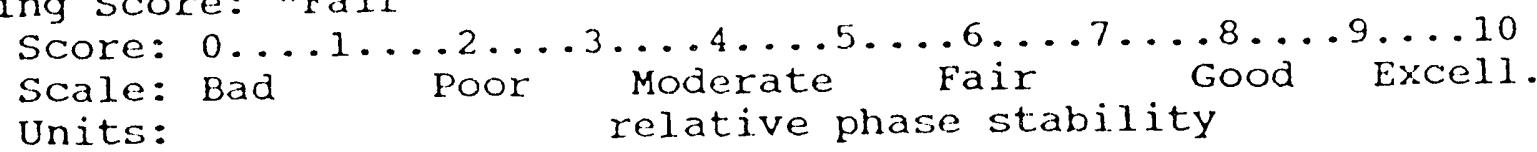

Relative metallurgical stability of base metal and final closure weld and heat affected zone during long term (1000 years) aging at moderate temperatures (up to $250 \mathrm{C}$ ).

Draft - has not been programmatically approved. 


\section{B) Chemical performance}

Weighting Factor: 30

B1) Resistance to general corrosion (oxidation, aqueous corrosion). Weighting Factor: 8

B1a) Oxidation

Weighting Factor: 4

Parameter: Time average oxidation rate (micrometers/year) passing score: $1.0 \mathrm{micrometer/year} \mathrm{maximum}$ Score: $0 \ldots 1 \ldots . \ldots 2 \ldots 3 \ldots 4 \ldots 5 \ldots 6 \ldots 7 \ldots 8 \ldots 9 \ldots 10$

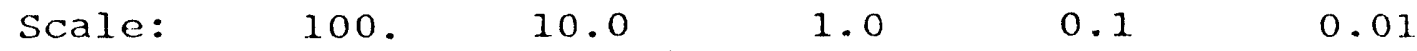
Units: micrometers/year

This is the average oxidation rate for the expected time, temperature, and environment for the containment period. The passing score then allows for up to 1 millimeter of wastage from oxidation in 1000 years.

Blb) Aqueous corrosion.

Weighting Factor: 4

Parameter: Time average dissolution rate (micrometers/year) Passing score: $1.0 \mathrm{micrometer/year} \mathrm{maximum}$

Score: $0 \ldots . \ldots 1 \ldots 2 \ldots 3 \ldots 4 \ldots . \ldots 6 \ldots . \ldots 7 \ldots 8 \ldots 9 \ldots 10$

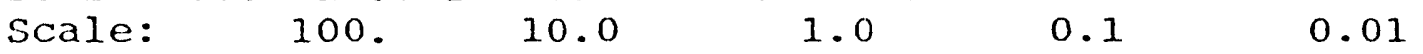

Units: micrometers/year

This is the average aqueous corrosion rate for the expected time, temperature, and environment for the containment period. The passing score then allows for up to 1 millimeter of wastage from aqueous corrosion in 1000 years. 
B2) Resistance to pitting, crevice, or other localized attack.

Weighting factor: 10

B2a) Critical potential for pitting

Weighting Factor: 5

Parameter: E(critical) - E(corrosion)

Passing score: 100 millivolts minimum difference

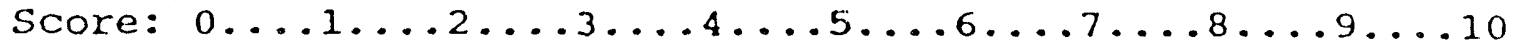

$\begin{array}{llllll}\text { Scale: } 0 & 100 & 200 & 300 & 400 & 500\end{array}$

Units: difference (mV)

The difference between the critical potential for pit initiation and the free corrosion potential under the expected metallurgical (including the aged material) and environmental conditions.

B2b) Threshold ionic concentrations for pitting/crevice attack (for example: chloride)

Weighting Factor: 5

Parameter: Likelihood of concentrations causing attack. Passing score: Moderate

Score: $0 \ldots . \ldots 1 \ldots 2 \ldots . \ldots 3 \ldots 4 \ldots 5 \ldots 6 \ldots . \ldots 7 \ldots 9 \ldots 10$

Scale: High Moderate Low None

Units: $\quad$ Subjective likelihood

The relative probability that chemical species in the environment which are known to cause or enhance pitting or crevice attack will occur in concentrations sufficient to propagate a pit or crevice through the container wall. This includes consideration of topics such as nominal ionic concentrations expected, possible concentrating effects, thermal conditions, and quantity of water present, all as functions of. time.

Draft - has not been programmatically approved. 
B3) Resistance to environmentally accelerated cracking EAC (stress corrosion cracking and hydrogen embrittlement).

Weighting factor: 10

B3a) Threshold stress intensity for corrosion cracking

Weighting Factor: 2

Parameter: $\mathrm{K} 1 / \mathrm{K} 1 \mathrm{scC}$

Passing score: 0.8 critical intensity stress for SCC

Score: $0 \ldots 1 \ldots .2 \ldots 3 \ldots 4 \ldots 5 \ldots 6 \ldots 7 \ldots 8 \ldots . \ldots 9$

Scale: 1.0

0.6

0.4

0.2

0

Units:

stress intensity/critical stress intensity

This is the ratio of expected stress intensity Kl (due to residual stresses, applied stresses, and internal flaws), to the critical stress intensity Klscc for SCC under expected

metallurgical (including the aged material), physical, and environmental conditions.

B3b) Degree of sensitization (austenitic alloys/SCC)

Weighting Factor: 2

Parameter: EPR ratio

Passing score: 58 maximum

Score: $0 \ldots 1 \ldots . \ldots 2 \ldots 3 \ldots 4 \ldots 5 \ldots 6 \ldots 7 \ldots 8 \ldots 9 \ldots 10$

Scale: 100

Units:

10

EPR ratio \%

0.1

Electrochemical potentiokinetic reactivation (EPR) test. The worst case is likely to be the final closure weld and heat affected zone after long term aging.

B3c) Threshold potential (austenitic alloys/TGSCC)

Weighting Factor: 2

parameter: E(critical) - E(corrosion)

passing score: 100 millivolts minimum difference

Score: $0 \ldots 1 \ldots . \ldots . \ldots 3 \ldots 4 \ldots 5 \ldots 6 \ldots . \ldots 8 \ldots 9 \ldots 10$

$\begin{array}{cccccc}\text { Scale: } 0 & 100 & 200 & 300 & 400 & 500\end{array}$

Units: mililivolts

The difference between the critical potential for TGSCC and the free corrosion potential under the expected metallurgical and environmental conditions. 
B3d) Likelihood of sufficient concentration of ionic species for corrosion cracking (for example: chloride for austenitic alloys, ammonia or nitrite for copper alloys)

Weighting Factor: 2

Parameter: Likelihood of EAC ion concentrations occurring. Passing score: Moderate

Score: $0 \ldots . \ldots 1 \ldots 2 \ldots . \ldots 4 \ldots 4 \ldots 6 \ldots 7 \ldots . \ldots 9 \ldots 10$

Scale: High Moderate Low rone

Units: Subjective likelihood

The relative probability that chemical species in the

environment which are known to cause or enhance EAC will occur in concentrations sufficient to propagate a crack through the container wall. This includes consideration of topics such as nominal ionic concentrations expected, possible concentrating effects, thermal conditions, and quantity of water present, all as functions of time.

B3e) Likelihood of sufficient hydrogen concentration to cause embrittlement

Weighting Factor: 1

Parameter: Likelihood of embrittling $H$ concentrations. Passing score: Moderate

Score: $0 \ldots 1 \ldots . . \ldots 3 \ldots 4 \ldots 5 \ldots 6 \ldots . \ldots 7 \ldots 8 \ldots . \ldots 10$

Scale: High Moderate Low None

Units: $\quad$ Subjective likelihood

The relative probability that the hydrogen concentration in the environment will cause sufficient $\mathrm{H}$ uptake to cause

embrittlement. This includes consideration of topics such as sources and sinks for hydrogen, radiation fields, and the material condition.

B3f) Hydrogen sensitive phases (for example: martensite or sensitized material for austenitic alloys, oxide inclusions for copper alloys)

Weighting Factor: 1

Parameter: Phase fraction

Passing score: 0.01 maximum

Score: $0 \ldots 1 \ldots 2 \ldots 3 \ldots 4 \ldots 5 \ldots 6 \ldots 7 \ldots 8 \ldots 9 \ldots 10$

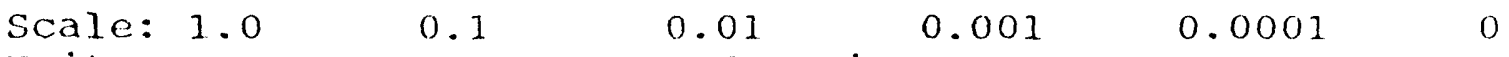

Units: fraction

Fraction of material composed of phases susceptible to hydrogen cracking, particularly after aging in the final closure weld and heat affected zone.

Draft - has not been programmatically approved. 
Weighting Factor: 2

Parameter: Likelihood of microbiologically influenced corrosion) Passing score: Moderate

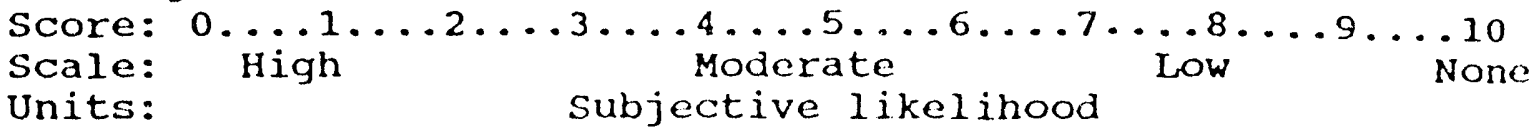

The relative probability that microbiologically influenced corrosion of the material will occur in the repository environment at a rate sufficient to cause container failure.

C) Predictability of performance

Weighting Factor: 15

C1) Existence of models to explain and predict degradation phenomena, and models to extrapolate existing performance data to repository time scales and conditions, or ability to develop such models.

Weighting Factor: 5

Parameter: Subjective opinion of "Modelability" Passing score: NA

Score: $\quad 0 \ldots 1 \ldots 2 \ldots 3 \ldots 4 \ldots 5 \ldots 6 \ldots 7 \ldots 8 \ldots 9 \ldots 10$

Scale:

Units:

Low

Medium High Modelability

Estimate of the likelihood that the degradation phenomena can be modeled sufficiently to allow performance prediction.

c2) Existence of long-term performance data.

Weighting Factor: 5

Parameter: Literature review finding

Passing score: INA

Score: $\quad 0 \ldots 1 \ldots 2 \ldots 3 \ldots 4 \ldots 5 \ldots 6 \ldots 7 \ldots 8 \ldots 9 \ldots 10$

Scale:

None

Moderate

Extensive

Units: relative data availability

Long term data include results from years or decades of expostre to known environments from which extrapolation to longer times is possible if models of the degradation modes exist. Data on materials other than the candidates may be useful if the degradation mode phenomenology is similar enough to be described by the same model.

Draft - has not been programmatically approved. 
C3) Other performance predictability issues.

Weighting Factor: 5

Parameter: Relative licensability

Passing score: NA

Score: $\quad 0 \ldots \ldots 1 \ldots . \ldots 2 \ldots 3 \ldots 4 \ldots 5 \ldots 6 \ldots . \ldots 7 \ldots . \ldots 9 \ldots 10$

Scale:

Low

Moderate

Units:

relative 1 icensability

High

Expected ease or difficulty in demonstrating sufficient performance predictability to allow licensing. This is a subjective combination of topics such as: model development and validation, data availability and validation, prior licensing experience and practice, etc.

D) Compatibility with other materials

Weighting Factor: 10

Di) Interactions with waste form.

Weighting Factor: 5

Parameter: Subjective opinion of "Compatibility"

Passing score: "Fair"

Score: $0 \ldots \ldots 1 \ldots 2 \ldots 3 \ldots 4 \ldots 5 \ldots 6 \ldots \ldots 7 \ldots 8 \ldots . \ldots 9 . \ldots 10$

Scale: Bad Poor Moderate Fair Good Excellent

Units: relative compatibility

Whether the material is likely to interact with the waste forms (spent fuel, cladding, glass waste form, glass pour canister, etc.) in any way which will compromise performance of the waste package. Examples might included: galvanic coupling, formation of aggressive chemical species, interdiffusion effects, etc.

D2) Interactions with the package enviroment and borehole liner.

Weighting Factor: 5

Parameter: Subjective opinion of "Compatibility"

Passing score: "Fair"

Score: $0 \ldots 1 \ldots 2 \ldots 3 \ldots 4 \ldots 5 \ldots 6 \ldots 7 \ldots 8 \ldots . \ldots 9 . \ldots 10$

Scale: Bad Poor Moderate Fair Good Excellent

Units: relative compatibility

Whether the material is likely to interact with any features in the nearby emplacement enviroment (borehole liner, seals, grout, rock, rockbolts, skids, lubricants, etc.) in any way that will compromise performance of the waste package or other repository component. Examples might include: galvanic coupling, formation of aggressive chemical species, interdiffusion effects, etc.

Draft - has not been programmatically approved. 


\section{E) Fabricability}

Weighting Factor: 15

E1) Fabricability of container body.

Weighting Factor: 5

Ela) General formability

Weighting Factor: 2

Parameter: Subjective opinion of formability

passing score: "Fair"

Score: $0 \ldots 1 \ldots . \ldots 2 \ldots 3 \ldots 4 \ldots . \ldots 5 \ldots 6 \ldots 7 \ldots . \ldots . \ldots 9 \ldots 10$

Scale: Bad Poor Moderate Fair Good Excell.

Units: relative formability

Availability of processes to form container components from the material considering properties such as ductility, microstructure, weldability, etc.

Elb) Product quality

Weighting Factor: 2

Parameter: Subjective opinion of quality

Passing score: "Fair"

Score: $0 \ldots 1 \ldots . \ldots 2 \ldots 3 \ldots 4 \ldots 5 \ldots 6 \ldots 7 \ldots 8 \ldots . \ldots 9 \ldots 10$

Scale: Bad Poor Moderate Fair Good Excell.

Units: relative quality

Ability to produce reproducible properties such as, composition, microstructure, residual stress, surface finish, etc.

Elc) Inspectability

Weighting Factor: 1

Parameter: Subjective opinion of inspectability

Passing score: "Fair"

Score: $0 \ldots 1 \ldots 2 \ldots 3 \ldots 4 \ldots 5 \ldots 6 \ldots 7 \ldots 8 \ldots . \ldots 9 \ldots 10$

Scale: Bad Poor Moderate Fair Good Excell.

Units: relative inspectability

Ability to inspect the fabricated material and document properties such as those discussed in Elb.

Draft - has not been programmatically approved. 
E2a) General process considerations Weighting Factor: 3

Parameter: Subjective opinion of weld process Passing score: "Fair" Score: $0 \ldots . . \ldots . \ldots 2 \ldots 3 \ldots 4 \ldots 5 \ldots 6 \ldots 7 \ldots 8 \ldots . \ldots 9 \ldots 10$ Scale: Bad Poor Moderate Fair Good Excell. Units: relative process quality

Is the material conducive to a high quality final closure in a remote operation, considering topics such as filler requirements, number of passes, repairability, process reliability and safety, etc. It may be possible to quantify this criterion by standard tests once the welding process is selected.

E2b) External process influences

Weighting Factor: 2

Parameter: Subjective opinion of external influences Passing score: "Fair"

score: $0 \ldots . \ldots 1 \ldots 2 \ldots 3 \ldots 4 \ldots 5 \ldots . \ldots \ldots \ldots . \ldots 8 \ldots 9 \ldots 10$

Scale: Bad poor Moderate Fair Good Excell.

Units: relative tolerance of external influences

Is the material tolerant of external influences on the weld quality, considering topics such as joint cleanliness, alignment, preheat variation, material condition, etc.

E3) Inspectability of closure.

weighting Factor: 5

E3a) General process considerations Weighting Factor: 3

parameter: Subjective opinion of inspectability

Passing score: "Fair" Score: $0 \ldots .1 \ldots 2 \ldots . \ldots 3 \ldots 4 \ldots 5 \ldots 6 \ldots 7 \ldots 8 \ldots . \ldots 9 \ldots 10$ Scale: Bad Poor Moderate Fair Good Excell. Units: relative inspectability

Does the material lend itself to inspection of the final closure weld, considering topics such as weld grain structure, typical weld flaw NDE signals, etc.

Draft - has not been programmatically approved. 


\section{E3b) Sensitivity Weighting Factor: 2 Parameter: Ratio of (detection limit flaw size)/(critical fla'.: size) \\ Passing score: 0.5

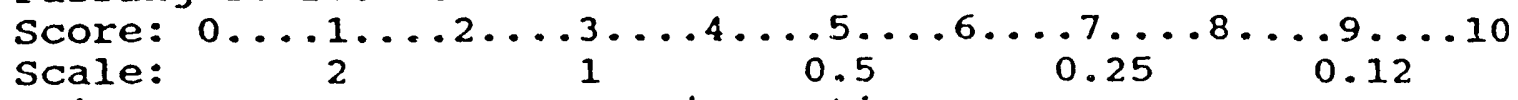 Units: size ratio}

Are critical flaw sizes in the welded material large enough to be readily detectable in rapid, remote, NDE techniques.

\section{F) Cost}

Weighting Factor: 10

F1) As-fabricated container costs.

Weighting Factor: 5

Parameter: $\$$ per container

Passing score: NA

Score: $\quad 0 \ldots \ldots 1 \ldots 2 \ldots . \ldots 3 \ldots 4 \ldots 5 \ldots 6 \ldots 7 \ldots 8 \ldots 9 \ldots 10$

Scale:

$125+100$

75

$50 \quad 25$ K\$

Units:

Expected cost of fabricated, closed, and inspected container ready for emplacement. Constant year dollars. No minimum passing score.

F2) Associated exceptional repository handling costs.

Weighting Factor: 5

Parameter: Relative added cost

Passing score: NA

Score: $0 \ldots \ldots 1 \ldots 2 \ldots 3 \ldots$.

Scale:

Units:

High

Moderate Relative cost

Exceptional repository handling costs specific to the material under consideration. Costs resulting specifically from physical or chemical properties of the container material. Examples might include: handling a heavier waste package made from pure copper which has been made thicker to assure mechanical strength, careful handing of brittle materials, special handing of toxic materials, etc. No minimum passing score. 
G) Previous experlence with the material.

Weighting Factor: 1c

G1) Previous engineering experience with the material and closure. Weighting Factor: 4

Gla) Variety of applications

Weighting Factor: 2

Parameter: Variety of applications

Passing score: NA

Score: $0 \ldots \ldots 1 \ldots . \ldots 2 \ldots 3 \ldots 4 \ldots 5 \ldots 6 \ldots . \ldots . \ldots 8 \ldots 9 \ldots 10$

Scale: None

Several

Units:

Variety of applications

Glb) Years of experience

Weighting Factor: 2

Parameter: Years in service

Passing score: NA

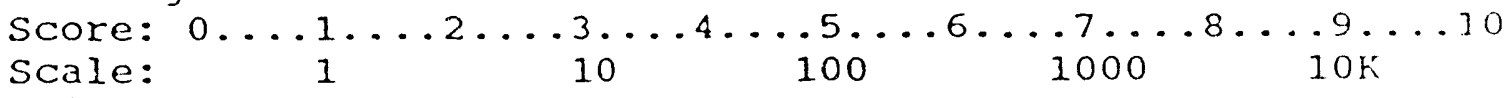

Units:

Years

G2) Available data base on the material and closure.

Weighting Factor: 3

Parameter: Relative amount of available data

Passing score: NA

Score: $\quad 0 \ldots \ldots 1 \ldots . \ldots 2 \ldots 3 \ldots 4 \ldots 5 \ldots 6 \ldots 7 \ldots . \ldots 9 \ldots 10$

Scale:

Units:

Moderate

Extensive

Relative available data

Draft - has not been programmatically approved. 
G3) Existing engineering standards for the material and closure.

Weighting Factor: 4

G3a) ASTM standards

Weighting Factor: 2

Parameter: ASTM coverage

Passing score: NA

Score: $0 \ldots .1 \ldots . \ldots . \ldots 3 \ldots 4 \ldots . \ldots 5 \ldots 6 \ldots 7 \ldots 8 \ldots . \ldots 9 \ldots 10$

Scale: None Moderate Extensive

Units: $\quad$ Relative extent of ASTM standards

Extent of consideration given the material (or equivalent materials) by ASTM standards.

G3b) Other Standards

Weighting Factor: 2

Parameter: Availability of standards

Passing score: NA

Score: $0 \ldots .1 \ldots 2 \ldots . \ldots 3 \ldots 4 \ldots 5 \ldots 6 \ldots 7 \ldots 8 \ldots . \ldots 9 \ldots 10$

Scale: None Moderate Extensive

Units: Relative extent of other standards

Availability of standards for application of the material, such as ASME Boiler and Pressure Vessel code consideration of the material, or other engineering, construction, or testing standards. 
Appendix B

Qualifications of the Peer Review Panel Members 
Resume

ROBIN L. JONES

ADORESS:

1054 Windsor Drive, Menlo Park, Californid 94025

$\begin{aligned} \text { Telephone: } & 415 / 325-9570 \text { (Home) } \\ 415 / 855-2790 & \text { (Work) }\end{aligned}$

SUMMARY: $\quad$ PhD metallurgist with 25 years materials research experience and 15 years research managemert experience. Areas of specialized professional competence include physical and mechanical behavior of metals and ceramics, interrelation of properties and microstructure, environment assisted cracking, fracture mechanics, and failure analysis. Emphasis of recent work has been on corrosionrelated materials problems in energy conversion and power generation systems.

EOUCATION ANO EMPLOYMENT HISTORY:

$1959-62$

1962

$1963-66$

1966

1965.72

1966

1967

1971

$1972-1978$
Gonville and Caius College, Cambridge University, England B.A. (Hons) in Natural Sciences (Mctallurgy major) Metallurgy Ureprement, Cambridge University, England Pho (Metallurgy). Dissertation title "The Hechanical Properties of bispersion Strengthened Alloys". Advisor: Dr. A. Frily

Prantion Institute Pesereh Laboratories, Philatelphia, Pa. Research Metallurgist, Metallurgy laboratory Senior Metallurgist, Metalluray latoratory Croup leader, Mretalluray Laboratory SRI International (formely Stanford Research Institute) 
1972

$1972-1978$

1978-Present

$1978-1980$

$1980-1985$

1985..Present

\section{Menlo Park, California}

Senior Metallurgist, Materials Research Center

Manager, Metallurgy Program, Materials Research Center

Electric Power Research Institute, Palo Alto, California

Project Manager, Systems and Materials Department, Nuclear

Power Division

Program Manager, Systems and Materials Department.

Senior Program Manager, Materials and Systems Development

Department

RESEARCH FXPERIENCE:

Three years of university postgraduate work and twelve years of contract research in two not-for-profit research institutes mainly related to the physical and mechanical properties of metals and ceramics.

Research topics have included:

o Fundamental aspects of the mechanical behavior of precipitation and dispersion strengthened alloys

o Cohesion and adhesion of metals in ultra-high vacuum

o Basic aspects of the low and intermediate temperature deformation of hexagonal close packed metals

o Developinent of beryllium-reinforced composites

o Iffects of thermomechanical processing on the microstructure and properizes of titanium alloy:

o Hechanisme of stress-corrosion cracting and liguid metal rmbrittienerent of zirconium alloys

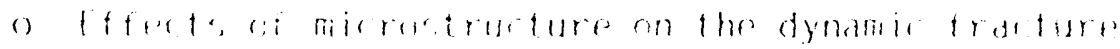
behavior at titamijmi

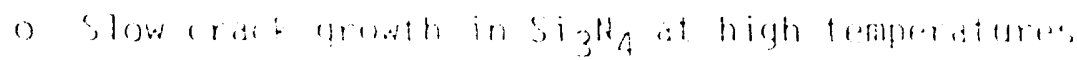

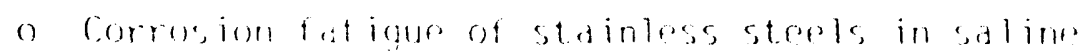
rivirurments.

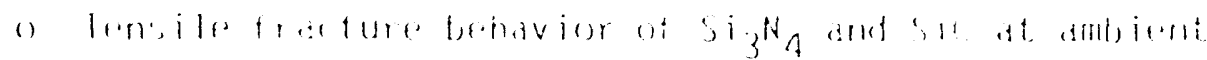
t.mentature 
o Adhesive properties of phosphonate-containing dental restorative materials

o Materials limitations in advanced energy-generation and conversion systems

- Examination and interpretation of service failures of ferrous and nonferrous metallic components

o Evaluation of the technoeconomic impact of advanced materials

o Development of high-strength titanium alloys with improved fracture toughness

Most of the techniques used in physical/mechanical metallurgy research have been employed or are familiar.

Author of more than 70 open literature publications (1ist attached) and more than 40 major government and commercial contract reports.

RESEARCH MANAGEMENT AND SALES EXPERIENCE:

$1966-72$

Franklin Institute Research Laboratories

Initially responsible for developing contract support for myself and a technician.

Promoted to Group lear: in 1971 and directed the research and sales act $\because$ ties of 2 PhD's, 2 technicians and a secrotary.

Authored morm lhan asesearch proposals and maintained an accept. ". , te coropesals funded: proposals

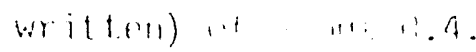

Partir ipated in lome-term budget and projedet development. plamime at the departmental level. 
Initially responsible for a poorly performing group consisting of 1 PhO, 2 professionals, 3 technicians and a secretary.

Completely redirected the activities of the group into new research areas and made necessary staffing adjust-ments including $h::$ s, fires, and transfers.

Group performance improved and size expanded (consisted of 3 Pho's, 3 professionals, 2 technicians, and a secretary when I resigned).

Authored more than 50 research proposals and maintained an acceptance ratio of about 0.5 .

Attended several management training courses provided by SRI.

Participated in long-term budget and project deveiopment planning in the divisional level.

1978-Present

Electric Power Research Institute

Initialty responsible for pianning and implementing Targe EPRI projects on corrosion fatigue of reactor pressure vessel steels and evaluation of comsequences of itrees, rorension cracting in but piping.

lusing $19 / 9$ was responsible for 19 contrats having a

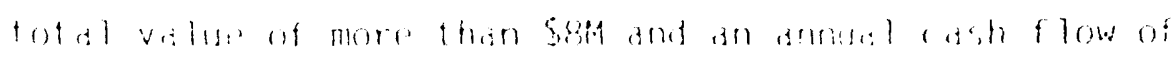
dixut $5 \% .6$.

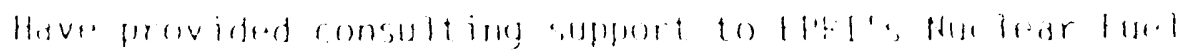

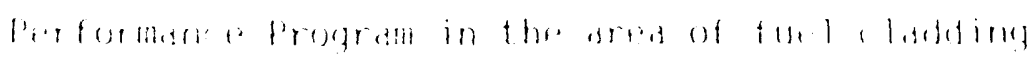
bringior. 


\section{During early 1980 shared (with T. U. Marston) program management responsibility for EPRI's Nuclear Pressure Boundary Technology Program.}

In May 1980 was promoted to Program Manager and was assigned responsibility for developing a new program on corros sn-related problems in nuclear plant structural materials with an annual budget of about $\$ 10 M$. Since 1984 have also been responsible for the externally funded BWR Owner Group Program on Intergramular Stress Corrosion Cracking.

Have continued to be professionally active and have authored or coauthored more than 40 technical publications since joining EPRI.

\section{TEACHING EXPERIENCE:}

1962. -66

$1969-70$

University of Cambridge

Taught small-group tutorials which are used in Cambridge to supplement formal undergraduate lecture courses. Subjects taught covered the complete spectrum of undergraduate metallurgy from extraction to bonding theory.

University of Penmsylvania

Taughe a two emester graduate courese, "Introduction io Metallurgy," designed for metal lurgy graduate students with no formal U.S. undergraduate metallurgy background.

PIRSOHAL:

$$
\begin{aligned}
& \text { Marital satus: Hivered (one hild) }
\end{aligned}
$$

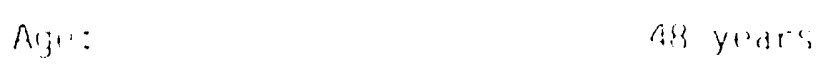

$$
\begin{aligned}
& \text { Hedth: tinest }
\end{aligned}
$$




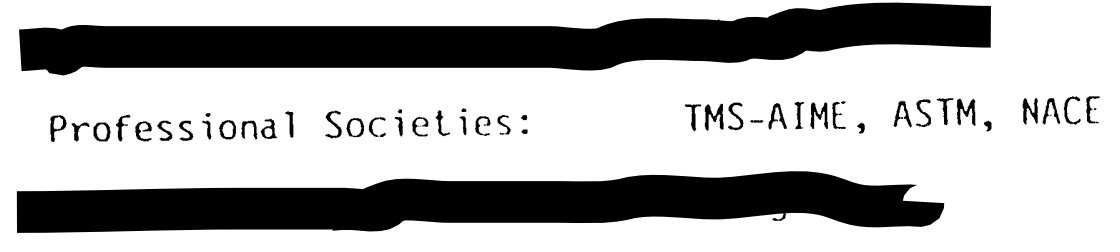




\section{GEOFFREY R. EGAN}

\section{SPECIALIZED PROFESSIONAL COMPETENCE}

Fatigue, fracture, and stress analysis of welded structures including pressure vessels, offshore platforms, bridges. and steel framed buildings; fracture control procedures for nuclear pressure vessels; design procedures for nuclear fuel transport containers: integratıon of fracture mechanics, stress analysis, and NDE for fracture sate design; materials selection procedures, welding methods and procedures. and properties of welded joints.

Recent work includes elastic-plastic finte element analysis, the effect of imperfections on structural integrity. significance and effect of residual and restraint stresses on structural periomance. measurement of residual stresses: selection of welding procedures for avording hydrogen cracking: analyses of detects in containments: repair welds and procedures: analyses of reheat treatment crackıng: prediction of stress corrosion crack growth in BWR piping: analyses of sate end failures in BWH vessels; evaluation of fatigue performance of deep water platforms: fracture analyses of steam generator suppon components: evaluation of defects in main steam piping: fracture controls for chilled natural gas pipetines; inspection of nuclear steam generators: steam generator performance studies; significance of IGA in steam generator tubes; analysis of coal pulverizer fatigue life: review and evaluation of inspection records; renspection programs; assessment of document tracking systems: sampling programs for weld quality assessments: analysis of inspection requirements for cast austenitic power plant components: prudency hicurings; licensing hearings: and litigation support.

\section{BACKGROUND AND PROFESSIONAL HONORS}

- B.E. (Mech.), University of Canterbury, New Zealand (1966)

- DIC. Imperial College of Science and Technology, England (1970)

- Ph.D. University of London (1972)

- Member, American Society of Mechanical Engineers

- Member, American Welding Society

- Member, Institution of Mechanical Engineers (Chartered Engineer)

- Member, The Welding Institute

- Member, The American Society for Nondestructive Testing

- Member, The American Society of Naval Enigineers

\section{SELECTED REPORTS, PUBLICATIONS, AND INVITED LECTURES}

Fatigue Data Workshop. National Bureau of Standards, Boulder, Colorado (January 1988)

Dimensionless Damage Approach to Fatigue Crack Growth. International Conference on Fatigute of Welded Constructions. The Welding Institute, Brighton, UK (with J. L. Grover) (April 1987)

Integrily Issues for Cast Austemic Materials in the Primary Pressure Boundary. Rlectm: Powe: Research institute (with R. C. Cipolla) (October 1986).

Inspection of Centrifugally Cast Stamless Steel on Pressurized Water Reactors. Flectuc Power

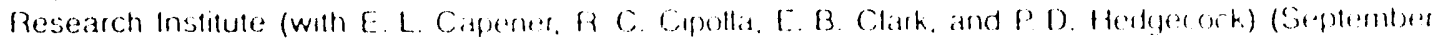
1986)

The Cognac Fatigue Experment. Fifteenth Armual Ottshore Technology Conference, Houston. Texas: (with J. D. Burk, R. D. Larrabee, and P. W. Matsinall) (May 1983)

Analysis of Tie Girder Cracking and Sindege Chosure of frame du Chen Brodge (19833)

Improved Radiographic Flaw Siang ly Doghal Image Pocessimg. Londen. F negland (1939) 
On-Line Monitoring of Critical Components to Improve Reliabulity. Symporium on Critical Materials and Fabrication Issues, ASME, San Francisco, California (August 1980).

The Significance of Defects in Welded Long-Span Bridge Structures, New York Academy of Scionces, O. H. Amman Centennial Conference. New York (Novernber 1979).

The Application of Small Scale Tests to the Prediction of Structural Integrity. Seminar on Small Scale Testing. Milan, Italy (May 1979).

The Application of Elastic-Plastic Fracture Mechanics in Fracture Safe Design. Nuclear Engineenng and Design, Vol. 45, No. 1 (January 1978).

The First US/Japan Joint Symposium on Corrosion Problems in Light Water Reactors. Japan (1978).

Stress Corrosion Crack Growth and Fracture Predictions for BWR Piping. 1978 ASMEICSME Pressure Vessels and Piping Conference. Montreal, Canada (with R. C. Cipolla) (1978).

Recent Advances in Residual Stress Measurement, International Conference for The Welding Institute. London. England (1977).

Residual Stresses in Welded Construction and Their Effects, The Welding Institute, London. England (1977).

Failures in Welded Structures, ASME. WAM. Allanta, Georgia (1977).

Repair Welds Wiihout Post-Weld Heat Treatment, International Institute of Welding. Sydney, Australia (1976)

Damage Tolerance Requirements for Heavy Wall Pressure Vessels. Third Annual ASM Materialsi Design Forum Prevention of Structural Fallure Through Quantitative NDE and Fracture Mechanics, San Francisco, California (July 1975).

Techniques for Assessing Fraclure Toughness. Conterence on Mechanics and Physics of Fracture. Cambridge University. England (1975)

Steel Castings for Structural Use. Proceedings, Offshore Technology Conference. Newcastle. England (with S. J. H. Still) (February 1974).

The Application of Fracture Toughness Data to the Assessment of Pressure Vessel Integrity. Second International Conterence on Pressure Vessel Technology. San Antonio. Texas (October 1973)

Finite Element Techniques in Fracture Mechanics. Stuttgant University. Germany (April 1973).

Third International Congress on Fracture, Munich. Germany (Apul 1973).

J-A Path Independent Integral for Characterizing Fracture Behavior. Welding Institute Research Bulletin (March 1973).

A Comparison of Deformation Parameters for Work Hardening and Non-Work Hardening Be'havior. International Journal of Fracture (1973)

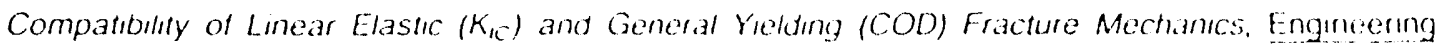
Fracture Mechatics. Vol 5. p. 167 (1973)

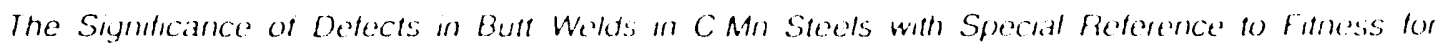

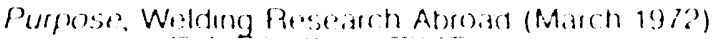

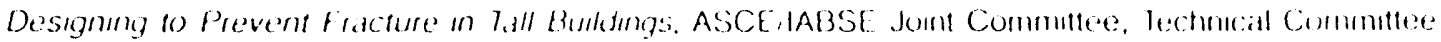
18. State-ot-the-Art Report (with S. I. Rolfe) (January 1972)

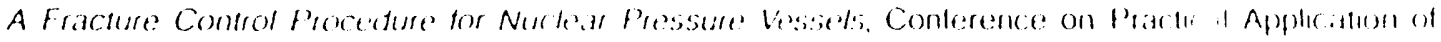

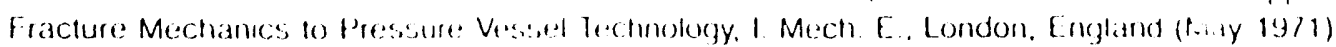

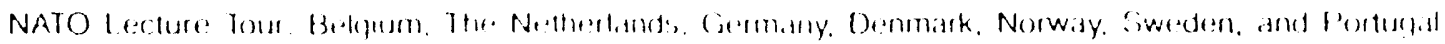
(1971) 
Richard Paul Gangl off

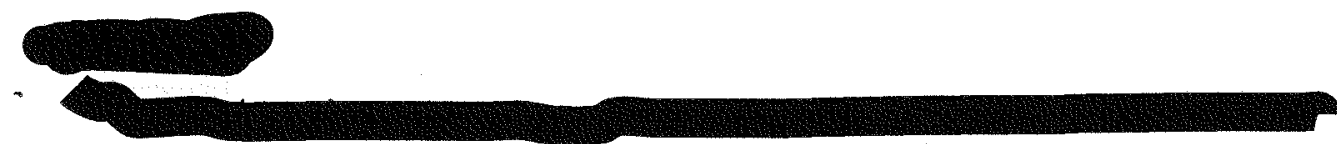

- Bducation:

B.S. in Metallurgy and Materials Science Lehigh University, 1970

M.S. in Metallurgy and Materials Science Lehigh University, ly7a

Ph.D. in Metallurgy and Materials Science lehigh University, 1974

Professional Experience:

Department of Metallurgy and Materials Science, Lehigh University, Bethlehem, PA

Instructor, $\quad 1970-1972$

Research Assistant, 1972-1974

Corporate Research and Development Center, General Electric Co. Schenectady, NY

Metallurgist, 1974-1980

Corporate Research Science Laboratories, Exxon llesearch and Engineering Annandale, $\mathrm{NJ}$

Staff Metallurgist, $1980-1982$

Senior Staff Metallurgist, $1982-1986$

School of Engineering and Applied Science, University of Virginia, Charlottesville, VA

Associate Professor of Materials Science, $1936 \ldots$

Honors and Awards:

BS with Highest Honors

Tau Heta Pi

Sigma $X i$

Henry Marion llowe Medal, 1986, ASM 


\section{Professional Societies and Committees:}

American Society for Metals

Chairman, Metals Handbook Commitiee on Environmental Effects in Fatigue, 1984

Member, International Materials Review Comnittec:

American Institute of Mining and Metallurgical Engineers

Chairman, Hudson-Mohawk Chapter, 1979

Member, Environmental Effects Committee

Member, Board of Review for Metallurgical Transactions

American Society for Testing Materials

Chairman, Task Group on Elevated Temperature Cracking, 1982-83:

Chairman, Task Group on Small Cracks, 1983-835

Chairman, Subcommittee E24.04 on Subcritical Crack Growth, 1985

Member, Executive Committee E24 on Fracture Mechanics, 1985-

\section{Research Interests:}

The metallurgy, mechanics and chemistry of metal fatigue and fracture, with emphasis on mechanistic understanding of failure modes necessary for high performance materials and quantitative life prediction methods. Current research focuses on hydrogen embrittlement, corrosion fatigue, stress corrosion cracking and experimental fracture mechanics of ferrous, nickel based and aluminum a 1 loys.

Publications:

R.P. Gangloff, "Crack Tip Models of Hydrogen Environment Embrittlement: Applications to Fracture Mechanics Life Prediction", Mat Is. Sci. Engr.., in press (19838).

R.P. Wei and R.P. Gungloff, "Fnvironmentally Assisted Crick Growth in Structural Alloys: Perspectives and New Directions", in 20th National

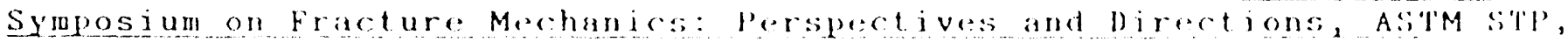
R.P. Wei and K.P. Gangloff, eds., ASTM, Philadelphia, Pa, in prests (1988).

R.P Gangloft, "A Review and Analysis of the fhreshold for Hydrogen

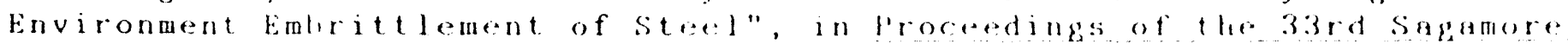

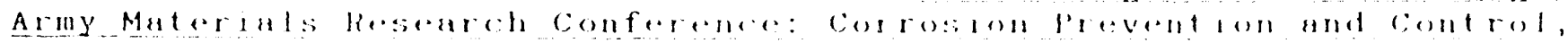
U.S. Army Materials Technology laboratory, Watertown, MA, in press; $(1988)$.

K. H. Gangloff, "Ethylene Inhibition of Giseous Hydrogen timbrittement in

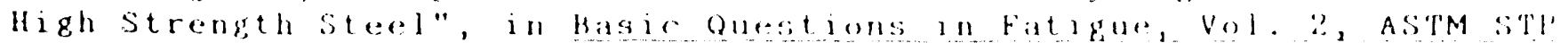

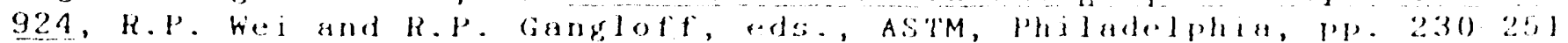
(1988). 


\section{Publications (continued):}

P.L. Andresen, R.P. Gangloff, L.F. Coffin and F.P. Ford, "Appications of Fatigue Analyses: Bnergy Systems", in Fatigue 87, Vol. III-A, R. 0 . Ritchie and E.A. Starke, Jr., eds., EMAS, West Midlands, UK, pp. 17231751 (1987).

R.P. Gangloff and D.J. Duquette, "Corrosion Fatigue of Metals: A jurvey of Recent Advances and Issues", in Chemistry and Physics of Fracture, R.M. Latanision and R.H. Jones, eds., Martinus Nijhoff fublishers HV, Netherlands, pp. 612-645 (1987).

R.P. Gangloff and R.P. Wei, "Small Crack-Environment Interactions: The Hydrogen Embrittlement Perspective", in Small fatigue Cracks, R.O. Ritchie and J. Lankford, eds., TMS-AIME, Warrendale, Pa., pp. 239-264 $(1986)$.

R.P. Gangloff and A. Turnbull, "Crack Electrochemistry Modeling and Fracture Mechanics Measurement of the Hydrogen Embrittlement Threshold", in Modeling Environmental Effects on Crack Initiation and Propagation, R.H. Jones and W.W. Gerberich, eds., TMS-AIME, Warrendale, Pa., pp. 55-8I $(1986)$.

R.P. Gangloff, "Inhibition of Aqueous Chloride Corrosion Fatigue by Control of Crack Hydrogen Production", in Critical Issues in Reducing the Corrosion of Steel, H. Leidheiser, Jr. and S. Haruyama, eds., NSF/JSPS, Tokyo, Japan, pp. 28-50 (1985).

R.P. Gangloff, "The Environmental Effect on Fatigue Crack Propagation", in Metals Handbook: Mechanical Testing, 9 th edition, Vol. 8, ASM, Metals Park, ohio, pp. 403-410 (1985).

B.P. Gangloff, "Crack Size Effects on the Chemical Driving Force for Aqueous Corrosion Fatigue", Metall. Trans. A., Vol. 16A, pp. 953-969 $(1985)$.

R.P. Gangloff and R.O. Ritchie, "Environmental Effects Novel to the Propagation of Short Fatigue Cracks", in Fundamentals of Deformation and Fracture, B.A. Bilby, K.J. Miller and J.K. Willis, eds., Canbridge University Press, Cambridse, Uk, pp. $529-558$ (1985).

R.P. Gangloff, "Oxypen Inhibition Model of the Chemical crack sige fiffect in corrosion fatigue", in Embritt lement by the localiaed crack Environment, R.P. Ganglofr, ed., TMS-AlMk, Warrendale, PA, pp $265-290$ $(1984)$.

R.P. Gangloff, "Solid Cadmium kmbrittement of lextured Zircaloy-2", in Embrittlement by liguid and Solid Metals, M.H. Kamdar, ed., TMS-AIMF,

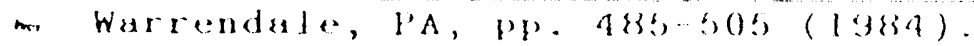

R.P. Gangloff, "filectrical Potential Monitoring of the Formation and Growth of Small fatigue Cracks in Embrittling Enviroments", in Advancess in Cract Length Messurement, C.J. Beevers, ed., kMAs, United kingdom, pr. $175-231,1982)$. 
Publications (continued):

R.P. Gangloff, "The Criticality of Crack Size in Aqueous Corrosion Fatigue", Res. Mech. Let., Vol. 1, pp. 299-306 (1981).

R.P. Gangloff, "Quantitative Measurements of the Growth Kinetics of Small Fatigue Cracks in loNi Steel", Fatigue Crack Growth Measurement and Data Analysis, ASTM STP 738, pp. 120-138, ASTM, Philadelphia (1981).

R.P. Gangloff, "Electrical Potential Monitoring of Crack Eormation and Subcritical Growth from Small Defects", Fat. Engr. Matlis. and struct., vol. 4, No. 1, pp. 15-33 (1981).

R.H. Vanstone and R.P. Gangloff, "The Effect of Processing Parametcrs on the Microstructure and Mechanical Properties of Rene 95 "onsolidated from Gas Atomized Powders", in Rapid Solidification Processing, Principles and Technology II, pp. 317-330, Claitors Press, Baton Rouge, LA (1980).

R.P. Gangloff, "The Behavior of Unirradiated Zirconium-lined and Copper-Plated Zircaloy-2 Tubing Under Simulated PCI Conditions", General Electric Company Report, GEAP-25093 (1979).

R.P. Gangloff, D.E. Graham and A.W. Funkenbusch, "The Influence of Environment Purity on Gaseous Iodine Embrittlement of Zircaloy-2 and High Purity Zirconium", Corrosion, Vol. 35, No. 7, pp. 316-325 (1979).

D.S. Tomalin, R.B. Adamson and R.P. Gangloff, "The Performance of Irradiated Copper and Zirconium Barrier Modified Zircaloy Cladding Under Simulated PCI Conditions", Zirconium in the Nuclear Industry, ASTM STP

681, pp. 122-144, ASTM, Philadelphia (1979).

R.P. Gangloff and R.P. Wei, "Fractographic Analysis of Gaseous Hydrogen Induced Cracking in 18Ni Maraging Steels", Fractography in Failure Analysis, ASTM STP 645, pp. 87-106, ASTM, Philadelphia (1978).

R.P. Gangloff and F.P. Wei, "Gaseous Hydrogen Embrittlement of lligh

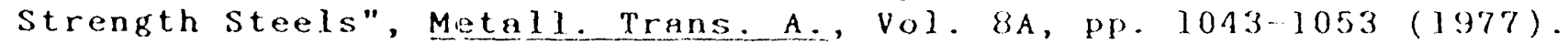

L.F. Coffin and R.P. Gangloff, "Integrated laboratory Methods for Evaluating PCI in Zircaloy-2 fuel cladding", Proc. Conference Water Reactor fuel Performance, pp. 346-355, Amer. Nuc. Soc. (1977).

R.P. Gangloff and R.P. Wei, "Gaseous Hydrogen Assisted Crack Growth In $18 \mathrm{Ni}$ Maraging Steels", Scripta Met., Vol. H, pp. (ibl-6if7 (1974).

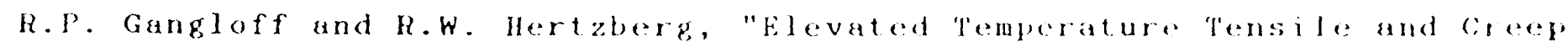
Rupture Behavior of the Unidirectionally Solidified Ni NiaNb Eutectic Composite", Pros. Conf. on In-situ Composites, Vol. 2, pl. 83. 10:3, NMAB, Washington $(1972)$.

K. P. Gangloff, R.W. Kraft and J.b. Wood, "Fiberlesis Heglon l)efects in Unidirectionally Solidified Al-Ala Ni", Met. Trans., Vol. 3, pl. $348-350$ $(1972)$. 
Books edited:

Embrittlement by the Localized Crack Environment, ed. R.P. Gangloff, TMS-AIME, Warrendale, PA (1984).

Basic Questions in Fatigue, Vol. Il, ASTM STP 924, eds., R.P. Wei and R.P. Gangloff, ASTM, Philadelphia, PA (1988).

20th National Symposium on Fracture Mechanics: Perspectives and

Directions, ASTM STP, eds. R.P. Wei and R.P. Gangloff, ASTM, Philadelphia, PA, in press (1988).

Internal Reports:

General Electric - 12

Exxon - 14

Presentations $(1980-1987)$ :

Invited - 38

Contributed - 19

Company Seminars - 14

Consulting:

Naval Research Laboratory

Exxon Kesearch and Engineering Company

Crouse-Hinds

Infilco Degremont

Stephenson and Balthrop, Ltd.

Courses Developed:

The Fracture Mechanics of Engineering Materials

The Physical Metallurgy of Structural Alloys

Short Courses:

Modern View of Fatigue, Union College, 1975-present

Aircraft Design and levelopment, NAVAlR, lysbi-present 
2. Position 6/87 - Present: Vice President, Planning \& Nuclear Safety, GPU Nuclear Corporation, One Upper Pond Road, Parsippany, NJ 07054.

3. Degrees: B.S., Electrical Engineering, Bucknell University, 1958

M.S., Nuclear Engineering, Purdue University, 1959

Ph.D., Nuclear Engineering, Purdue University, 1962

4. Training/Setininars

Numerous Technical and Educational Short Courses/Seminars

Sone recent programs include:

- EEI Executive Management Program (4 weeks) 1982

- Utility Finance \& Accounting Workshop (3 days) 1986

- Teamwork and Leadership Seminar (6 days) 1986

5. University of New Mexico Service: 13 years

1965-1968: Assistant Professor of Nuclear Engineering

1968-1973: Associate Professor of Nuclear Engineering

1973-1978: Professor of Nuclear Engineering

1972-1974: Assistant Dean, College of Engineering

1974-1975: Acting Chaiman, Chemical \& Nuclear Engineering Department

1975-1978: Chaiman, Chemical \& Nuclear Engineering Department

6. Other Work Experience - research, industrial, etc.:

6/87-Present: Vice President, Planning \& Nuclear Safety, GPU Nuclear Corporation, One Upper Pord Road, Parsippany, Nu 07054.

1992 - 1987: Vice President, Nuclear Assurance Division, GPU Nuclear Corporation

1930 - 198: Director, Training \& Education, GPU Nuclear Corboration

1979 - 1980: Director, Reliability Engineering, GPIJ Service Corporation, Parsippany, NJ

1313 - 19;: Manager, Generation Productivity Department, Gell Service Corporation, Parsippany, N.J

1970 .. 19\%: Sabbatical ieave - Project Engineer, Electric Power Research Institute

1970-1971: ASEE - Ford Foundation Resident Fellow, Associate Rractor Engineer. Indian Point Nuclear Power Station, Con Idison of Hew York, Inc.

1965 - 196: Research participant in the field of fast burst reactor reflector effects and high yield hurst reactors, one-hilf time at Sandia Corporation

$1900-1907$ : leave of absence from UNM - Research Associate. Nuclear Research Division, Atomic Weapons Research [stablishment, Aldenteston, Berkshire. England

1as - lgt: :5-14, Civil Service, Reactor Specialist, Nuclear lffects Branch, white Sands Missile Range, New Mraxico 
Pobert L. Long - Resume

Page 2

6. Other Work Experience -. research, industrial, etc.: (cont'd)

1962 - 1964: 1st Lt., U.S. Army, Nuclear Effects Engineer, Reactor Specialist, Nuclear Effects Branch, White Sands Missile Range, New Mexico

1960 - 1962: Student Research Associate, Argonne National Laboratory, Argonne, Illinois

Sumer 1960: Instructor and technical reader, Purdue University, Lafayette, Indiana

7. Consulting:

1981 - 1987: Argonne Universities Association Review Committee for Division of Educational Progra is at Argonne National Laboratory

1981: National Research Council, Assembly of Engineering, Nuclear Manoower Committee

1979 - 1980: National Science Foundation Review Committee for Engineering Chemistry and Energetics

1977 - 1979: Consultant to Nuclear Engineering \& Operations Department, Electric Power Research Institute, Palo Alto, California

1976: Lecturer overseas (Southeast Asia) for U.S. Information Agency

1973 - 1978: Consultant to U.S. Department of Energy (formerly ERDA and USAEC) on Citizen's Workshops on Energy and the Environment

1971 - 1978: Occasional consultant for utilities and other universities on public education aspects of nuclear energy

1971 - 1973: Consultant on Power Reactor Operator Training to General Physics Corporation, Columbia, Maryland

1965 - 1973: Part-time consultant to Fast Burst Reactor Facility, white Sands Missile Range, New Mexico

8. Scientific \& Professional Societies of Which a Member:

- .unerican Nuclear Society (have held numerous responsibilities on national and division committees)

- U.S. Council for Energy Awareness

- Not presently active in sigma $x_{i}$, AAAS, AIChE, ASEE

9. Honors \& Awards:

1958 - 1959: USAEC NuClear Engineering Fellowship

1974 - 1975: Chaiman, Education Division, American Nuclear Socicty

1975 - 1970: Chaiman, Nuclear Engineering Debartment Heads Committee

1980

Als 25 th Anniversary Exceptional Member Award

10. Pescribtion of Professional Experience:

$\rightarrow$

a. $6 / 87-$ Present:
On June 1, 1937 l was reassigned as Vice President and Director of the newly created Planning \& Nuclear Safety Uivision, Gle Nuclear Corporation. This Uivision incluctes the Licensing \& Regulatory Atfairs, Comporate Planning, Nuclear Safety Asses sment and Risk Management Departments. 
P.obert L. Long - Resume

Page 3

\section{Description of Professional Experience (cont'd)}

The new Division is expected to broaden and raise the level of nuclear safety/risk assessment, and provide increased interest in and understanding of nuclear safety issues within GPU Nuclear.

b. 4/82 - 5/87: On April 1. 1982 I was elected VP \& Director of the Nuclear Assurance Division, GPU Nuclear Corporation, which included the Quality Assurance, the Nuclear Safety Assessment, Training \& Education, and Emergency Preparedness Departments. I also served as Acting Director of this Division from February - September 1980.

c. 2/80 - 3/82: Director, Training \& Education, GPU Nuclear Corporation, Parsippany, NJ. I had responsibility for the direction of Corporate, TMI-1. TMI-2, and Oyster Creck Training Departments, and the System Laboratory.

d. 8/79 - 1/80: Director, Reliability Engineering, GPU Service Corporation, Parsippany, NJ. I was responsible for the direction of five functions providing technical support to the TMI Generation Group and the three GPU operating companies. These functions included Quality Assurance Department, the System Laboratory, the Information Management Department, the Nuclear Safety Assessment Department, and the Generation Operations Support staff.

e. 4/79 - 7/79: Member of TMI-2 Recovery Team. Arriving on site Harch 29, 1979, I had varied responsibilities including organization of the Data Reduction and Management Group, head of the Accident Assessment Documentation Team and Supervisor of the Technical Planning Group. I also was appointed to the GPU Accident Investigation Task Force.

f. 6/78 - 3/79: Manager, Generation Productivity, GPU Service Corporation, Parsippany, N.J. I was responsible for the staffing and program development of the newly-formed Generation Productivity Department. Activities included the development of an availability improvement program for implementation throughout the GPU System. The program was concer ad with total plant performance for all fossil and nuclear units.

9. 1965 - 1978: Faculty member, Nuclear Enginesring Department, University of Hew Mexico. Except for the two leaves-of-absences in 1966-1967 and 1970-1971, and a sabbatical leave in 1976-1977 I was actively engaged in teaching and research, primarily in experimental reactor physics. Juring 1965-1968 I was engaged in half-time research at sandia Laboratories and served as Project tongineer for the design of the SPR-1I, fast burst reactor. During 1967-1969, adain half-time. I participatad in the design and carrying out of experiments to characterize the dynamic behavior of 
Robert L. Long - Resume

Page 4

10. Description of Professional Experience (cont'd)

SPR-II. During 1969-1970 I directed a campus fast reactor physics experimental facility and directed the Ph.D thesis of $C$. C. Price on reflector effects on fast burst reactors.

I was a licensed Senior Reactor Operator on the UNM AGN-201M training reactor, 1967-1978, and served as Chief Reactor Supervisor. 1968-70 \& 1973-76 - In 1969-70 I supervised the move of the reactor into a new laboratory, the complete redesign and assembly of the nuclear instrumentation and control system, and an increase in maximum operating level from 0.1 to 5 watt. I served as Director of the Nuclear Engineering Laboratories, 1971-1976.

During 1972-1974 I served as Assistant Dean (half-time) of the College of Engineering. During that time period I also served as principal investigator for a contract with Consolidated Edison Company of New York to analyze axial xenon redistribution and power shaping in large pressurized water reactors. Under contract with the USAEC, I also developed two "neighborhood TV short courses" on nuclear energy and energy and the environment for use in public education efforts.

Effective July 1, 1974 I was appointed Acting Chairman of the Department of Chemical and Nuclear Engineering, and in February 1975 I was appointed to a four-year term as Department Chairman to begin July 1, 1975.

From 1974-1976 I supervised the design, development and on-campus installation of a fossil power plant simulator (Ph.D dissertation for R. Busch) under sponsorship of the New Mexico Energy Resources Board and Public Service Company of New Mexico.

From 1977-1978 I served as principal investigator on a project, sponsored by the New Mexico Energy Iristitute, to detemine generally accepted pre-activity background levels for radon in the very active uranium mining and milling Grants/Ambrosia Lake area of New Mexico.

Together with M. J. Ohanian, University of Florida. I worked as a representative of the Nuclear Engineering Department Heads Committee to increase the support of government sponsored energy R\&D in university engineering colleges. This activity included successful introduction through the U.S. Senate of education support amendments to the 1974 (RPA and 1977 Dor. Authorization ACts. It also included organization of university/government exchange meetings with USAEC, ERDA, and NRC, and an LPRI/University exchange meeting. 
Pobert L. Long - Resume

Page 5

10. Description of Professional Experience (cont'd)

My teaching was centered around the development and presentation of effective laboratory courses, while also periodically teaching the following lecture courses: Introduction to Nuclear Engineering, Applications of Nuclear Energy for Non-Engineers, Reactor Kinetics and Control, Nuclear Systems Design.

h. 1976 - 1977: On Sabbatical leave with the Electric Power Research Institute, Palo Alto, California. During my 12-month sabbatical I worked as a project engineer in the Nuclear Engineering and Operations Department with responsibility for managing projects in availability engineering and development of an "optimized" utility power systems data base. I also supervised and worked with an EPRI contractor to complete a PWR steam-generator performance survey. These various projects provided an opportunity to visit and closely interact with many utility, manufacturer, and government agency personnel.

i. 1977 - 1979: Consultant, EPRI. Upon return to the UNM campus, I continued as as an EPRI consultant to monitor reliability data base and records management projects. I also coordinated the conduct of an EPRI Availability Engineering Workshop held in Albuquerque in October 1977. While with GPUSC I have continued as consultant to EPRI on availability engineering programs.

j. 1971 - 1972: Consultant, General Physics Corporation. I rewrote the Reactor Engineering Volume of the General Physics Corporation "Academic Program for Nuclear Plant Personnel."

k. 1970 - 1971: ASEE-Ford Foundation Resident Fellow, serving as Associate Reactor Engineer with Con Edison of New York, Inc. During my 13-month assignment I was involved primarily in the coordination and planning of the repairs to the Indian Point Unit \#1 primary coolant system. I also performed various tasks of the Unit \#1 reactor engineer. I was principal co-author with R. B. Hayman of the Company's initial Quality Assurance program report for Unit \#1. On a few occasions, I also assisted in the training program for the Unit ${ }_{\pi 2} 2$ operators and in the preparation of Unit \#2. procedures.

1. 1966 - 1967: Temporary Research Associate, Nuclear Research Division, Atomic Weapons Research Establishment. During my 14-month assignment I prepared the commissioning schedule for VIPER, Mark I, a fast burst reactor, assisted in the safety analysis and evaluation of the reactor and served as a senior reactor physicist and shift supervisor during the initial startup. I also planned the training progralil and presented some of the lectures for the initial startuo staff. 
Pober: L. Long - Resume

Page 6

\section{Description of Professional Experience (cont'd)}

m. 1962 - 1965: Reactor Specialist (GS-14), WSMR Fast Burst Reactor

Facility. I served as the facility supervisor during the final design, construction, startup, and first year of operation of the FBRF, a fast burst reactor. This included responsibility for training of the staff, monitoring of contractor performance, preparation of the Final Safety Analysis Report, preparation of the startup and operating procedures, and analysis of the reactor physics operational data.

n. 1960 - 1962: Student Research Associate, Argonne National Laboratory. I was trained and certified as a co-operator, operator, and superviur on the Argonne Thermal Source Reactor (ATSR) while performing my doctoral dissertation research. I designed and built a reactivity measuring system for determination of neutron absorption resonance integrals. I also assisted in the training of replacement operators for the ATSR.

11. Principal Publications:

- "An Electrical Analogy of Nuclear Reactor Neutron Flux," with J. R. Eaton, Nuclear Science and Engineering, 12, 82-90 (1962),

- "Precision Limitations in the Measurement of Small Reactivity Changes," with E. F. Bennett, Nuclear Science and Engineering, 17, 425-432 (1963).

- "Operational Characteristics of the WSMR Fast Burst Reactor," Neutron Dynamics and Control, AEC Symposium Series, 7, CONF-650413 (May T966).

- "Measurements of the Physics Characteristics of the Fast Pulsed Reactor, VIPER," with M. H. Taggart et al., IAEA Symposium Series, Fast Reactor Physics and Related Safety Problem, Karlsruhe, Germany, November 1967.

- Reactivity Contributions in the Glory Hole of the Sandia Pulsed Reactor-II," Trans. Am. Nuc. Soc., 11, 1 (1968). Also published in Nuclear Applications, 6, 1 TT969T.

- Fast Burst Reactors, Editor with P. D. O'Brien, Proceedings of the ANS National Topic Meeting on Fast Burst Reactors, The University of New Mexico, January 28-30, 1969, AEC Symposium Series, CONF-690102 (1969).

- "Reflector and Decoupling Experiments with Fast Burst Reactors," with R. L. Coats, AEC Symosium Series, Fast Burst Reactors, CONF-690102 (1969).

- "Prompt Neutron Decay Constants in a Reflected Fast Burst Reactor," with C. C. Price, Proceedings of the Symposium on Dynamics of Nuclear Systems, University of Arizona, March 23-25, 1970.

- "Repair of Themal Sleeve and Primary Coolant Pipe at Indian Point Unit $\# 1$, with D. J. McCormick. Trans. Am. Nuclear Snc., 14 Supplement? (1971).

- "Enviromental Problems Associated with the Repair of a Nuclear Power Reactor Primary Coolant System," with C. L. Liebler, Proceedings of the Institute of Environmental Sciences (May 19/2), pp. 388-392.

- "Courses Alout the Environmerit for Non-Technical Students, "Proccedings of the Institute of Enviromental Sciences, (May 1972), pp. 398-399.

"Educationat Aspects of the Energy Crisis," New Mexico Acadrilly of Science Bulletin, 14, No. 2, DD. 45-48 (Decomber T373). 
P.obert L. Long - Resume

Page 7

11. Principal Publications (cont'd)

- "Status of Nuclear Engineering Education," with M. J. Ohanian, Proceedings of AEC/ANS Nuclear Engineering Department Heads Workshop on Research in Nuclear Power Systems, pp. 2-20, University of New Mexico, TJanuary 1975).

- "A Nuclear Energy Elective for 'Engineers', with J. W. Lucey and R. L. Carter, Engineering Education, 65, No. 7, pp. 752-754, (Apri) $1975)$.

- "Axial Power Shaping in Large Pressurized Water Reactors," with H. M. Jorge and S. N. Purohit, Proceedings of the Second Power Plant Dynamics, Control and Testing Symposium, pp. 25-1 to 25-11, KnoxviTle, (September 3-5, 1975).

- "Proceedings of U.S./Japan Seminar on Fast Pulse Reactors, Editor with S. An and H. Wakabayashi, University of Tokyo, (January T976).

- "Enhancement of Electric Power Plant Reliability Data Systems," with R. J. Duphily, Proceedings of the Fourth Reliability Engineering Conference for the Electric Power Industry, EEI, New York, (June 1977).

- "Methods to Improve Electric Power Plant Availability," Proceedings of the 1977 Power Generation Conference, ASME, Long Beach, CaTifornia (September 1977).

- "Introduction to Availability Engineering," Proceedings of the EPRI Availability Engineering Workshop, Editor, R. L. Long, et al, EPRI Report NP-759-WS (March 1978).

- "Engineering for Availability," with E. B. Cleveland, Power Engineering, 82 , No. 7 (July 197u).

- "Survey of Eiectric Power Industry Data Needs," with E. B. Cleveland, Inservice Data Reporting and Analysis, PVP-PB-032, ASME (December 1978).

- "Three Mile Island Accident Technical Support," with T. M. Crimmins and W. W. Lowe, Nuclear Technology, 54, pp. 155-173 (August 1981).

- "Applications and Development of RAM Information Systems at GPUN," with J. L. Weiser, Proceedings 1979 Reliability Conference to the Electric Power Industry (Apri] 1979).

- "A Post TMI-2 View on the Responsibilities of Nuclear Engineering Educators," 1980 ASEE Annual Conference Proceedings, ASEE, Amherst, MA (June 1980).

- "Use of Behavioral Learning Objectives for Simulator Training," with R. A. Knief, Proceedings of the Society of Applied Learning Technology (September 1981).

- "Operator Training and Requalification at GPU Nuclear," with R. J. Barrett and S. L. Newton, Proceedings of CSNI/OECP/NEA, Charlotte, NC (October 1981), NUREG/CP-0031, Vol 1, pp. 299-313 (June 1982).

- "Nuclear Personnel Training After TMI-2: The GPIJN Response," with D. P. Gaines and R. A. Knief, Progress in Nuclear Energy, Pergamon Press, Vol 10, Number 3, pp 349-36T (798?).

- "Sumary Report of the GPIJ Nuclear TMI-2 Lessons Le irned Workshop," Proceedings of ANS Executive Conference. TMI-2 A Learning Experience (october 13-16, 1985).

- "Emergency Planners, Look Back at TMI-2," Proceedings of AldS Topical Meeting on Radiological Accidents: Perspectives and limeraency Preparedness, CONF-86093?, JSDJE, $47-43$ (March TO87).

"Findan Factors Contributions to fuclear Power Safety: A Progress Report," with .l. Christensen, American Association for the Advancement of science (Ma; 1985). 
kobert L. Long - Resume

Page 8

11. Principal Publications (cont'd)

- "Evolution of GPU Nuclear's Training Program," with R. P. Coe, Proceedings of CSNI Specialist Meeting on Training of Nuclear Reactor Personnel, Orlando, FL (April 21-24, 1987).

- Approximately thirty sumaries in the Transactions of the American Nuclear Society, 1962-present, on various topics including fast burst reactors, power reactor experiences, nuclear engineering, training and educational methods, public education in energy and environment issues, and availability engineering.

- Numerous technical reports on research design and development projects.

\section{Review Committees}

Have served on Review Committees of National Science Foundation, National Academy of Sciences, Electric Power Research Institute, Institute of Nuclear Power Operations and Argonne National Laboratory Division of Educational Programs. Currently serve on Advisory Council of the Nalional Academy for Nuclear Training, the Accreditation Board of Engineering Technology Board of Directors, and the Advisory Committee of the EPRI Nuclear Power Division.

13. ANS Activities

1965-1978: Treasurer, Program Chairman, Executive Committee, Trinity Section

1967-1976: Secretary, Several Committee Chairs, Executive Committee, Education Division

1974-1975: Chaiman, Education Division

1975-1976: Chairman, NE Department Heads Organization

386-1987: Chairman, Northern New Jersey Section

1980:

ANS 25th Anniversary Exceptional Member Award

1974-Present: NE Accreditation Visitor

1983-1986: ANS Alternate Representative to ABET B00

1987-Present: ANS Representative ABET BOD

14. References: Available on request.

15. Personal: Family

- Ann (wife)

Beth (daughter - age 26)

Jeff (son - age 24)

Mark (son - age 20)

other Interests - church school teaching and choir, woodworking, athletics (spectator and participant), reading

Home Address - 104 Brooklawn Drive, Morris P?ains, N. 07950

Telephone - Home: (201) 455-0087

office: (201) 316-7484 


\section{MARTIN PRAGER. PH.D. \\ 125 EAST GTTH STREET \\ MEW YORK. N. Y. 10028 \\ $(212) 634.4270$}

CURRENT TITLE

EDUCATION

AWARDS AND

ACHIEVEMENTS

WORK HISTORY

1978-Present

$1985-$ rerent

$1074-1985$
Materials Consultant

Ph.D. in Materials Engineering--UCLA 1969

Master of Metallurgical Engineering--Cornell 1962

Bachelor of Chellical Engineering--Cornell 1961

AwS Davis Silver Medal for Structural welding (1978)

IEEE Award for Best Substation Paper (1977)

Listed in Who's who in Engineering, who's who in

Technology Today and American Men and bonen of Suience

P.E. Registration

$$
25
$$

More than $20^{\circ}$ years experience including the following: ioo Executiva Materins - Associate Director, The Metal, Properties Council,

Inc, 345 East 47 Strect, New York, NY 10017

- Responsitie for management of programs relating

to toughness, rank propagation, corrosion fatique,

elevated teme "ure properties, and remaining lif́e

analysis.

- Actively involved in computerization of mechanical.

property data for evaluation and analysis for áSME

Codes and Standards work.

- Organizes data collection programs for nuclear

power anci offshore applications.

- Manager of numerous testing programs relating to

hyärogen enbrittlement, stress-corrosion, toughness,

creep and welding of steels.

- Technical Director, pressure Vesscl iesearch

Committee, helaing Research Council, 345 East 47 Street, New York, NY 10017

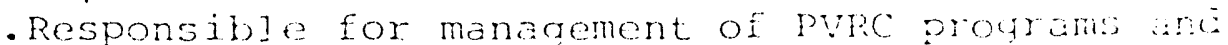

headquartors operations.

- Consultant to major corporatoms and jubusizia

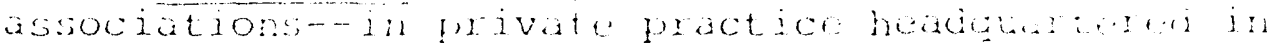

New lork Ciry.

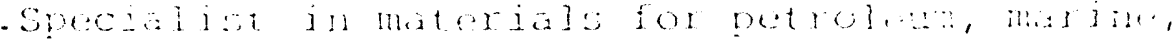

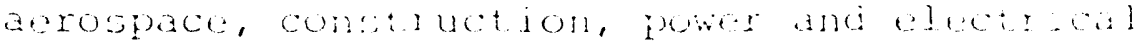

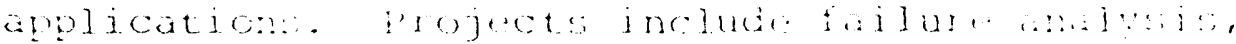

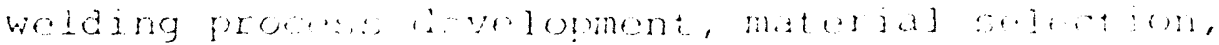

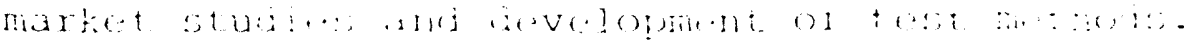

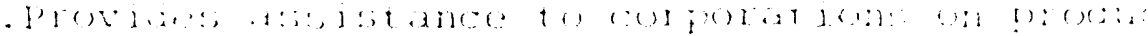

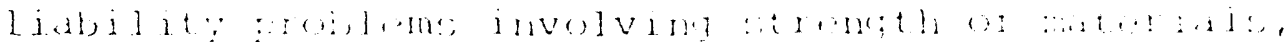

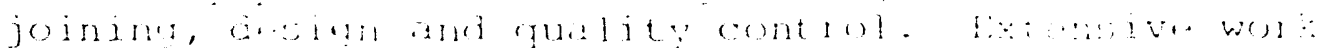

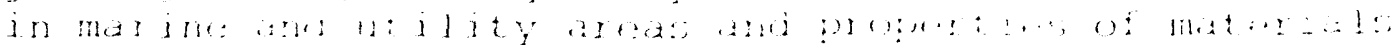

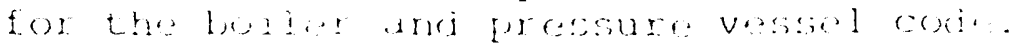

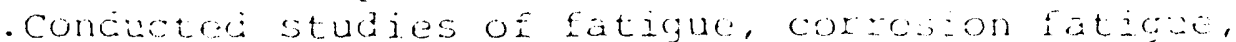

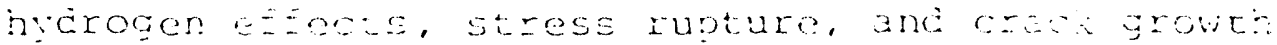

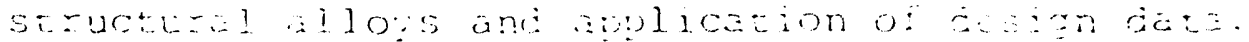


$1969-1974$

$1968-1969--$

$1962-1968--$

INATIONAI ACTIVITIES
-Manar r, Application Engineering--Copper Development Association, 405 Lexington Avenue, New York, N.Y. 10017 -Directed development activities in welding, bonding, coating, soldering, and processing of copper and copper alloys. Evaluated methods of pipe and tube joining and filler metals. Prepared design manuals and technical publications. Planned and administered development contracts. - Provided technical services for problems in performance, fabrication, and selection of copper and copper alloys. Extensive field work in U.S.A. and abroad.

- Supervised welding development, qualification. and on site construction for world's first coppernickel hulled fishing vessels. Developed and implemented design and fabrication innovations. Carried out corrosion and NDT surveys for ship construction projects.

- Completec studies for Ph.D. begun on part-time basis. Dissertation on fracture mechanisms providec solutions to practical problems encountered at prior job.

-Senior Engineer--Rocketdyne Division of Rockwell International, Canoga Park, Caífornia 91304

- Developed heat treatments to optinize strength, ductility, toughness, magnetic response, and weldability, all recognized by NASA publication.

Designed devices for multiaxial stressing and wela testing.

- Identifica previously unknown cause of embrittlement. Experience in analysis of failures due to thermal ano mecharical fatique, stress corrosion, embrittlement, environmental effects and creep.

Served on uetal properties council subcomitcee on corrosion Eatique of propellers AWS Comitites for belaing landbook, Brazing Manual, and Soldering Manal AS: ianduoor Contributor IEeE outoor Substations Welaing Research Council subcommitee on copper ana Coper Alloys Member NACE, ASTH, AHS, ASM, IERE, AlME Member, Afs Special Commitee on Materials 
CURRICULUM VTTAE

ROGER WASHBURNE STAEHLE

22 Red Fox Road

North Oaks, MN 55127

(612) $482-9493$

Telecopier (612) 484-5735

Vital

Residences: Detrojt, Michigan

Toledo, ohzo

Colunbus, Ohio

Washington, D.C.

pittsburgh. Pennsylvania

Columbus. Ohio

Twin Cities, Minnesora
$1934-1935$

$1935-1937$

1937-1957

$1957-1961$

January-June. 1959

1961-1.979

1979-Present

\section{Education}

- B. Met. Engr. The Ohio State University, 1957

- M.S. Met. Engr. The Ohio State University. 1957

- Westinghouse Reactor Eagineering School. (6 months). 1959

- Ph.D., The Ohio State University. 1965

Employment

Naval officer and Nuclear Engineer with United States Navy and Atomic Energy Conmission (with Vice Admiral H. G. Rickover). Naval Nuclear Reactor Development. 1957-1961

- Graduate Scudent, Research Associate, and International Nickel Fellow. The Ohio Stare University, 1961-1963

- Graduate Student, Research Associate, and Batcelle Fellow. The Ohio State University, 1963-1964

- Assistant Professor. The Ohio State University, 1965-1967

- Associate Professor. The ohio State University. 1967-1970

- Professor. The Oh10 State Universicy. 1970-1979

- Director. Fontana Corrosion Center. 1975-1979

- Dean. Instituce of Technology, University of Minnesota. 1979-1983

- Professor. Chemacal Engineering and Materials Science. Institute of Technology, University of Minnesota, 1983-1938.

- President \& Chairman. Automated Transportation Systems. Inc. (now Taxi-2000) Minneapolis. 1984-1986. (On leave from Universicy of winnesota)

Industrial Consultant. North Oaks. HN. 1986-Present (On leave from University of Minnesota) 
Consulting

Artive

Anerican Nuclear Insurers: Baker \& Mckenzie: Carlisle Rubber:

Carolina Power \& Light; Davy Mckee; Dow Chemical U.S.A.:

Furnas Nuclear Project: Lawrence Livermore laboratories:

Manta \& Welge; Miller. Canfield, Padiock, and Stone; Newman \&

Holtzinger: Nuclear Elecrzic Insurance, Lid.; Nuklearna

Elektrarna Krsko: Rivkin. Radler. Dunne, and Bayh; Robbins,

Zelle, Larson \& Kaplan; San Diego Gas \& Electric: Shaw, Piteman.

Potts \& Teowbidge: Southern California Edison; UPPSS;

Inactive:

AEC; Allied General Nuclear Services; Alyeska; American

Association of Railroads: American Institute of Chemical Engineers:

Antinow \& Fink: Apache Corporation; Arizona Nuclear Power Project;

ARPA-DOD; Babcock \& Wilcox; Batcelle Columbus; Batcelle

Northwest; Bechtel; Betris Atomic Power: Bonewitz; Borg Warner;

City of Austin. South Texas Project: Columbia Nitrogen; Commonwealth

Edison: Consumers Power: Convair; Cozen. Begier, \& O'Connor;

Electric Power Research Institute: Eltech, Division of Diamond

Shamrock; EPCO; Florida Power \& Light; General Dynamics; General

Electric, Evendale; General Electric, Schenectady: General Public

Utilities; Gulf States Utilities; Haight, Dickson, Brown \& Bonesteel:

Illinois Tool Works; International Nickel Company; Iowa Electric Lighe

\& Power: Isham. Lincoln \& Beale: Knolls Atomic Power Lab; Leonard.

Street \& Deinard; Lowenstein, Newman, Reis \& Axelrad; Luce, Forward, Hamilton \& Scripps: $3 M$ Company: McGraw-Edison: Mead Paper; Midwest Research Institute; NUS Corporation; New Brunswick Power \& Light: Northeast Utilities; Northwest Area Foundation: Oak Ridge; Olin Corporation: Owen Illinois: Paclfic Gas \& Electric; Packer Engineering: Parameter Inc.: Quarles \& Brady: Reuten \& Proctor; Rexnord; Richards Manuacturing Comany; Ric-wil: Rockwold

International: San Jose Technology cencer; Sandia laboratories; SCy Corporation: Shell Development: Solax Energy Research Institute: Steel. Hector, Ex Davis: Texaco; The Williams Company: Thiokol; Todal Shipbuilding; TVA; Union Camp; Union Carbide (Paducah Enrichment Ilant); Vandeverer, Garzia, Tonkin, Herr, et al. : Varnum, Riddering, wierengo bo Chriscenson; Westinghusse; Wisconsin klectric. 


\section{Board Memberships, Advisory Comnitrees, Commissions:}

Automated Transportation Systems, Inc., (now Taxi-2000)

Board of Directors, Co-Founder, Corporate Secretary. President. Chairman, 1983-present

The Charles Babbage Institute, Trustee, 1979-1983

Citizens League. Board Member. 1982-1984

Data Card Corporation, Board Member, 1979-1983

Donaldson Company. Inc., Board Member 1979-1983

First Midwest Venture Capital. Technical Advisory Comnittee, $1980-1982$

Great Northern Iron Ore properties, Trustee, 1982-present

Minnesota Allianca For Science, Advisory Comintee and Founder, $1982-1985$

Midwest Research Institute, Board Member, 1979-1.982

Minnesota Comission For Educational Excellence. 1983-1986

Minnesota Cooperacion Office. Board Member, 1979-1983

Minnesora High Technology Council, Board Metiber and Co-Founder, $1982-1983$

Minnesora Wellspring. Board Member and Co-Founder, 1981-1983

North Star (Research Corporation) Board of Directors. I981-1983

Packer Engineering, Board Member, 1981-1987

Teltech Resource Nerwork. Eoard Member and Founding Menber. $1984-1987$

Department of retallurgical Engineering. The Ohio State University, Advisory Comnitree 1987-present

\section{Honors}

- National Acadeny of Engineering, 1978

- Incernalional vickel Professor of Corrosion Science and Engineering, $1971-1976$

Hillis Rodney thitney Award from NaCE for Outstaring Contributions to Corrosion Research, 1980

AS4 Fol10\%, 1975

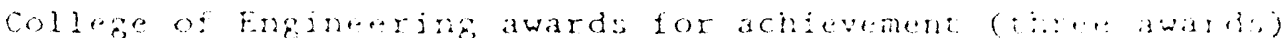
1966,1969, and 1970

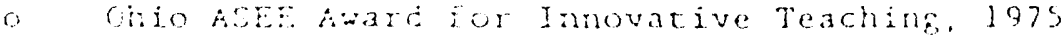

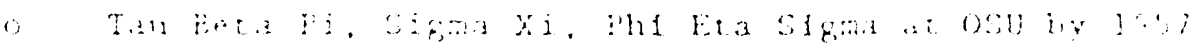

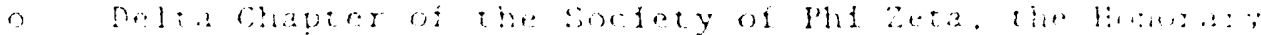

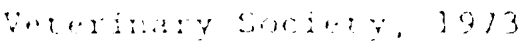

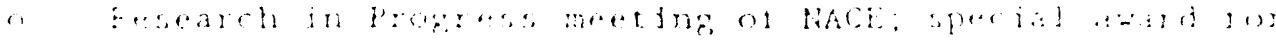

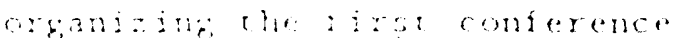




\section{Societv Memberships, Present}

Electrochemical Society

- Corrosion Division, 1972-preserte

- Secretary-Treasurer. 1972-1973

- Vice Chairman, 1974-1975

- Chairnan, 1976-1977

American Society for Metals

- Corrosion Oxidation Committee Chairman, 1973

- Ecitorial Policy Committee, 1979-1981

Niational Association ö Corrosion Engineerir.E

- Fesearch Committee, 1969-1981

Vice Chairman. 1972

o Interntional Relations Committe, 1973-1981

Society Memberships. Past

American Institute of Metallurgical Engineers

American fiuclear Society

American Society for Testing \& Materials

Federation of Materials Society

o Conservation Committer, Chairman, 1978-1981

o Comilee lo Develop a Materials Collection with the Smithsonian Institution, 1978-1981 
Accomplishments as Dean of the Institute of Techmology. University of: Minnesota.

- Co-founded and co-developed major collaborative linkages between the Institute of Technology and the community through the Minnesoca High Technology Council. Minnesota hellspring. and the Alliance for Science. Outside collaborating organizations included technological, banking/Iinancial, Governor and Governor's Office, Legislative, Labor bnions, public sector, a-12 schools. liberal arts colleges in the unnesoca region, and other colleges within the lingueriay.

0 Organized or co-organized. with appropriate iaculiy, the following collaborative University-community (incisiry) centers:

- Charles Babbaze Institute

- Microelectronic and Information Sciences Center (MEIS)

- Corrosion Center

- Producivity Center

- Institute for Mathematics and IEs Applicaions (IMA)

- Biocechnology Center

o

Organized collegiate development progran for the Institute OE TEchnology: raised approximately $\$ 12$ million fron private sources for the Institute of Technology

o

Organized and initiaced the Corrosion Center at the Institute of Technology and brought funds to the lniversity or Minnesota at the rate of 1 million per year starting in 1979. Continuous funding to 1987 by Department of Energy.

○

With sudents, organized and extended najor undergaduate extracurricular programs

Chat of University of Minnesota Consolinkad Fuad Drive, 1282

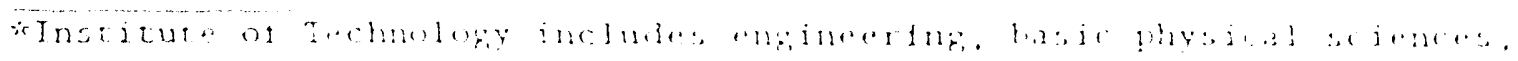

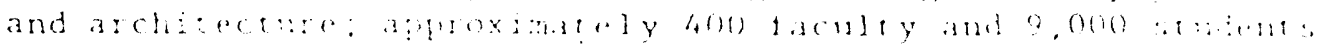




\section{University Participation at Ohio State University}

- Responsible for $\$ 6.0 \times 10$ in research incone at ohio State Universicy including largest industrial grants obtained by OSU proressor: Edison Electric Institute. $\$ 1$ million in 1972: $\$ 1.7$ million in 1975 from Electric Pow Research Institute; $\$ 2.3$ million in 1978 from El -tric Power Research Institute Teaching and Learning Task Force, 1970-1974

- University Research Committee, 1969-1972

o College of Engineering Research Commitcee, 1969-1973 and $1978-1979$

o Ad Hoc Faculty Comitcee for Development of Recreation Facilities, $1969-1972$

- Organized joint Progran with English Department to Develop Direct Teaching of English in Engineering Classes, 1974-1978

o University Comittee on Patents and Copyrights, 1973-1975

o Co-organizer of Joint Seminar Program Between History and Metallurgical Engineering Departments, 1973-1978

$\circ$

Menber, Blo-Engineexing Coordinating, Comnittee, 1971-1978

Developed Fontana Research Center at The Ohio State University

Developed research group of approximately 40 which included: full-ime research staff, professional co-workers, senior technicians, visitimi srintists, industrial fellows, post doctoral students, graduate students, undergraduate assistants, administrator, and secretaries. Puilt laboratories including $\$ 1$ mill fon of high pressure high temperatum, electrochenical equipant.

Areas studied wrete tollowilg:
o Corrosion and pissingir

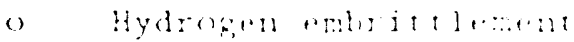

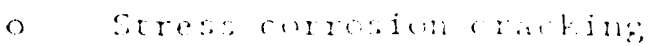

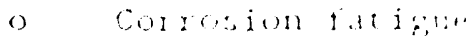




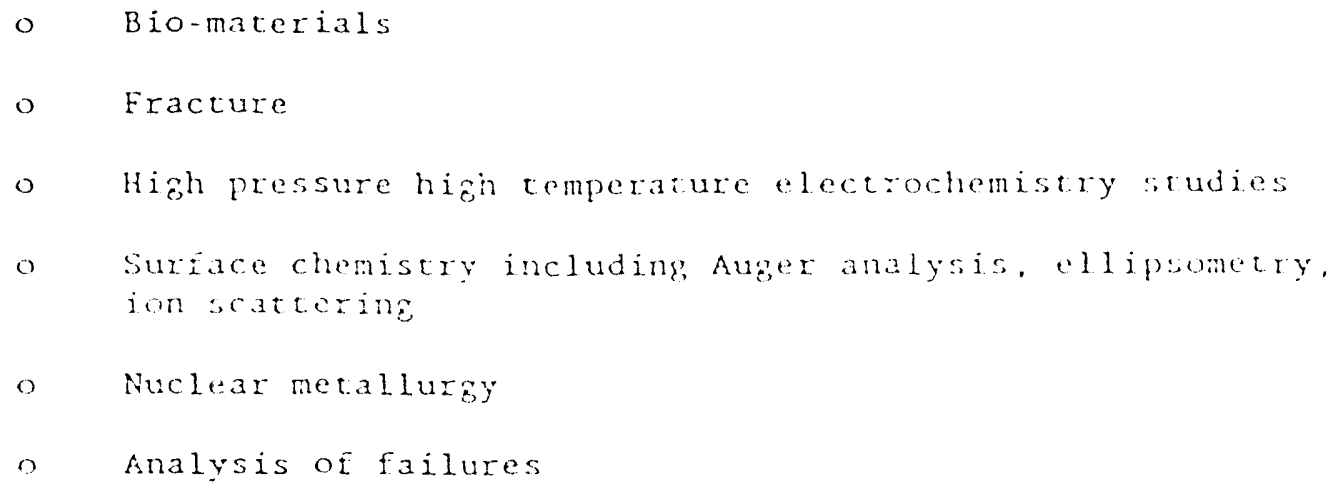

$\circ$ Analysis of failures

Also conducted interdisciplinary research progran with Department of Veterinary Medicine and Department of Orthopaedics on materials for orthopaedic implants

College Teaching at Ohio State and University ö Minnesota

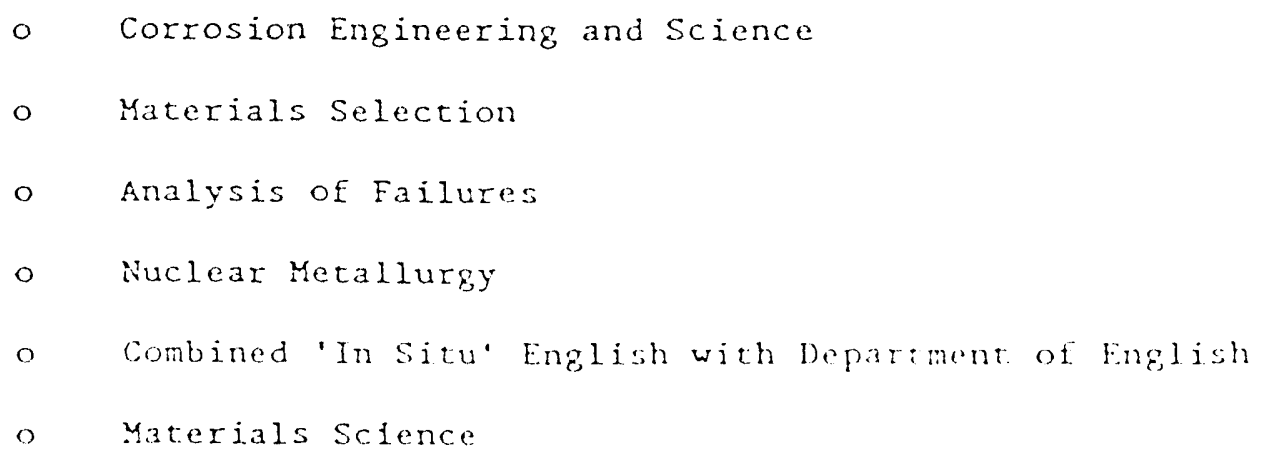


Post Graduate Education (Short Courses): Organizer and Major Promoter of Following:

- Corrosion of Engineering Materials Short Course given at OSU, 1966-1979. given seven times. ic

o Stress Corrosion Cracking short Course given at OSU, 1967 . 1979. given four timesix

- Corrosion Short Courses given on site at International Nickel. Olin Mecals, Convair, and General Electric

o Corrosion Short Course sponsored by AIChE twice pez year through 1935

- Advanced Aqueous Corrosion Short Course given at osu in $1968 *$

o Chemical Scability ó Engineering Materials Short Course given twice per vear for liCIA and for the continuing, Education Institute througn 1979

0 Seminars for Flectric Power Research Institute:

- Inconel. 1974

- Condenser. 1975

- Decontamination, 1.975

\section{General Activities and Accomplishments}

- Chairman and Organizer of Eirst Research in Progress Program, NACE, 1967

- Editor, Corrosion Journal, 1973-1979

O Co-Editor with the late M. G. Fontana and Co-Founder of Advances in Corrosion Science and Technology. Plenum Press. $1970-$ present

o Editor, llandbook on Strcs Corroston Caacking and Corrosion Fatipue of Metala, in prones:

o Chaiman, U.S.A. Coryosion Delegition to U.S.S.R. in Sovember 1975

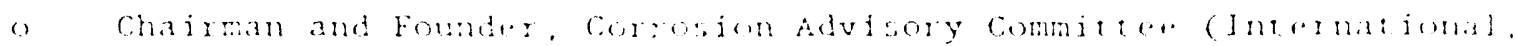

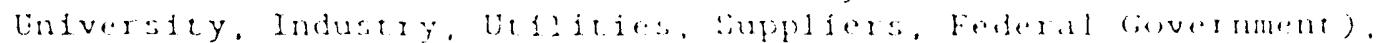

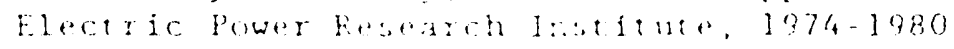

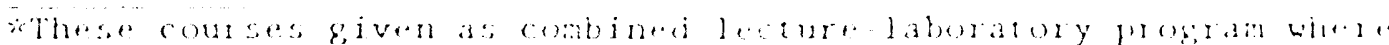
students at tend lectures hald aly and combat gulded laturatory

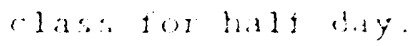




\section{General Activities and Accomplishments (continued):}

- Chairman, Shipboard Incinerator Materials Development, National Materials Advisory Board, NRC, 1975-1977

Chairnan, Advisory Panel, Metallurgy Division, National Bureau of Standards, 1975-1977

Member, Panel for Katerials Research, National Bureau of Standards, $1976-1978$

Chairman and organizer of International Conerences:

- Fundamental Aspects of Stress Corrosion Cracking, osU, 1967

- Localized Corrosion. Williamsurg, VA, 1971

- Corrosion Fatigue: Chemistry, Mechanics, and Microseructures, University ol Connecticut, 1971

- High Temperature High Pressure Electrochemistry or Aqueous Solutions, University of Surrey, England, 1973

- Stress Corrosion Cracking and Hydrogen Enbrittlement of Iron Base Alloys, Firminy, France, 1973

- Materials Problems and Research Opportunitio in Coal Conversion, OSU, 1974

- Passivity and Its Breakdown of. Iron and Iron Base Alloys, Honolulu, 1975

- Firse U.S. -Japan Symposium on Corrosion problems in Light Water Reactors. Mt. Fuji, Japan, 1978

- Reliability of Materials for Solar Energy Systems. Solar Energy Research Institute, Colden, Colorado, 1978

Member. Editorial board o: Surace Ecience Magarne, 1979-1984

Menber Advasory Conmitere to Sandia laboratory on extraction ol energy from mapina sources

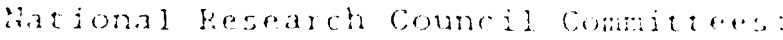

HIPP - Panel on haste loolat fon Pilot Plant 1979-1989

Fus-2 - Panel on bualuaton ot ihe tug-2 Waste

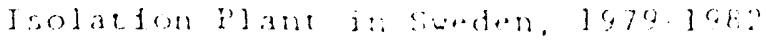


Gereral Activities and Accomolishoent: (continuod):

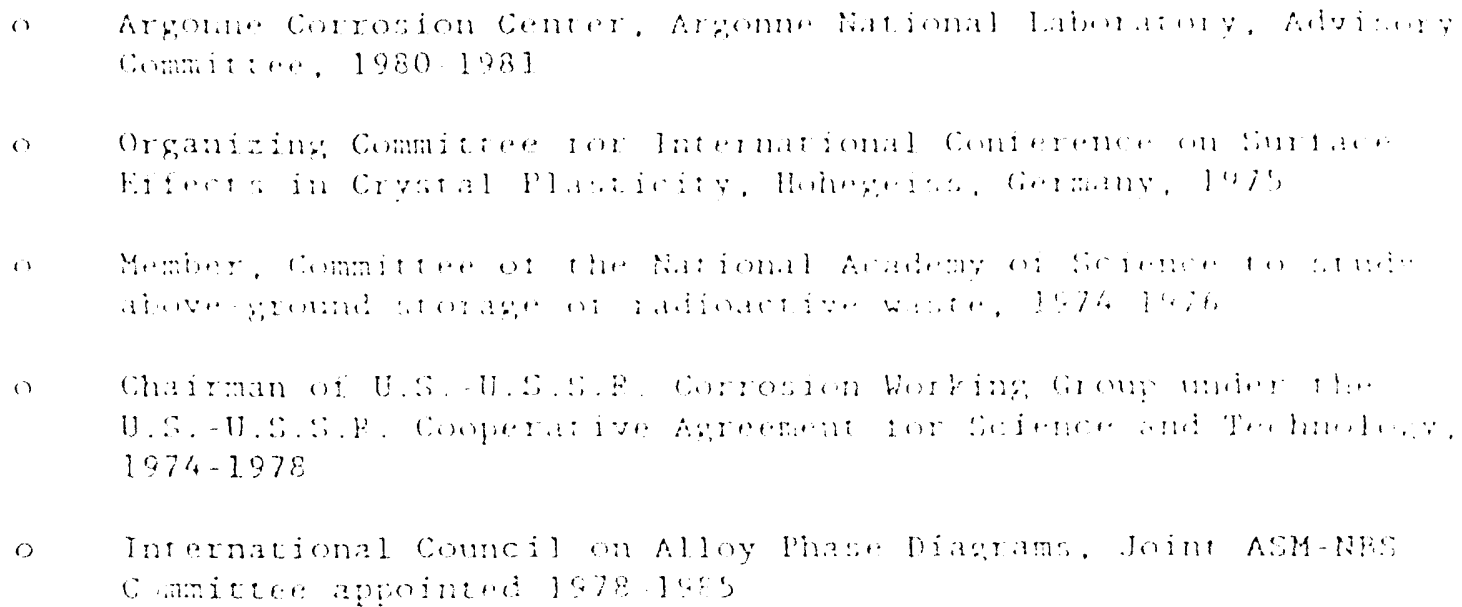

\section{Foreign Conirats}

Lectured in and collaborations with workers in the following romta ies:

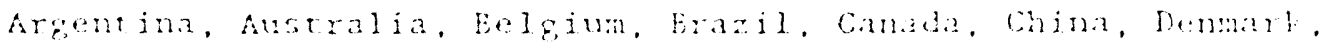

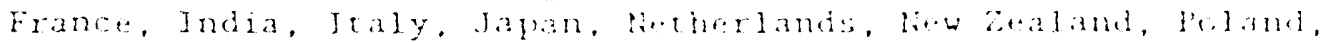
Portugal. Sweden, Union of Somta Atrica, B.S.S.R., United Fingina, west Gevany 
Appendix $C$

Suggested Revisions to the Selection Criteria 
Selection Criteria Peer Review Panel Comments

\begin{tabular}{|c|c|c|c|c|}
\hline Item No. & Page No. & Panel Comments & Author Reply & Panel Response \\
\hline$i$ & $\bar{z}$ & 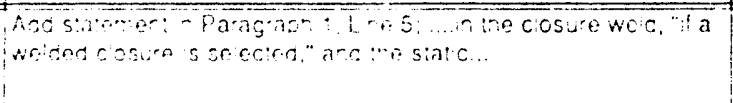 & Accept with minor text moctication. & \\
\hline 2 & 2 & 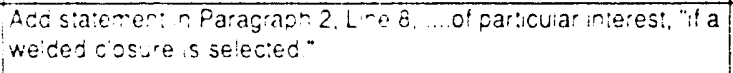 & Addressed in liem 1 & \\
\hline 3 & 3 & 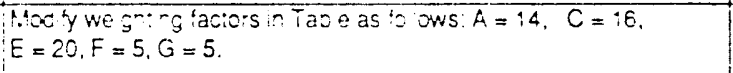 & Accept recommendation. & \\
\hline 4 & 3 & 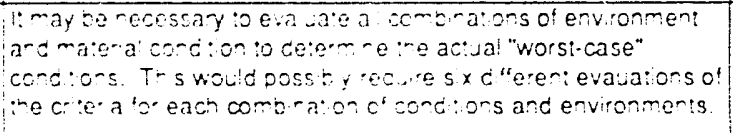 & 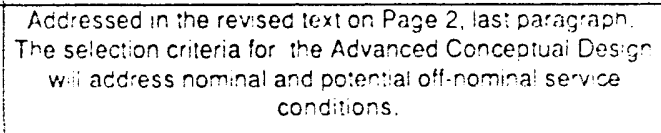 & \\
\hline 5 & 4 & 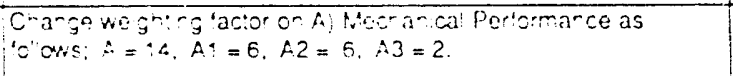 & Accept recommendation. & \\
\hline 6 & 4 & 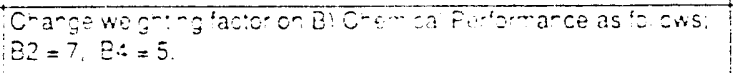 & Accept recommenca:o & \\
\hline
\end{tabular}


Selection Criteria Peer Review Panel Commenis

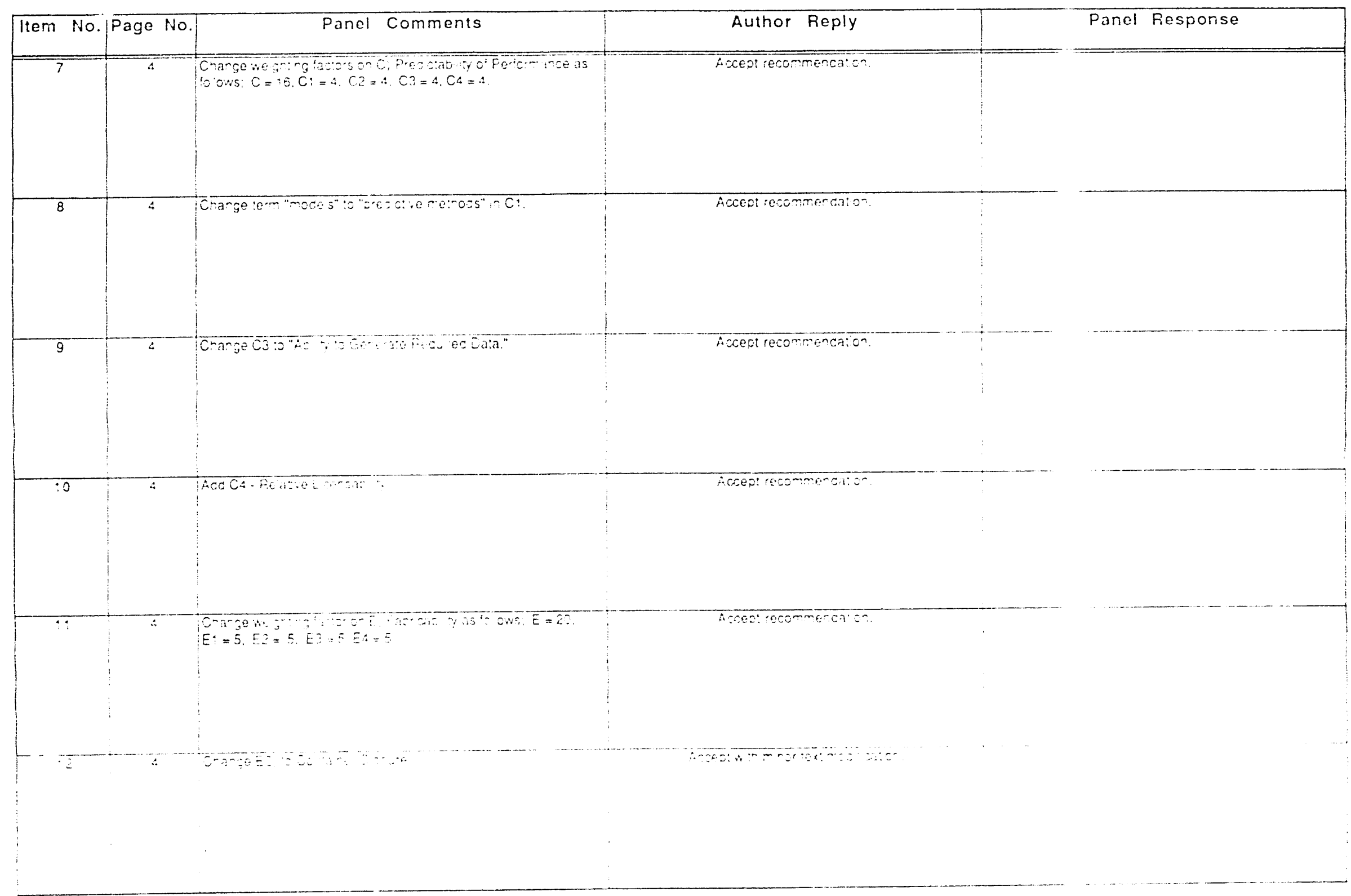


Selection Criteria Peer Review Panel Comments

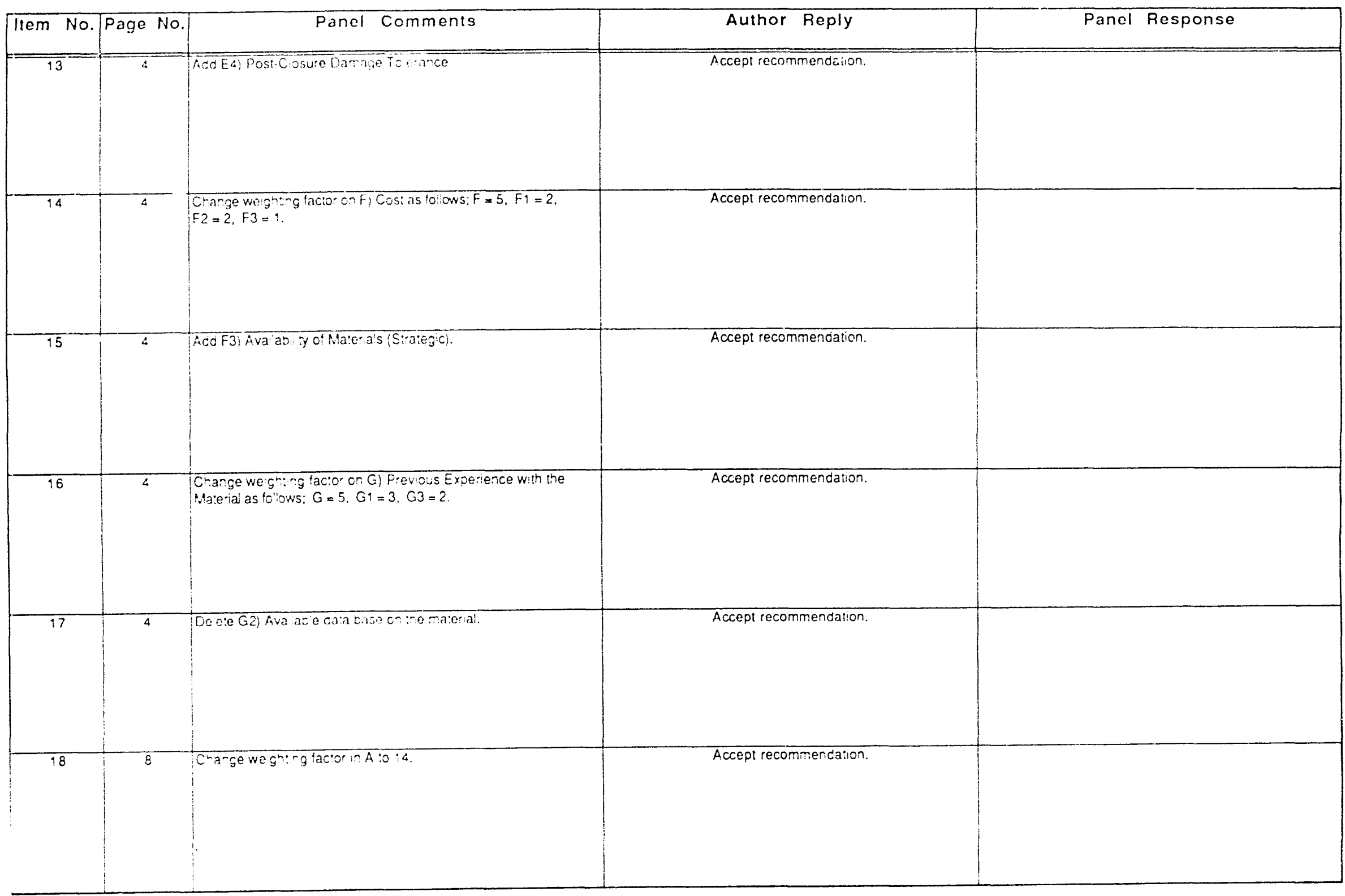




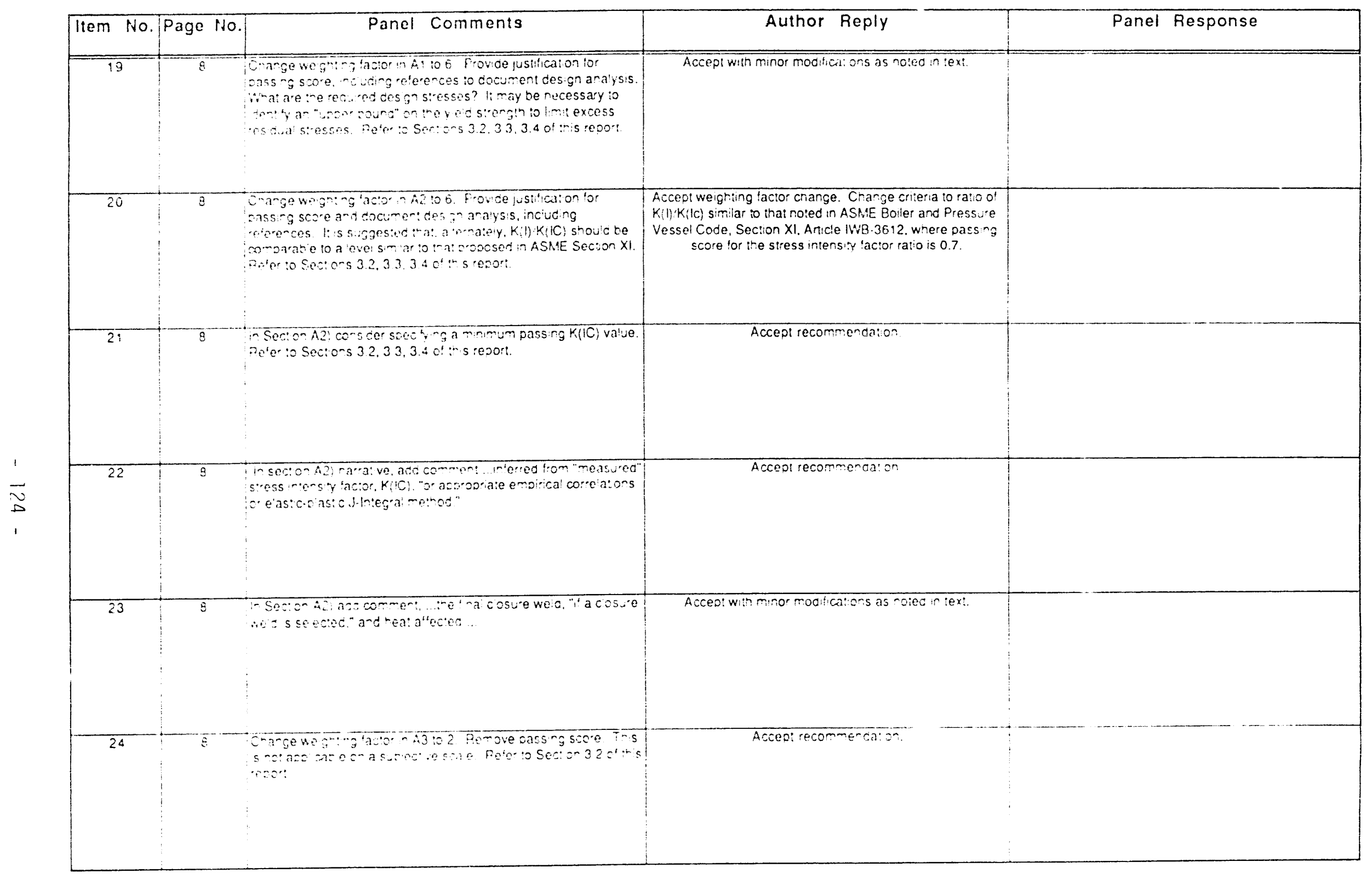


Selection Criteria Peer Review Panel Comments

\begin{tabular}{|c|c|c|c|c|}
\hline Item No. & Page No. & Panel Comments & Author Reply & Parel Response \\
\hline 25 & 8 & 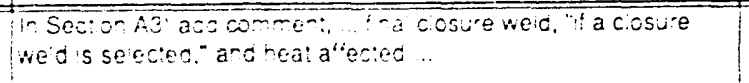 & Accepi with minor modications as noted in text. & \\
\hline 26 & 9 & 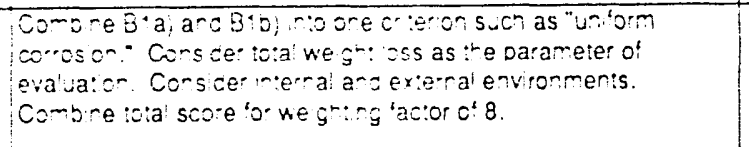 & Accedt w:th minor modtications as noted in text. & \\
\hline 27 & .0 & 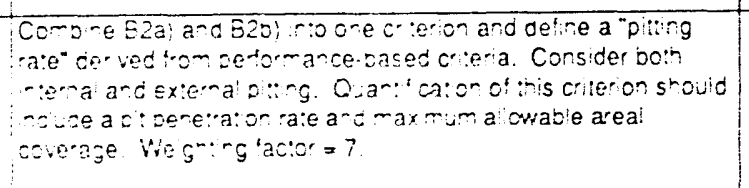 & $\begin{array}{l}\text { Acced with explanation (ciscussion) in test of revised } \\
\text { criteria. }\end{array}$ & \\
\hline 28 & $: 0$ & 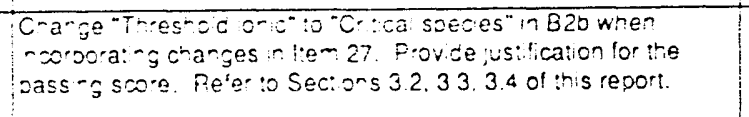 & Accepi win minor mooticatons as roled in ext. & \\
\hline 29 & & 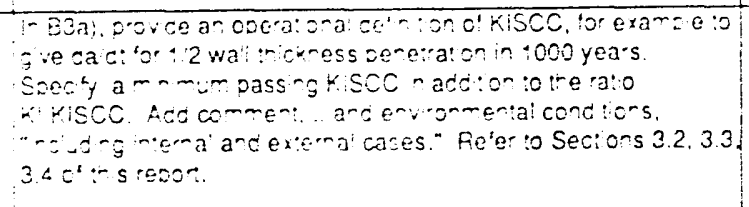 & $\begin{array}{l}\text { Fecet Partaly Soeclicalion of a minmum passing KiSCC } \\
\text { would dedend on the individual cand daie maier at. }\end{array}$ & \\
\hline 30 & & 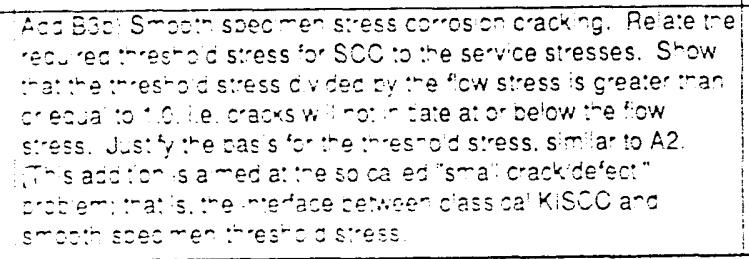 & Accept with moc fica: ons. & \\
\hline
\end{tabular}




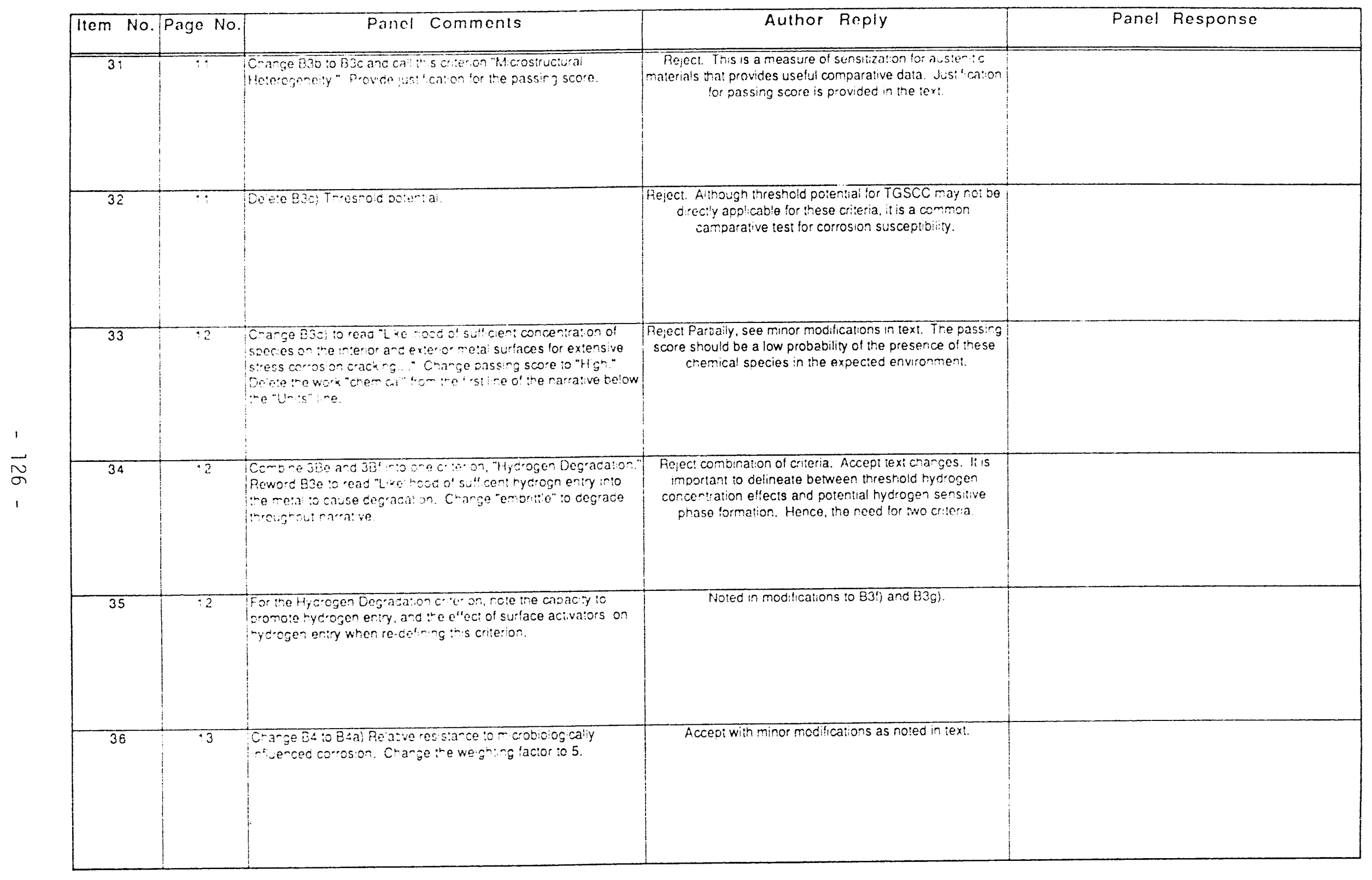


Selection Criteria Peer Review Panel Comments

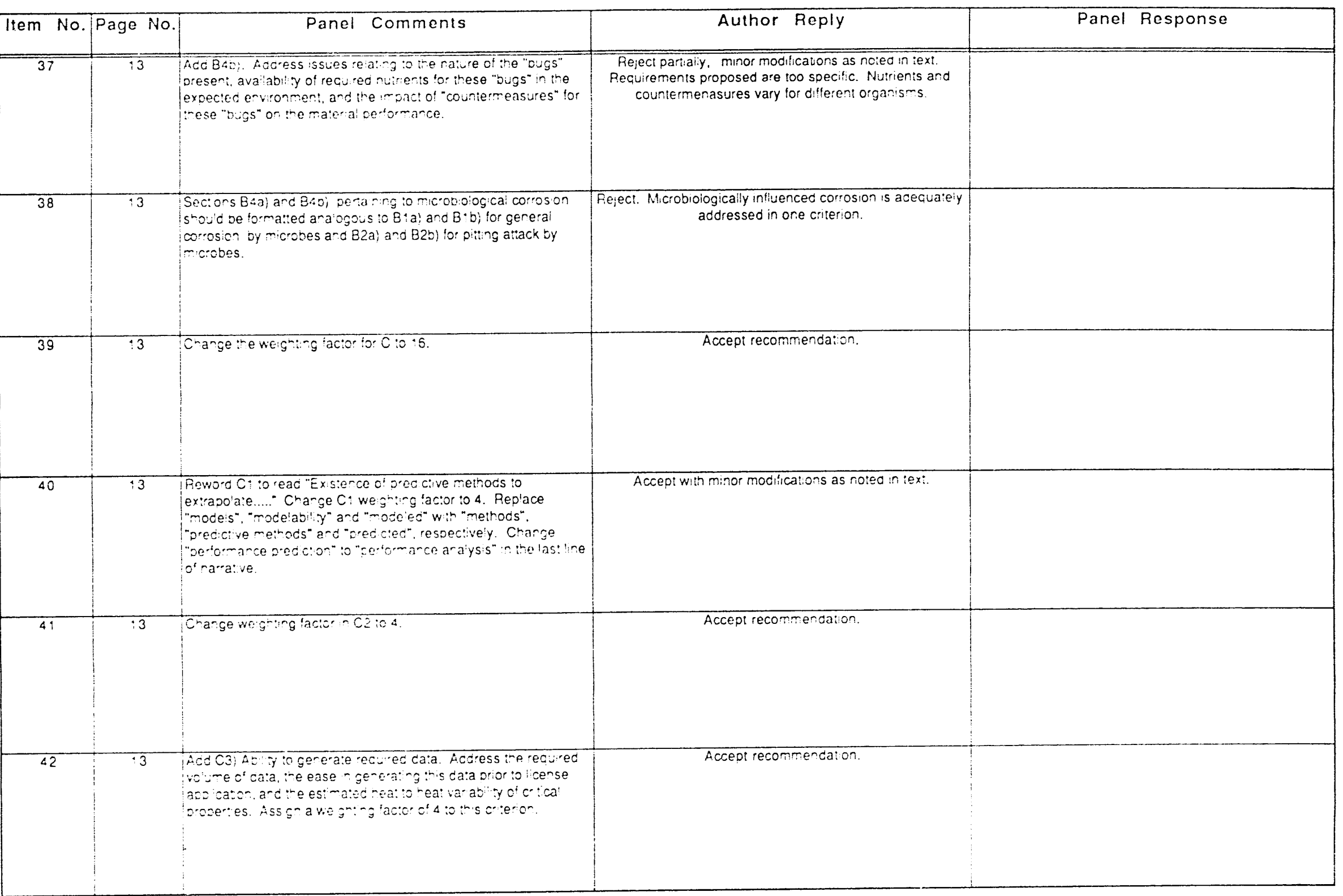


Selection Criteria Peer Review Panel Comments

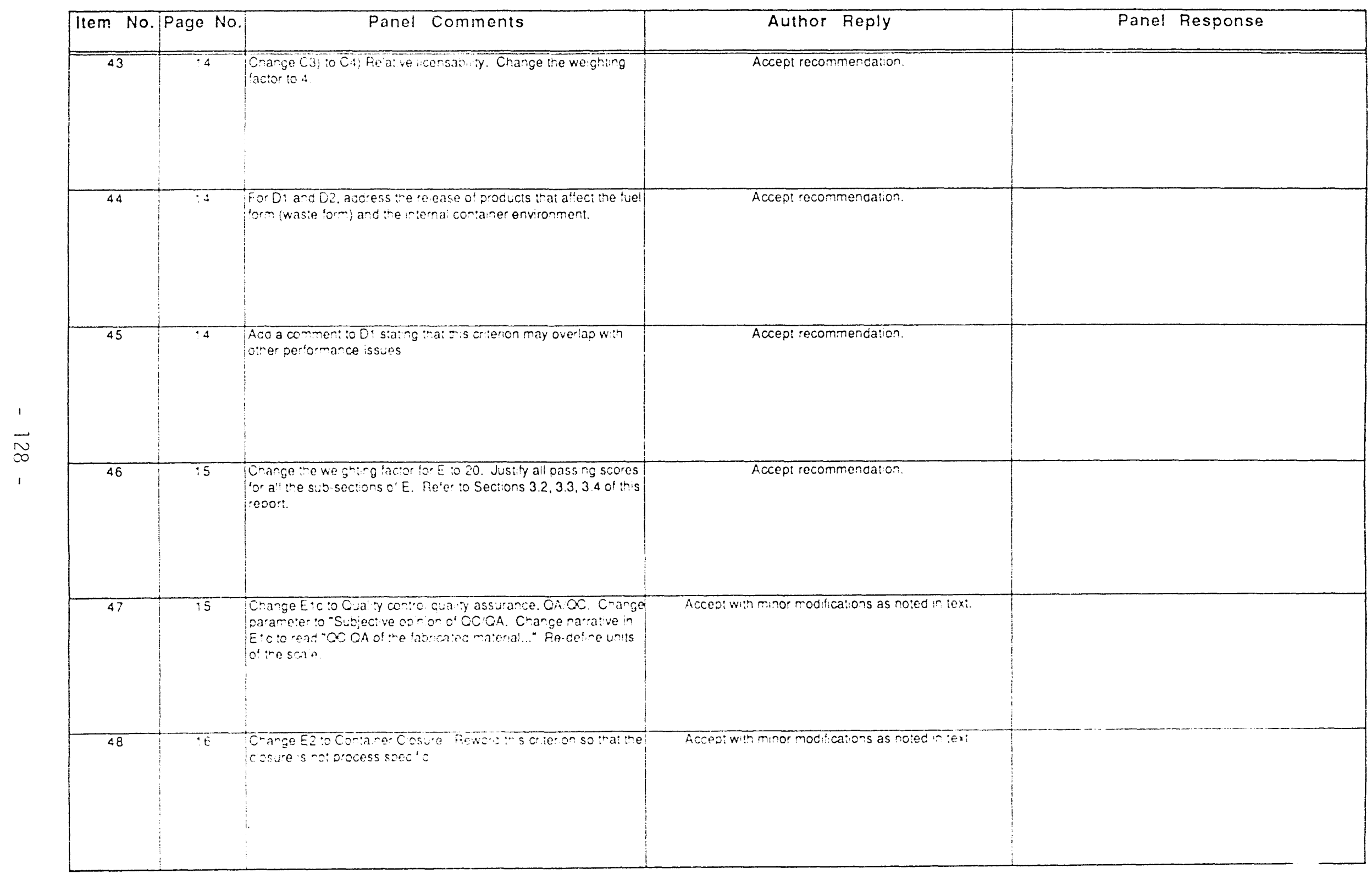




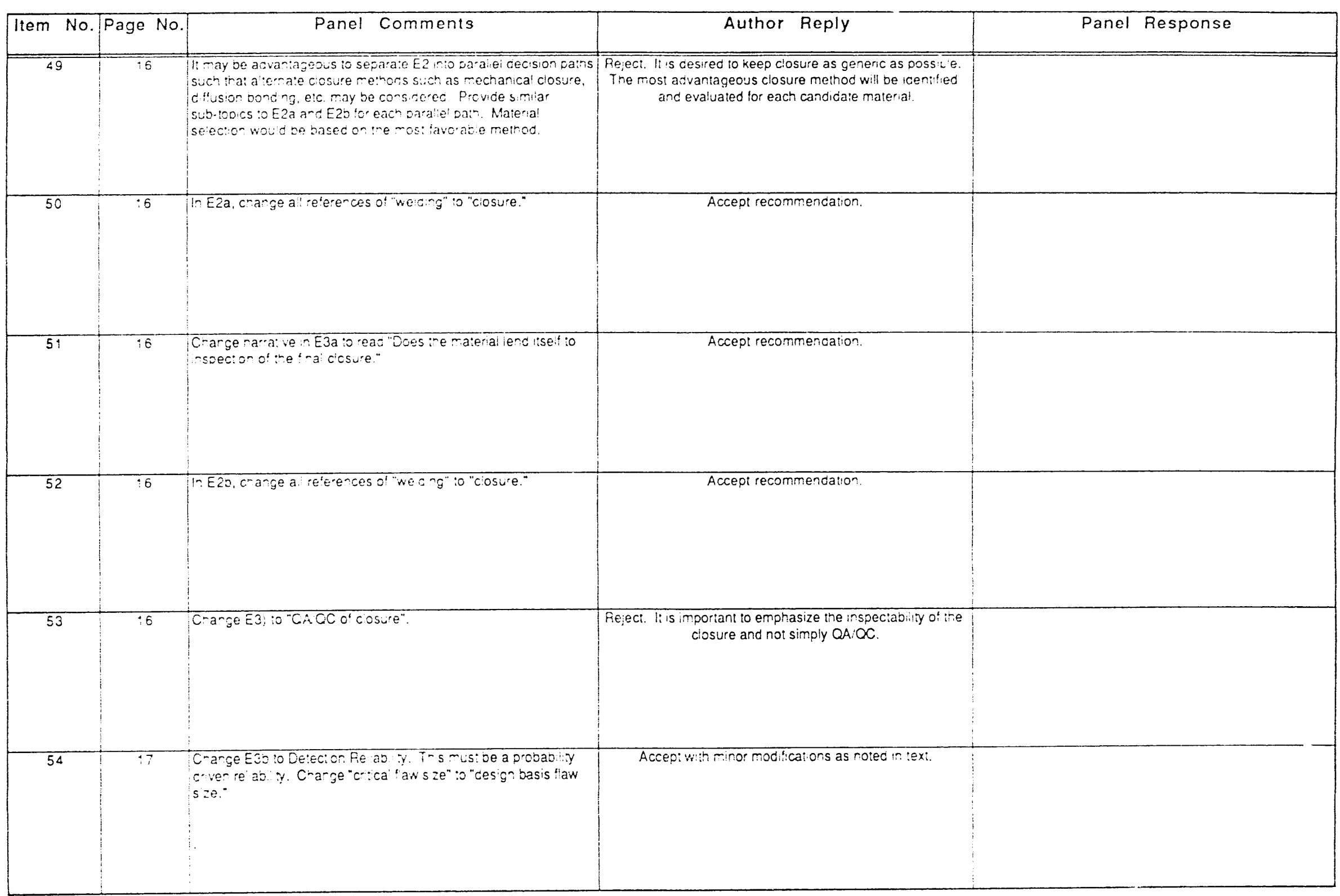




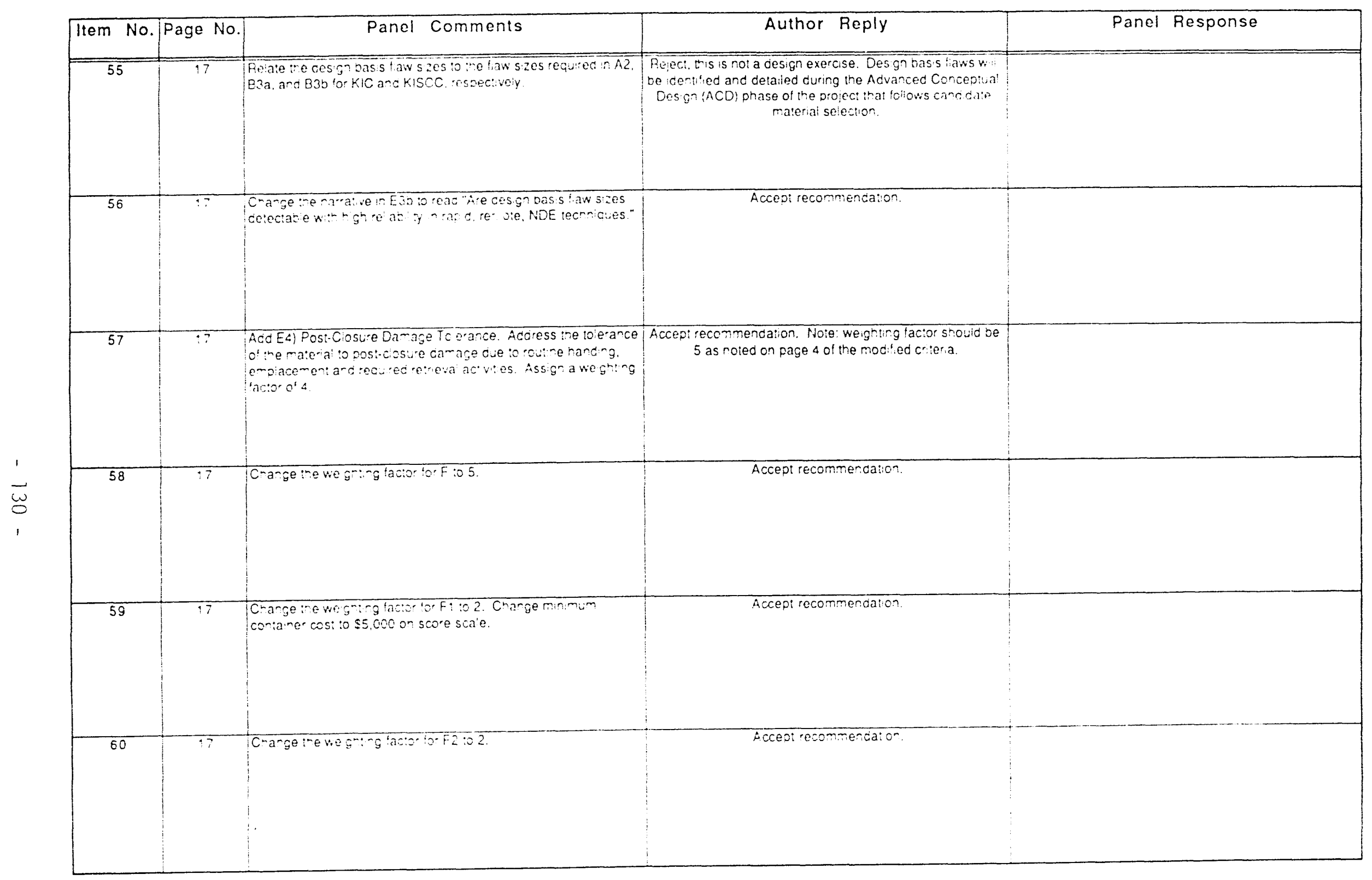




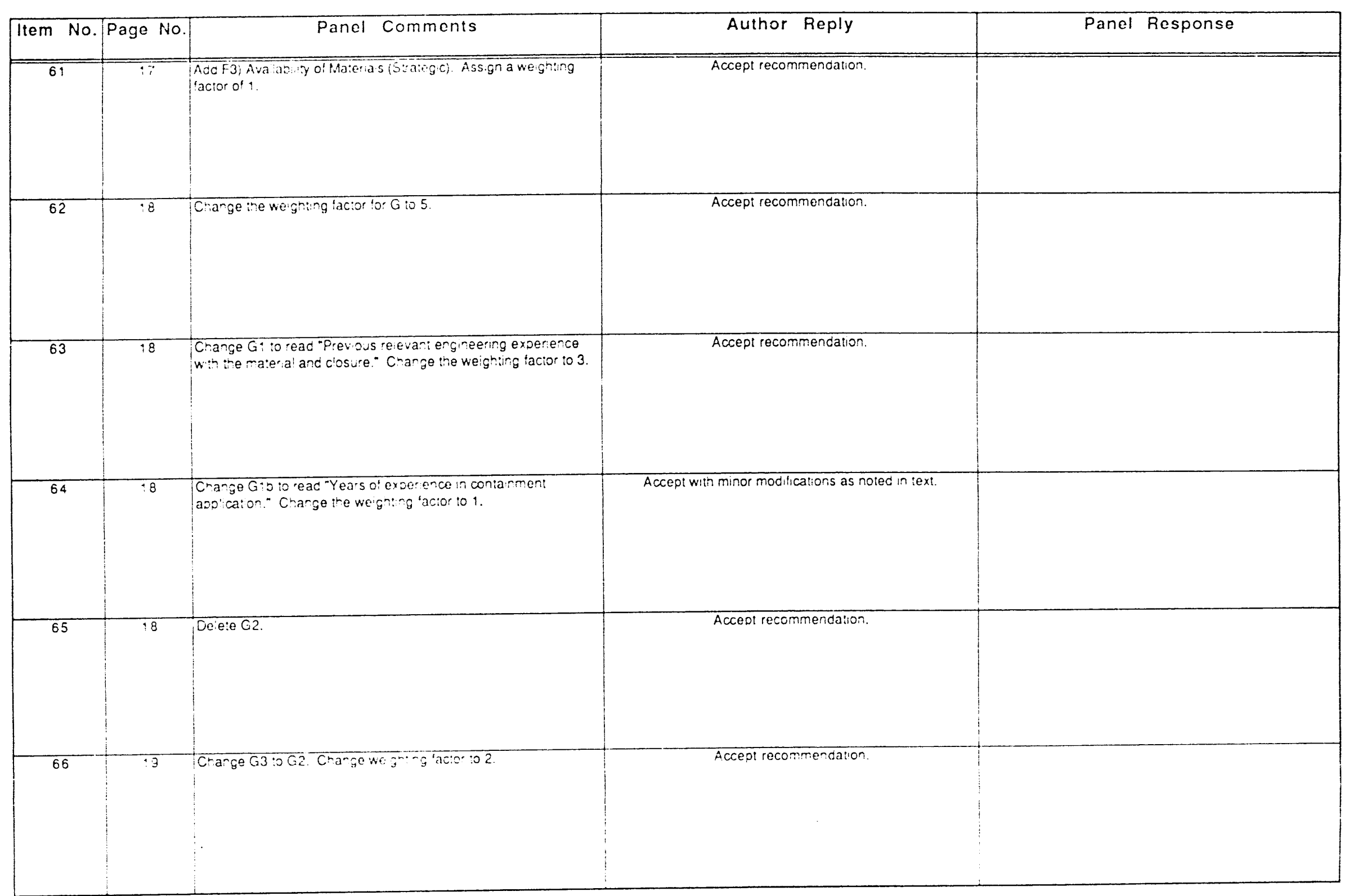


Selection Criteria Peer Review Panel Comments

\begin{tabular}{|c|c|c|c|c|}
\hline Item No. & Page No. & Panel Comments & Author Reply & Panel Response \\
\hline 67 & 19 & Crange G3a io G2a. Change Wivengning factor tor G2a to 1. & Accept recommendation. & \\
\hline 68 & 19 & Crange G30 to G20. Crange Wogh: a lacior tor G20 io & Accept recommendation. & \\
\hline
\end{tabular}

